\title{
Feasibility Study into the Potential for Gasification Plant in the New Zealand Wood Processing Industry
}

A thesis submitted in partial fulfilment of the requirements for the Degree of Master of Engineering in Chemical and Process Engineering

University of Canterbury

2008

Chris Penniall 


\begin{abstract}
The purpose of this research was to investigate the feasibility of installing gasification based combined heat and power plants in the New Zealand wood processing industry. This is in accordance with Objective Four of the BIGAS Consortium.
\end{abstract}

This thesis builds on previous work on Objective Four (Rutherford, 2006) where integration into MDF (Medium Density Fibreboard) was investigated. The previous research identified the most suitable form of combined heat and power was a BIG-GE (Biomass Integrated Gasification Gas Engine) process, due to both lower capital investment and overall breakeven electricity production cost. This technology has therefore been adopted, and the investigation has been carried further in this research to incorporate integration into sawmills and LVL (Laminated Veneer Lumber) plants.

It is recognised, however, especially when reviewing overseas successes and failures, that the base economics are only one factor in the feasibility of a plant. The research, therefore, has moved further to investigate New Zealand policy, the power market, lower capital alternatives and novel methods of integration.

The conclusion of the study is gasification based combined heat and power plants in the New Zealand wood processing industry can be equal or better in economic terms than other forms of renewable generation, however, the application is very niche. Lower capital cost alternatives, stable and low priced biomass feed and a favourable power market in regards to distributed generation is key to the viability of such a plant.

Government policy is favourable towards biomass gasification due to the target of $90 \%$ electrical generation by renewable resources by 2025 . Distributed generation is also encouraged in the Government's forward strategy. However, the technology has advanced further overseas due to capital grants and a premium paid for 'green' electricity. While the technology may be economic in its own right, active government support would lower the perceived risk increasing the likelihood of an investor taking interest in an initial project. 


\section{Acknowledgements}

Firstly I would like to acknowledge my supervisor Dr Chris Williamson. His knowledge and guidance during the course of my research has been invaluable.

My co-supervisor and leader of the overall project - Assoc. Prof. Shusheng Pang. The project exists because of his vision and hard work and for that I am very thankful.

I would also like to thank my colleague and friend Doug Bull. His passion for renewable energy and persistence in rebuilding the gasifier has been very helpful in many ways. 


\section{Contents}

1 INTRODUCTION AND BACKGROUND ...................................................................................

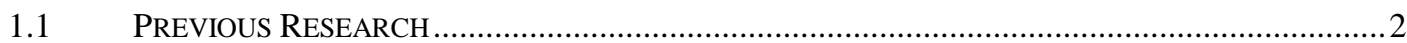

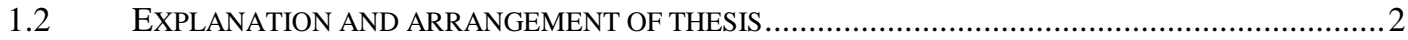

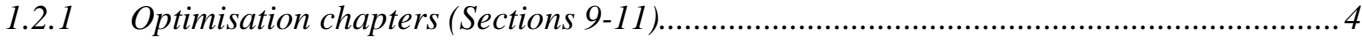

1.2.2 Case Studies (Sections 12-13) .............................................................................. 4

2 REVIEW OF SUCCESSFUL AND UNSUCCESSFUL GASIFICATION PLANTS ..............6

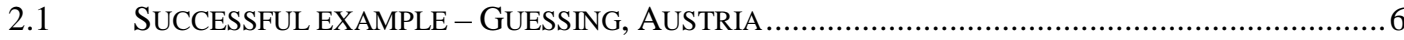

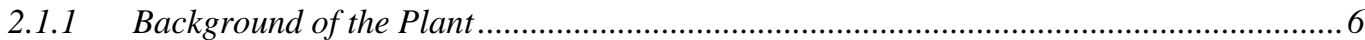

2.1.2 Lead-up to Commissioning ....................................................................................... 7

2.1.3 Conclusions as to the success of the Guessing plant ...................................................... 8

2.2 SuCCEFSSFUl EXAMPLE - HARBOORE, DENMARK (IEA BIOENERGY, 2004) .......................9

2.2.1 Conclusions from Harboore Denmark ......................................................................... 9

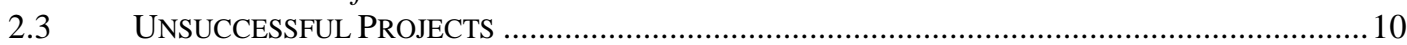

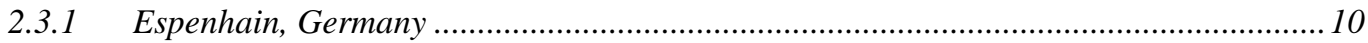

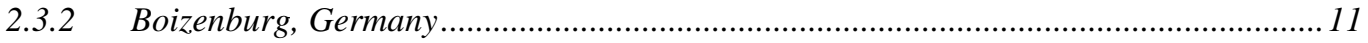

2.3.3 NH project (Meijer et al., 2007) ........................................................................... 11

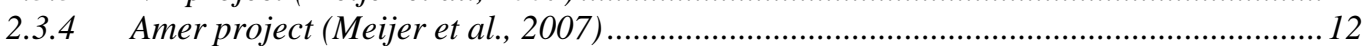

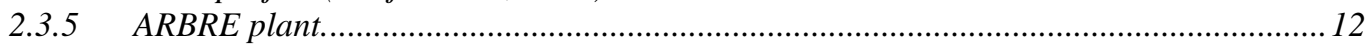

2.4 CONCLUSIONS AS TO THE FAILURES OF THE GASIFICATION PLANTS ................................ 13

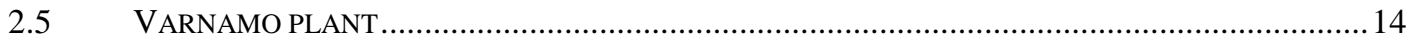

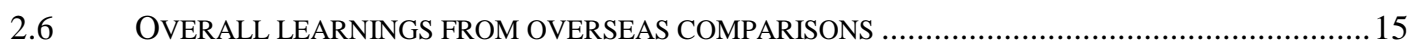

3 THE NEW ZEALAND ENVIRONMENT FOR BIOENERGY ..............................................16

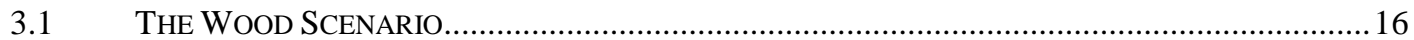

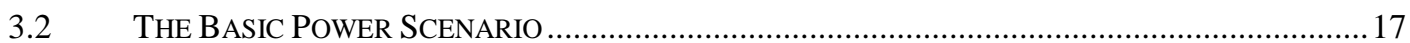

3.2.1 Future electricity price predictions ......................................................................... 18

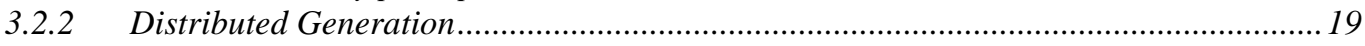

3.3 TECHNOLOGY FIT WITH GOVERNMENT ENERGY STRATEGY ..........................................20

4 BASE ECONOMIC STUDY METHODOLOGY ................................................................23

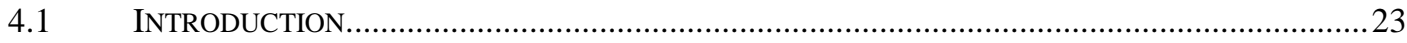

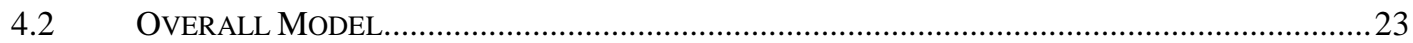

4.2.1 Input/Output Workbook ..................................................................................... 23

4.2.2 Chemical Equilibrium Model ................................................................................. 24

4.2.3 Energy Demand Models .......................................................................................... 25

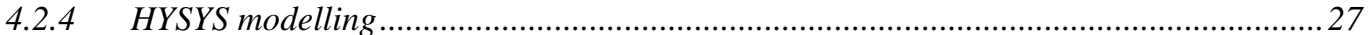

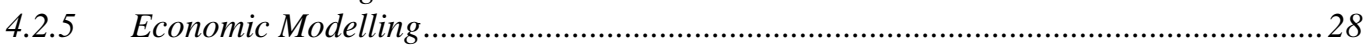

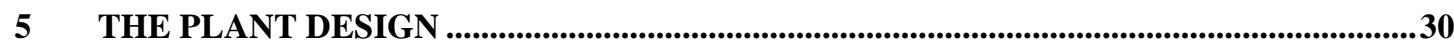

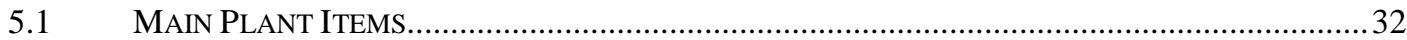

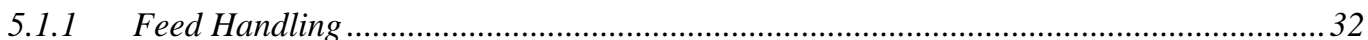

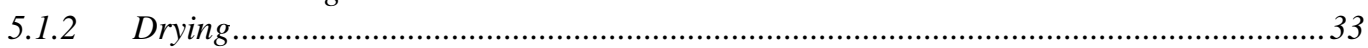

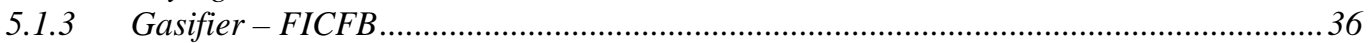

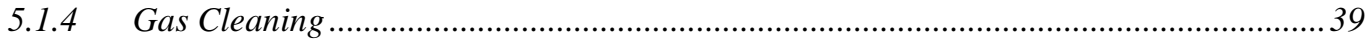

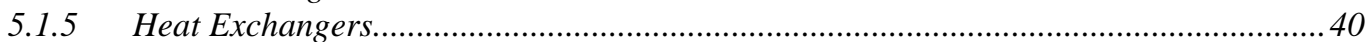

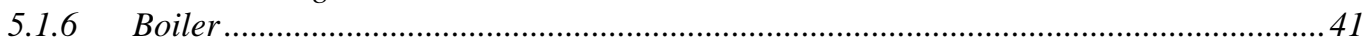

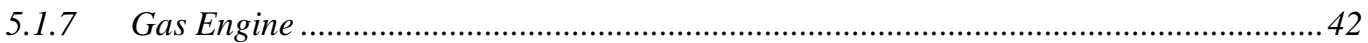

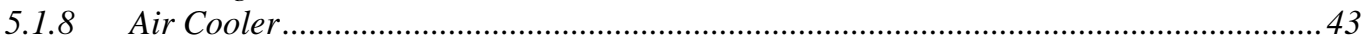

6 RESULTS AND DISCUSSION FOR BASE ECONOMIC STUDY ........................................44

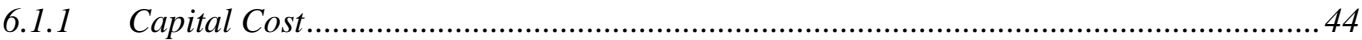

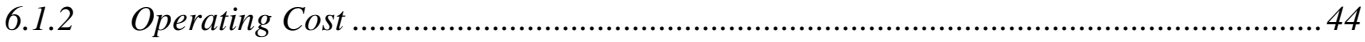

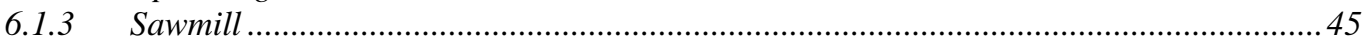

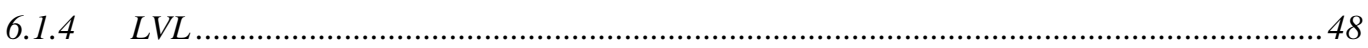

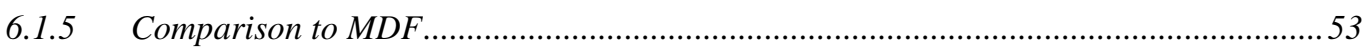




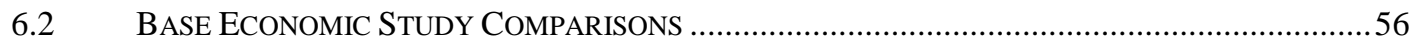

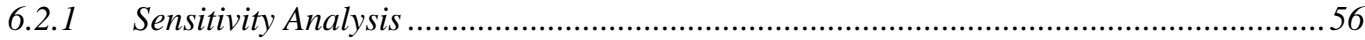

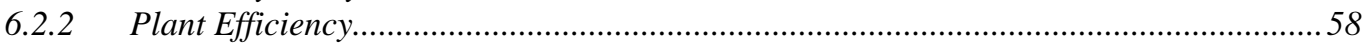

6.2.3 Comparison to other gasification based installations ...............................................60

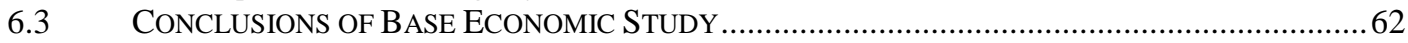

7 COMPARISON TO EXISTING COMBUSTION BASED TECHNOLOGY ........................64

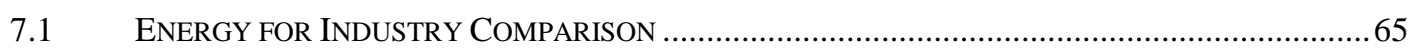

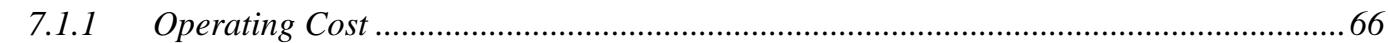

$7.2 \quad 60$ BAR STEAM AND EXTRACTING STEAM TURBINE PROCESS .........................................71

$7.3 \quad 40$ BAR STEAM AND EXTRACTING STEAM TURBINE PROCESS.............................................. 72

$7.4 \quad 30$ BAR STEAM AND EXTRACTING/FULLY CONDENSING PROCESS ...................................... 73

SENSITIVITY ANALYSIS COMPARISON .......................................................................... 74

7.6 CONCLUSIONS OF COMPARISON TO COMBUSTION BASED COMBINED HEAT AND POWER ........76

8 CHEMICAL EQUILIBRIUM MODEL MODIFICATION .......................................................77

8.1 IMPROVING THE ACCURACY OF THE EQUILIBRIUM MODEL PREDICTION...............................77

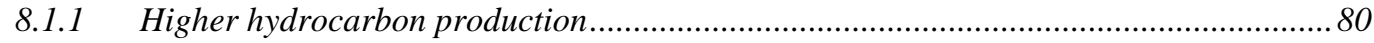

8.1.2 High moisture content........................................................................................ 81

8.1.3 Optimisation of the model to reflect experimental data................................................. 83

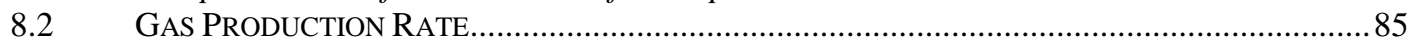

8.3 CONCLUSIONS OF THE CHEMICAL EQUILIBRIUM MODELLING MODIFICATION .......................86

9 CAPITAL ITEM ALTERNATIVES AND ECONOMIC EFFECTS ...................................88

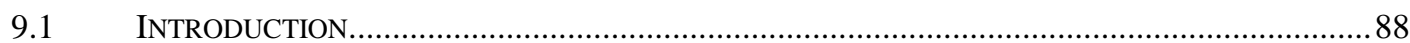

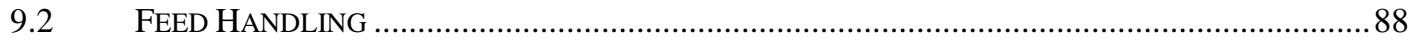

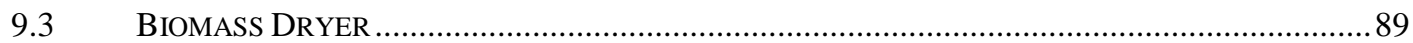

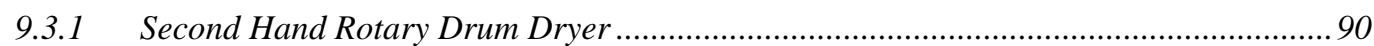

9.3.2 Multi-Deck Turbo Dryer ........................................................................................ 91

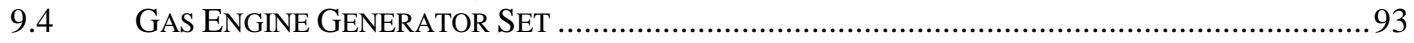

9.4.1 Calculation of engine derating .................................................................................. 95

9.4.2 Economics of incorporating a second hand gas engine into the base scenario................ 99

10 POWER MARKET OPPORTUNITIES..........................................................................100

10.1 LOCATION OF WOOD RESOURCE IN RELATION TO POWER MARKET …................................ 105

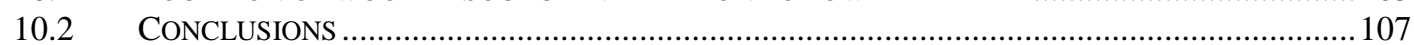

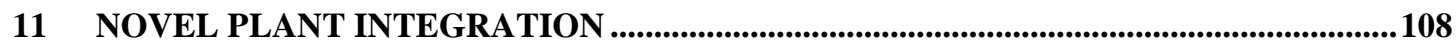

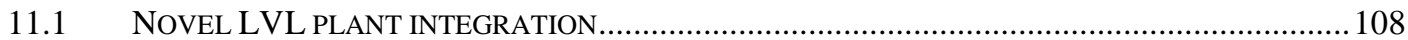

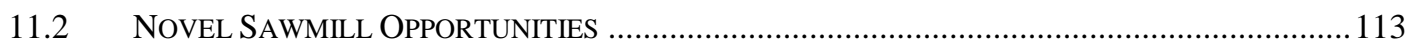

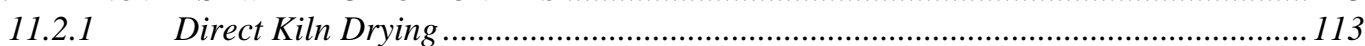

11.2.2 Potential Problems to Overcome .................................................................. 115

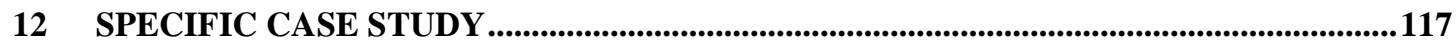

12.1 FULL SYSTEM MEETING ALL THERMAL AND ELECTRICAL NEEDS ....................................... 119

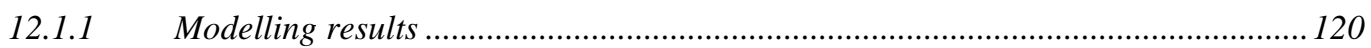

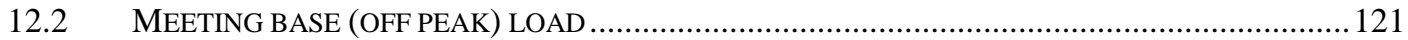

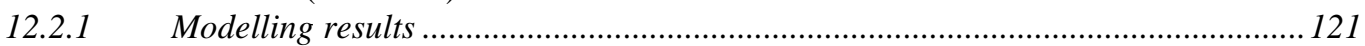

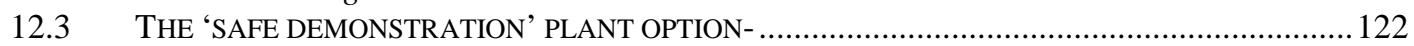

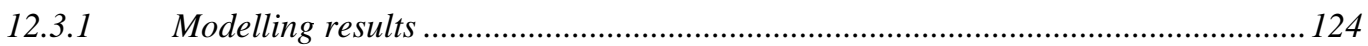

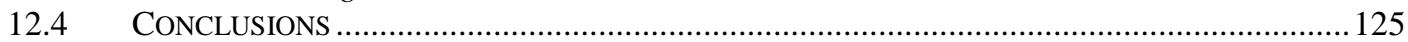

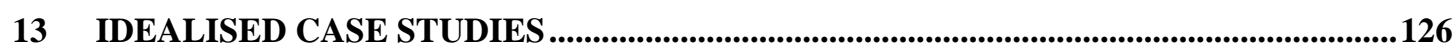

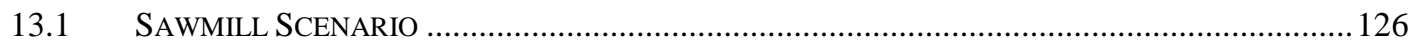

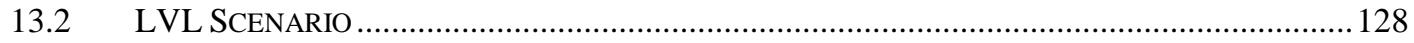

13.2.1 LVL A

13.2.2 LVL B

14 FINAL CONCLUSIONS AND RECOMMENDATIONS .............................................131

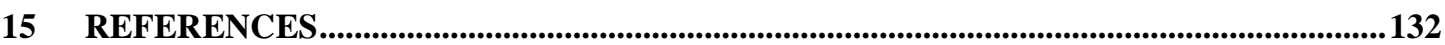


APPENDIX A - FINANCIAL STATEMENTS FOR GASIFICATION TO COMBUSTION

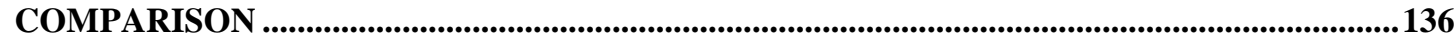

APPENDIX B - COMPONENT LIST OF MULTI-DECK TURBO DRYING SYSTEM ............138 


\section{List of Figures}

Figure 1: Operating hours of Guessing Plant. (TUV, 2008) ................................... Figure 2: Biomass supply cost for the Canterbury region in oven dried tonnes (odt). (J.

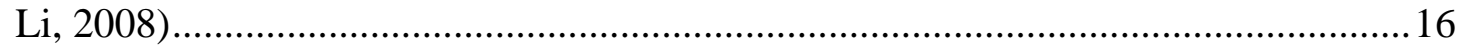

Figure 3: Historical electricity prices in New Zealand (Nominal). (Ministry of

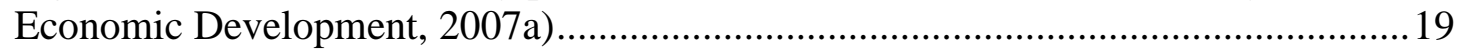

Figure 4: Historical electricity prices in New Zealand (Real). (Dang et al., 2007) ..... 19 Figure 5: Flow diagram of economic modelling of gasification plant........................22

Figure 6: The BIG-GE process modelled in this study ............................................... 31

Figure 7: Example of a perforated floor bin dryer. (Brammer \& Bridgwater, 1999). 34

Figure 8: Example of a rotary cascade dryer. (Brammer \& Bridgwater, 1999) .......... 35

Figure 9: Flow pattern of material inside a rotary cascade dryer. (Brammer \&

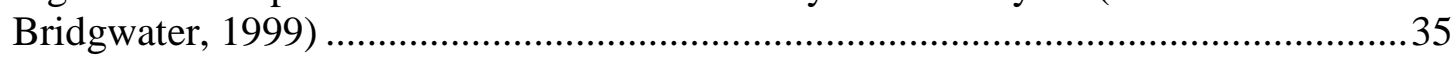

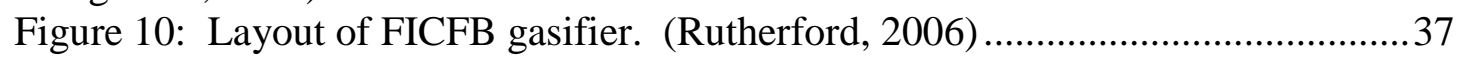

Figure 11: Capital cost of Gasifier - Gas Engine/Boiler process in a sawmill............46

Figure 12: Cash flow analysis of sawmill energy plant showing capital payback period

. .46

Figure 13: Electricity price required for sawmill energy plant to break even based on a

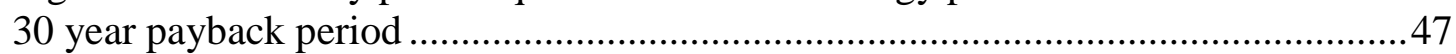

Figure 14: Capital cost of Gasifier - Gas Engine/Boiler process in LVL Mill A .......49

Figure 15: Capital cost of Gasifier - Gas Engine/Boiler process in LVL Mill B........49

Figure 16: Cash flow analysis of LVL Mill A energy plant showing capital payback

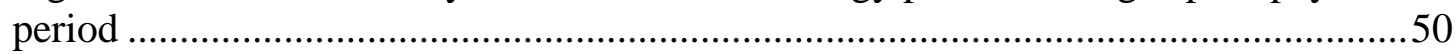

Figure 17: Cash flow analysis of LVL Mill B energy plant showing capital payback

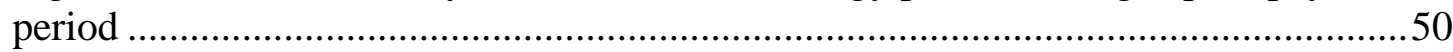

Figure 18: Electricity price required for LVL Mill A energy plant to break even based

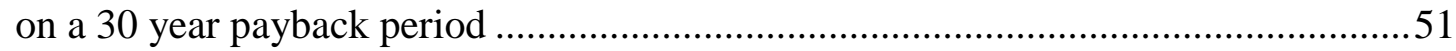
Figure 19: Electricity price required for LVL Mill B energy plant to break even based

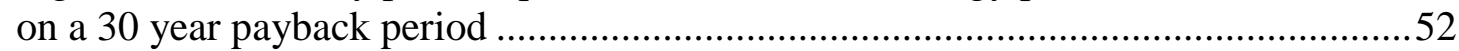
Figure 20: Capital cost of Gasifier - Gas Engine/Boiler process in a MDF plant........53 Figure 21: Cash flow analysis of MDF energy plant showing capital payback period54 Figure 22: Electricity price required for MDF energy plant to break even based on a

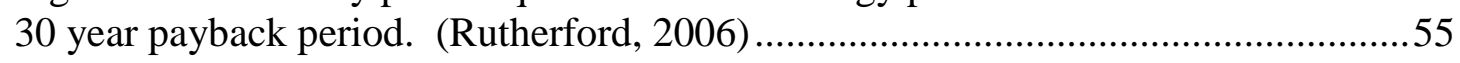

Figure 23: Sensitivity analysis for sawmill energy plant.........................................56

Figure 24: Sensitivity analysis for LVL Mill A energy plant ....................................56

Figure 25: Sensitivity analysis for LVL Mill B energy plant ....................................57

Figure 26: Sensitivity analysis for MDF energy plant (Rutherford, 2006).................57 Figure 27: Sawmill energy plant fuel efficiency showing electrical efficiency and total efficiency (electrical + thermal) vs. electrical generation...........................................59 Figure 28: LVL A energy plant fuel efficiency showing electrical efficiency and total efficiency (electrical + thermal) vs. electrical generation..........................................59 Figure 29: LVL B energy plant fuel efficiency showing electrical efficiency and total efficiency (electrical + thermal) vs. electrical generation..........................................6 60 Figure 30: MDF energy plant electrical efficiency vs generation capacity.

(Rutherford, 2006)

Figure 31: Typical total installed capital cost of a gasifier + gas engine plant based on cost per kWe. (Ahrenfeldt \& Knoef, 2005) .....

Figure 32: New plant generation costs assumed in base case to 2015. (Ministry of Economic Development, 2006) 
Figure 33: Basic flow schematic of extraction/condensing steam turbine

Figure 35: Cash flow analysis of gasification plant with $4.15 \mathrm{MW}$ of electrical

generation

Figure 36: Fully condensing turbine flow diagram................................................ 73

Figure 37: Sensitivity analysis for change in wood per tonne price for gasification and

combustion scenarios

Figure 38: Example of effect of cumulative biomass use with varying cost of feed

components

Figure 39: Demonstration of the effects of varying gasification temperature in the equilibrium model

Figure 40: Variation of equilibrium model temperature with the methane formation reaction having a $200^{\circ} \mathrm{C}$ approach to equilibrium.....

Figure 41: Visual representation of steam bypassing gasification reactions ...............82 82

Figure 42: Modelled producer gas composition as a function of variation in steam/biomass ratio based on original equilibrium model at $720^{\circ} \mathrm{C}$..........................83

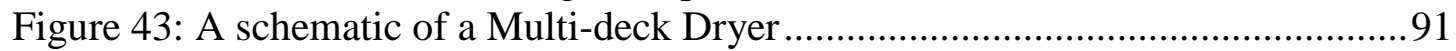

Figure 44: Average trading period price in 2007 for OTA2201 ..............................101

Figure 45: Wood resource by region compared to estimated power price for the region. (Electricity Commission, 2008; Ministry of Agriculture and Forestry, 2006)

Figure 46: Schematic of proposed novel LVL plant integration .............................. 109

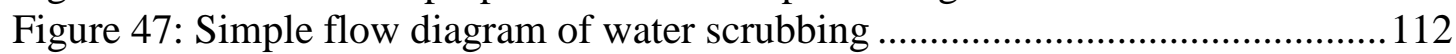

Figure 48: Gasification Direct Kiln Drying Process.................................................114

Figure 49: 'Safe demonstration scenario' incorporating combustion and gasification

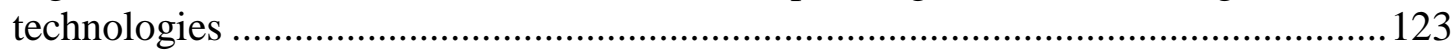

Figure 50: Sensitivity analysis for idealised sawmill scenario ...............................128

Figure 51: Sensitivity analysis for idealised LVL A scenario ................................130

Figure 52: Sensitivity analysis for idealised LVL B scenario ................................. 130 


\section{List of Tables}

Table 1: Basic economics of Guessing plant (Bolhar-Nordenkampf et al., 2002) ........8

Table 2: Heat Exchanger heat transfer coefficients (U). (Douglas, 1988)..................41

Table 3: Capital cost of a Gasifier - Gas Engine/Boiler process in a sawmill .............45

Table 4: Capital cost breakdown of Gasifier - Gas Engine/Boiler process for LVL

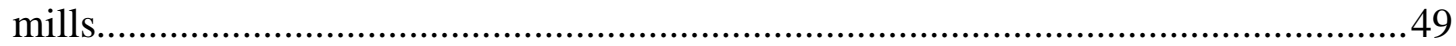

Table 5: Capital cost of Gasifier - Gas Engine/Boiler process in a MDF plant............53

Table 6: Capital cost of gasification based comparison to combustion technology ....68

Table 7: Comparison of economics between combustion and gasification scenarios .69

Table 8: Comparison of efficiency between combustion and gasification ...................70

Table 9: Capital cost estimate for 60 bar scenario ..................................................... 72

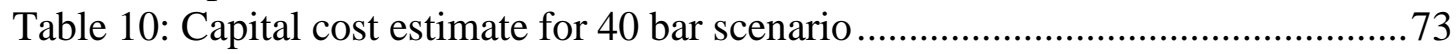

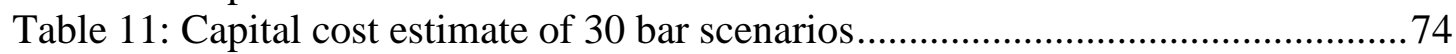

Table 12: Comparison of experimental to unmodified model producer gas results .... 84

Table 13: Comparison of experimental to optimised model producer gas results.......84 84

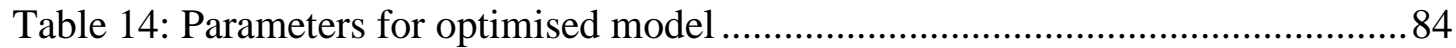

Table 15: Comparison of modelled data to the Vienna University of Technology 100

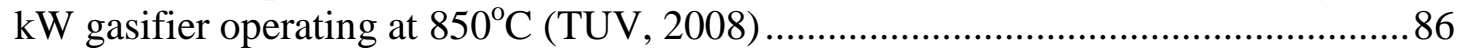

Table 16: Parameters for model compared to the TUV $100 \mathrm{~kW}$ gasifier ....................87

Table 17: Estimated capital costs for multi-deck turbo dryer....................................92

Table 18: No or low hour natural gas engine gensets from second hand industrial

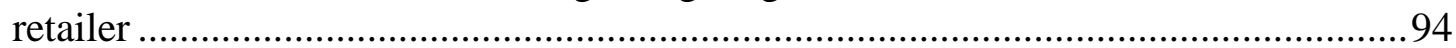

Table 19: High hour natural gas engine gensets from second hand industrial retailer 94

Table 20: Calorific value of producer gas based on chemical equilibrium model ......96

Table 21: Summary of air/fuel (A/F) ratio and energy density for natural gas and producer gas at varying levels of excess air..............................................................96

Table 22: Calculation of mole change factor using predicted producer gas fractions

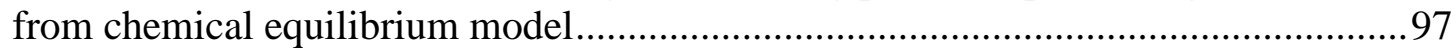

Table 23: Adiabatic flame temperature comparisons for natural gas and producer gas

Table 24: Comparison of average capital cost of second hand engines when derating

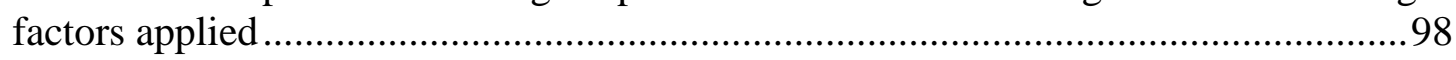

Table 25: Producer gas compositions and heating value of CAPE lab scale FICFB

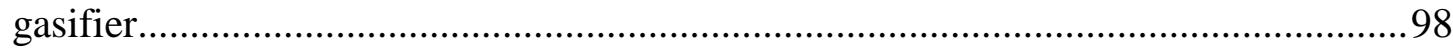

Table 26: Recalculated second hand engine capital costs based on CAPE lab scale

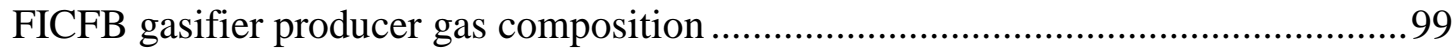

Table 27: Power price analysis for North Island main nodes ................................... 104

Table 28: Power price analysis for South Island main nodes ..................................104

Table 29: Average power price for selected nodes for July 2007............................106

Table 30: Capital cost for sawmill based energy plant configured for direct kiln drying

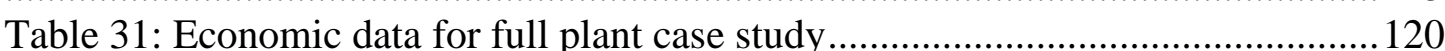

Table 32: Economic data for off peak plant case study ........................................... 122

Table 33: Economic data for 'safe demonstration' plant case study .........................124

Table 34: Capital cost for sawmill energy plant incorporating lower capital cost main plant items

Table 35: Capital cost for LVL scenarios incorporating lower capital cost main plant items 
Table 36: Profit and loss statement for gasification plant generating $7.8 \mathrm{MW}_{\text {th }}$ and $1.4 \mathrm{MW}_{\mathrm{e}}$

136

Table 37: Profit and loss statement for combustion based plant operating at 60 bar and generating $7.8 \mathrm{MW}_{\text {th }}$ and $1.4 \mathrm{MW}_{\mathrm{e}}$ 


\section{Introduction and Background}

The purpose of this research was to investigate the feasibility of installing gasification based heat and power plants in the New Zealand wood processing industry.

New Zealand's wood harvest is currently 20 million $\mathrm{m}^{3}$ of round wood per year (Cox, 2008). Around $20 \%$, or $4-5$ million $\mathrm{m}^{3}$ per year, ends up as wood residues (sawdust, bark or chips) during processing. Wood residue use currently accounts for around 25 PetaJoules (PJ) of New Zealand's 750 PJ of primary energy supply. However, only about two thirds of the wood processing residue is used for energy and much of the remainder is sent to landfill. Forest logging generates a further 4 million $\mathrm{m}^{3}$ of residues per year and, unlike wood processing residue, little of this is utilised. Considering these two sources of wood waste there is more than 5 million $\mathrm{m}^{3}$ (50 PJ) available per year for additional energy generation (Pang, 2008).

The wood processing industry is an intensive user of both heat and electricity (approximately $50 \mathrm{PJ}$ per year) while producing readily available and cheap fuel as residue. Both the quantity of residues available and the heat and power requirements for the wood processing industry provide drivers for the study of a gasification based combined heat and power plant.

This research meets the requirements of Objective Four of the BIGAS consortium (FRST Research Contract UOCX0402). The task of this objective was to develop a model for use in the process design of a pilot scale gasification plant and to undertake economic feasibility studies for this technology.

This particular research is one section in the study of gasification at the University of Canterbury. The overall study includes a pilot scale gasification plant constructed and run at the university as well as studies of energy demand and waste production at associated wood processing plants. The overall study is broken into four objectives (Pang \& Li, 2006) 
- Objective 1: Evaluate the current state of gasification technology and recommend a gasification technology best suited for development in New Zealand

- Objective 2: Technical development of selected gasification technology

- Objective 3: Quantify availability and cost of wood fuel and quantify energy demand in the wood processing sector

- Objective 4: Develop a model for the selected technology for use in the design of a pilot gasification plant and develop economic feasibility studies for this technology

\subsection{Previous Research}

Previous research on Objective Four was performed by Jack Rutherford (Rutherford, 2006). This included development of a chemical equilibrium model for a FICFB (Fast Internally Circulating Fluidised Bed) gasifier, as well as economic feasibility studies for a gasification based energy plant in an MDF (Medium Density Fibreboard) mill application. The study included scenarios for

- BIGCC (Biomass Integrated Gasification Combined Cycle)

- BIG-GT (Gasifier - Gas Turbine/Boiler plants)

- BIG-GE (Gasifier - Gas Engine/Boiler plants)

- Gasifier - Boiler plants

The conclusion from this previous study was that the BIG-GE process was the most economic, both from a payback on capital investment perspective and also initial capital investment requirements. This process has therefore been the focus for this thesis.

\subsection{Explanation and arrangement of thesis}

The thesis is broken up into several sections each of which culminate to asses the feasibility of a gasification plant in a New Zealand wood processing setting. While traditional economic analysis techniques have been used as a base, the research also moves beyond a simple economic study of gasification plant to explore both indirect economic and non-economic factors which influence the wider feasibility of the technology. It should be noted this thesis is written under the assumption that the 
reader has a base knowledge of gasification. If background reading is required then there are several previous theses from within the BIGAS Consortium which would be helpful (Brown, 2006; Bull, 2008; Rutherford, 2006), or books that will give an appropriate overview (Ahrenfeldt \& Knoef, 2005; Higman \& Burgt, 2003).

The literature survey (Section 2) reviews both successful and unsuccessful plants in an attempt to gauge what parameters could make a plant successful in a New Zealand context. The literature survey reflects the approach to this thesis in that the basic economics, efficiencies, and technical parameters of other plants are not reviewed or at least are not the focus of the review. Rather the literature survey moves beyond pure technology and economics to establish wider reasons for the feasibility or lack thereof.

The environment for bioenergy in New Zealand is investigated (Section 3), in terms of the wood and power situation, and how biomass gasification fits within the New Zealand energy strategy. This is partly to provide the sources of information for the base economic study, as well as a response to the success and failure review of overseas plants.

A base economic study (Sections 4-6) is performed on BIG-GE scenarios for sawmills and LVL mills. The results are compared to previous work on MDF (Rutherford, 2006). The methods of modelling and costing the plants have been included. Capital cost breakdowns, breakeven electricity prices, sensitivity analyses and plant efficiencies have been calculated for each scenario to allow comparison and give insights into potential ways to improve the economics, mainly in terms of capital cost and operating cost reduction.

Conjecture is often made as to what the actual advantage of a gasification system is over a traditional combustion based combined heat and power plant. Therefore, a direct comparison has been made between the two technologies (Section 7) for plants producing the same heat and power. Results are reported in terms of economics and operating efficiencies. 
Previous work (Rutherford, 2006) developed a chemical equilibrium model to predict gas composition for a FICFB gasifier for use in the study. The model, however, did not predict the composition with sufficient accuracy, therefore modifications have been made to the model (Section 8) in an attempt to closer match the gas composition of the pilot scale FICFB gasifier at the University of Canterbury.

\subsubsection{Optimisation chapters (Sections 9-11)}

Moving beyond the base economic study, investigations were made into potential ways of increasing the feasibility beyond the base scenario. The areas investigated were

- Capital item alternatives. In an attempt to reduce the capital cost of the base economic scenario alternatives to the main capital items were investigated based on either different unit operations to perform the same task, or the cost and suitability of second hand equipment.

- Power market. Having the combined heat and power plant gives a mill flexibility in the way it can utilise the power market. Investigation is made into different ways of configuring a mill to optimise the profit from a daily fluctuating electricity spot price. Investigation is also made into the differing average prices throughout the country in conjunction with the wood resource availability in various regions to establish if there are areas significantly more suitable to target for embedded generation.

- Novel approaches. Gasification is more flexible than traditional combustion in regards to potential plant configurations. Therefore novel approaches to reduce capital, operating cost and complexity of a gasification plant have been investigated for the sawmill and LVL scenario.

\subsubsection{Case Studies (Sections 12-13)}

The culmination of the research is to perform case studies which are split into two applications, an actual case study and an idealised case study.

The actual case study uses data from a sawmill considering increasing capacity and installing a kiln drying system. Capital and operating costs have been used based on 
the base economic study, however, different configurations of size, and also a 'safe demonstration' arrangement are investigated to give a spread of profit vs. risk.

The idealised case study incorporates what is considered to be realistic aspects of the optimisation chapters such as capital item alternatives and novel configuration to establish the feasibility of a plant if an optimistic scenario were to be realised. 


\section{Review of Successful and Unsuccessful Gasification Plants}

The intention of this chapter is to review a number of overseas gasification based plants. While economics are an important component of the feasibility of installing a plant they are only one factor. Many other external influences affect the likelihood of a gasification plant being installed such as the political climate, public perception, and perceived risk by investors. An analysis of both successful and unsuccessful plants is performed in an attempt to gauge what causes a make or break scenario beyond pure economics. The technical details of the plants will not be examined in detail as the success or failure for the most part is outside of any particular style or design of plant.

\subsection{Successful example - Guessing, Austria}

The most comparable example to the plant design in this study is that of the Guessing plant in Austria. The Guessing plant incorporates a FICFB gasifier which formed the basis for the design of the laboratory scale plant at the University of Canterbury, which in turn formed the basis of the plant modelled in this study. The plant has an electrical output of $2 \mathrm{MW}_{\mathrm{e}}$ and a heat output in the form of district heating of 4.5 $\mathrm{MW}_{\text {th. }}$

\subsubsection{Background of the Plant}

The Guessing plant was commissioned in January 2002 (Hofbauer, Rauch, Bosch et al., 2002). The gasifier was the first part to be commissioned with the gas engine commissioned after 1500 hours of operating the gasifier and gas cleaning system. Since that time the availability of the plant has increased to respectable levels of approximately $90 \%$ for the gasifier and $85 \%$ for the gas engine by 2006 (TUV, 2008) as can be seen in Figure 1. During the initial start-up there were control system tuning problems, the reason being there was no reference point due to this being the first full scale plant of this design. It took two months before stable operation was possible (Hofbauer, Rauch, Bosch et al., 2002), however, given the novel aspect of the technology this could be considered a very satisfactory commissioning time. 


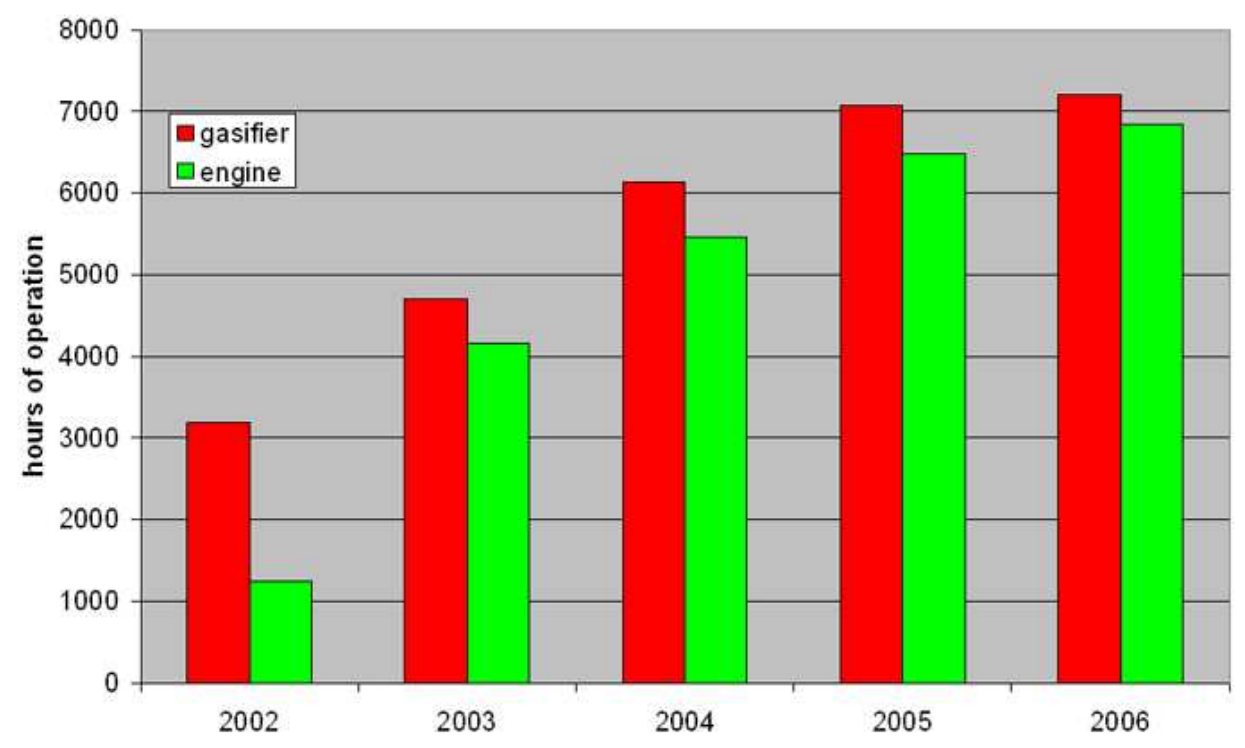

Figure 1: Operating hours of Guessing Plant. (TUV, 2008)

\subsubsection{Lead-up to Commissioning}

While post start-up information is useful, the lead up to the plant being commissioned is most interesting as it presents the base for why the project was able to go ahead, and then once it was built why it has operated successfully.

The concept began with the mayor of Guessing and other visionary people who wanted to supply the energy needs of Guessing by renewable fuels only (Hofbauer, Rauch, Bosch et al., 2002). The region was very poor and had high unemployment (Pfeifer, 2008) however $40 \%$ of the region was covered by wood (Hofbauer, Rauch, Bosch et al., 2002). This plant is therefore only one part of a string of projects in the area. There is now a district heating system, a liquid fuels plant, as well as the gasification plant. The area is therefore now supplied $100 \%$ by renewable energy (Hofbauer, Rauch, Bosch et al., 2002) which has created significant employment (Pfeifer, 2008).

In the year 2000 a network called Renet-Austria was created to support the design, construction, and commissioning of the plant. The members were the manufacturers of the plant - AE Energietechnik, and Jenbacher, the owner of the plant (a private investor), and the Vienna University of Technology. The work of the network is 
funded by the government and two federal states of Austria (Hofbauer, Rauch, Bosch et al., 2002).

The basic economics of the plant can be seen in Table 1. It can be seen a considerable amount of the plant cost was offset by government funding. Also, the price received for electricity generated is at a premium rate due to it being 'green' electricity and is guaranteed for a number of years.

Table 1: Basic economics of Guessing plant (Bolhar-Nordenkampf et al., 2002)

\begin{tabular}{ll}
\hline Investment cost & $10 \mathrm{M}$ Euro \\
Funding (EU, National) & $6 \mathrm{M}$ Euro \\
Operation cost per year & $10-15 \%$ of investment costs \\
Price for heat into grid & $2.0 \mathrm{c} / \mathrm{kWh}$ \\
Price for electricity & $12.3 \mathrm{c} / \mathrm{kWh}$ \\
\hline
\end{tabular}

\subsubsection{Conclusions as to the success of the Guessing plant}

From the reports written on the Guessing plant it can be indirectly concluded there were many factors that fell in line to make the plant a success.

- There was a favourable political climate as the mayor was the main instigator of the project. This could be considered in reverse to a typical scenario where the governing bodies need to be convinced about a technology or idea.

- The plant provided employment and helped lift the local economy which would likely provide a very positive public perception rather than the typical negative response when a new industry arrives in an area.

- The involvement of a large existing energy engineering company to design and build the plant in conjunction with the university research is seen as pivotal. While the university has the concepts and understanding of the functionality of the gasification system, the energy company has the expertise in actual energy plant design and construction. This provides an excellent synergy.

- Government funding of a considerable fraction of the plant drastically improves the economics from the plant owners perspective. This also reduces the perceived risk for the investor resulting in a greater likelihood of investing in a new technology (Meijer et al., 2007). 
- The premium paid for the green electricity improves the economics further making the plant economic to run and reduces investment risk.

- Any issues during construction, commissioning, and operation have been relatively minor. The plant has performed to design specifications. This is likely a result of the synergy of the combined skill set of the energy company and the university.

\subsection{Succefssful example - Harboore, Denmark (IEA Bioenergy, 2004)}

The plant was built in 1993 by Babcock and Wilcox Volund (BWV) as a $4 \mathrm{MW}_{\text {th }}$ woodchip fuelled updraft gasifier to provide district heating. The technology is based on a $1 \mathrm{MW}_{\text {th }}$ test facility at the Kyndby Power Plant. The gasifier was optimised from early 1994 to 1996 . By 2000 a tar cleaning system had been developed using condensers followed by a wet electrostatic precipitator. Initial work on tar cracking via catalysts proved unsuccessful. In 2000 two Jenbacher engines were installed rated at $650 \mathrm{~kW}$ and $770 \mathrm{~kW}$.

A reverse osmosis system for removing water soluble tar components was installed in 2000, however this proved to be a failure. In 2002 BWV developed a proprietary water cleanup system. Since 1994 the gasifier has been in operation for more than 70,000 hours, and the engines have been run for approximately 8000 hours. The ash discharged has a total organic carbon of less than $1 \%$, and is used as a fertiliser for the feedstock plantations. The wastewater discharged is close to the quality of potable water. The Municipality of Harboore believe this system to be a success because it is renewable, as well as having favourable economics and environmental impact compared to state of the art grate fired plants.

\subsubsection{Conclusions from Harboore Denmark}

- The technology was developed by Babcock and Wilcox Volund which is a large reputable company which allows sufficient support of new technology development.

- The project was based on results from a smaller scale test facility therefore experience of the technology was already available. 
- The development of the plant was staged. The gasifier was first installed and run for district heating, followed by the engines later. This allowed optimisation of the gasifier, allowing a satisfactory base for the gas engines.

- The plant is simple compared with, for example, BIGCC systems.

- The plant did have technical problems but these were overcome with appropriate solutions developed. This is assumed possible due to the staged development, and the involvement of the large and experienced technology developer.

- The customer believes the technology is superior in economics and environmental performance to traditional combustion based plants.

\subsection{Unsuccessful Projects}

Unsurprisingly, detailed information on projects that have failed is not as readily available as that from successful operations. A brief overview, however, of a few plants with the apparent reasons for failure has been investigated. More failed projects than successful projects were examined not as a pessimistic view, rather several needed to be examined to establish common themes for failure and to gather enough information to compare against successful plants.

The following two projects are plants that were commissioned but subsequently shut down.

\subsubsection{Espenhain, Germany}

The information for this plant is found in the Handbook of Biomass Gasification (Ahrenfeldt \& Knoef, 2005).

The system comprised of three 'Juch' co-current gasifiers and a CAT engine genset sized at $850 \mathrm{~kW}_{\mathrm{e}}$. The fuel for the plant was demolition wood. The plant started in July 1997, although guaranteed power could not be reached. In fact only $50 \%$ of expected load was achieved. The company subsequently ran into financial difficulties and went bankrupt. Despite several modifications to the plant it never performed well. In 1999 a new project with an independent research institute began and performed R\&D on gas cleaning but without success. 


\subsubsection{Boizenburg, Germany}

The information for this plant is again found in the Handbook of Biomass Gasification (Ahrenfeldt \& Knoef, 2005).

The system consists of a CHP plant producing $3 \mathrm{MW}_{\mathrm{e}}$ via three Jenbacher engines. The gasification process used an updraft steam/air gasification agent as the basis but involved a complex three stage process. The plant was put into operation in 1999, however there were technical problems. There were high tar levels to the engine $>1$ $\mathrm{g} / \mathrm{m}^{3}$ as well as poor char quality, high water vapour in the gas, and low gas quality. In spite of plans to improve the plant it was mothballed in 2000.

The following two projects are summarised from the paper 'The influence of perceived uncertainty on entrepreneurial action in emerging renewable energy technology; biomass gasification projects in the Netherlands' (Meijer et al., 2007). The reason being there is very little available information in literature on such project failures. Interestingly the majority of references in the paper in relation to the project reviews were interviews with people involved indicating a lack of published information.

\subsubsection{NH project (Meijer et al., 2007)}

The project began in 1993 as a collaboration with the province of North Holland, and several energy companies announcing they would build the first large scale biomass gasification plant in the Netherlands. In the early stages the entrepreneurs involved were concerned over the uncertainty in relation to the availability and price of biomass, and also the technology not yet being proven. In 1998 there was a liberalisation of the energy market. This turned the energy companies into competitors and changed their focus to lowering production costs and making low risk investments. At many stages the project partners disagreed within the consortium. Opinions differed on which technological configuration was best, and which technology supplier to select. The various entrepreneurs were too diverse to collectively undertake the project. In 1998 the decision was made to abort the project influenced by a combination of perceived uncertainties and diminished motivation. 


\subsubsection{Amer project (Meijer et al., 2007)}

The Amer project started out similar to the NH project in that it was a collaboration with several energy companies, together with a biomass supplier. In 1995 they announced to build a large scale gasifier near an existing coal fired power plant. In this time the energy sector had high expectations about gasification and little perceived risk with the technology. It was assumed biomass gasification would be a modification of the already proven technology of coal gasification. However, the wood supplier withdrew from the project due to better markets for their wood elsewhere. The project stalled until a new long term wood contract with a supplier was obtained. A German technology developer was used to build the gasifier. The developer had never built biomass gasifiers before, only coal, although they were very confident in being able to develop a gasifier to run on wood. In 1999 construction of the plant began.

During commissioning there were many technical problems and stable operation of the plant was not possible. The differing process characteristics compared to operating on coal had been underestimated. Even given the poor performance of the plant the energy company Essent became very motivated to make the project work given the amount of time and money that had already been invested. The energy company Essent itself became actively involved in the technological development. Essent took over maintenance and operation of the plant and ceased the contract with the German technology developer. In 2005 the plant was finally operational. However, the government announced a new emissions law that incorporated the gasifier which would make the system economically unfeasible. While exemption from this law was applied for and promised by the government, the exemption never materialised and the law came into effect in December 2005. The gasifier was subsequently shut down.

\subsubsection{ARBRE plant.}

The ARBRE plant was an atmospheric gasifier combined cycle plant with a net output of $8 \mathrm{MW}_{\mathrm{e}}$ (Waldheim, 2006). The project was instigated in 1993 with an EU call for gasification plant proposals. The plant construction began in the spring of 1998, and 
the plant went into liquidation in July 2002 (Piterou et al., 2008). There are several reasons as to the demise of the ARBRE project including organisational, financial and technical factors. As with other failed plants in this review there were several parties involved in a joint venture, with different motivations for involvement. The main company that initiated and financed the project withdrew for commercial strategy reasons. Another crippling hurdle was the bankruptcy of the turnkey contractor which increased the construction time. The third main issue was technical problems with the plant. The plant was a complex BIGCC based process. The plant attempted to link components that had been tested individually but not as an integrated system. There were conflicting opinions of the actual technical feasibility of the plant (Piterou et al., 2008). Other references suggest some problems arose as the lowest cost option was often chosen which resulted in re-engineering (Waldheim, 2006). As well as the development of the plant, a supply chain of short rotation crops was set up with local farmers. This is seen as providing an extra complication to the overall project. Commissioning of the plant was never completed and liquidation followed. A key to the failure may have been the lack of suitable scrutiny and oversight of the plant (Piterou et al., 2008). If this were in place many of the organisational and technical issues may have been controllable.

\subsection{Conclusions as to the failures of the gasification plants}

- A major factor in the failure of the plants was technical difficulties. It is suspected a major reason for the technical difficulties was a lack of research, and therefore lack of understanding and underestimation of the issues surrounding biomass gasification. The difference in these cases to the successful Guessing plant was the collaboration between the university who had performed significant research in the area, and the energy company which understood plant design allowing relatively trouble free construction, commissioning, and ongoing operation.

- In the case of the Espenhain plant, the investor went bankrupt. Very few projects are without technical issues and the developing companies need to be large enough to absorb unforeseen start-up costs (Ahrenfeldt \& Knoef, 2005).

- For those scenarios mainly based in the Netherlands, there were a lot of different parties involved. Within these parties there were differences of 
opinion and varying levels of motivation. This caused at the very least delays in the project. This shows that projects with multiple investors can hamper progress and divergence within the investor group can lead to project failure.

- External policy changes can have a significant effect. In the Netherlands examples, including the liberalisation of the electricity market and changes in environmental laws crippled plants both in the start-up and operational phase.

- The more complex plants encountered more problems. It is better to keep a plant relatively simple.

\subsection{Varnamo plant}

This plant is included after the conclusions of the successful and unsuccessful scenarios as it somewhat doesn't fit into either category. The Varnamo plant is a pressurised IGCC plant designed to generate $6 \mathrm{MW}_{\mathrm{e}}$ and $9 \mathrm{MW}_{\text {th }}$ of heat for district heating (VVBGC, 2008). The Varnamo plant is different to most in that it was set up very much as a research facility to prove the technology, rather than being a commercial venture, and is run by a non-profit company (Waldheim, 2006). Interestingly the plant was shut down in 2000 once the demonstration and development program was complete as the electricity and heat sales did not cover the operating costs of the plant (VVBGC, 2008). The plant was restarted after reorganisation and further funding under the CHRISGAS (Clean Hydrogen-rich Synthesis gas) project. However in December 2007 the Swedish Energy Agency made a decision not to release any further funding for the rebuild of the plant (CHRISGAS, 2008). The reason being as quoted from the CHRISGAS intermediate report (CHRISGAS, 2008)

"It has not been possible to get industries to commit themselves fully and invest money into the project; this being viewed by STEM as being the way to move forward to commercialise the technology and develop the know-how expected to result from the project."

Currently effort is being made to resolve the financing situation to allow the rebuild and demonstration work to continue (CHRISGAS, 2008). 


\subsection{Overall learnings from overseas comparisons}

Comparing successful operations to the failed projects the following overall learnings can be established and carried forward when considering the feasibility of a biomass gasification plant in the New Zealand scenario

- In an ideal scenario involve a political figure that has a high level of motivation to push the project forward, in a location where there will be significant public support. If a plant would boost the local economy of an area it is much more likely to gain external support or at the very least less opposition.

- Have a very good understanding of government policy in regards to all aspects of plant operation and economics and be aware of any potential changes to policy and how they will affect the feasibility of the plant.

- Minimise the number of groups with an invested interest in a project. The groups involved should be an investor, a significant engineering company with relevant experience in the field that is capable of designing and constructing a plant, and a university or research environment that can answer technical questions in order to avoid underestimations or surprises in the commissioning phase.

- Lock in a stable biomass supply at an agreed price.

- Significant government support in both the capital investment, and ongoing operating costs/revenues such as a premium for green electricity will lower the perceived uncertainties with a plant increasing the likelihood of an investor taking interest in a project.

- While it is important to limit capital cost, this should not be at the expense of quality or functionality of the plant.

- Do not be overly ambitious in regards to plant design. Larger, more complex systems have larger, more complex problems to resolve. 


\section{The New Zealand Environment for Bioenergy}

\subsection{The Wood Scenario}

The wood scenario in terms of availability and price is one of much conjecture. While there have been several studies and reports (Cox, 2008; Hall \& Gifford, 2007; J. Li, 2008; Weir, 2008) the opinions as to the availability and price of suitable residues is varied.

For the base economic study the work performed in Objective 3 is used as the reference point. This is in keeping with the overall project flow and also consistency of comparison as this was the basis used by Rutherford (2006). Figure 2 shows the estimated biomass cost supply for the Canterbury Region and forms the basis for estimation of the wood feed cost for an energy plant in a sawmill or LVL setting.

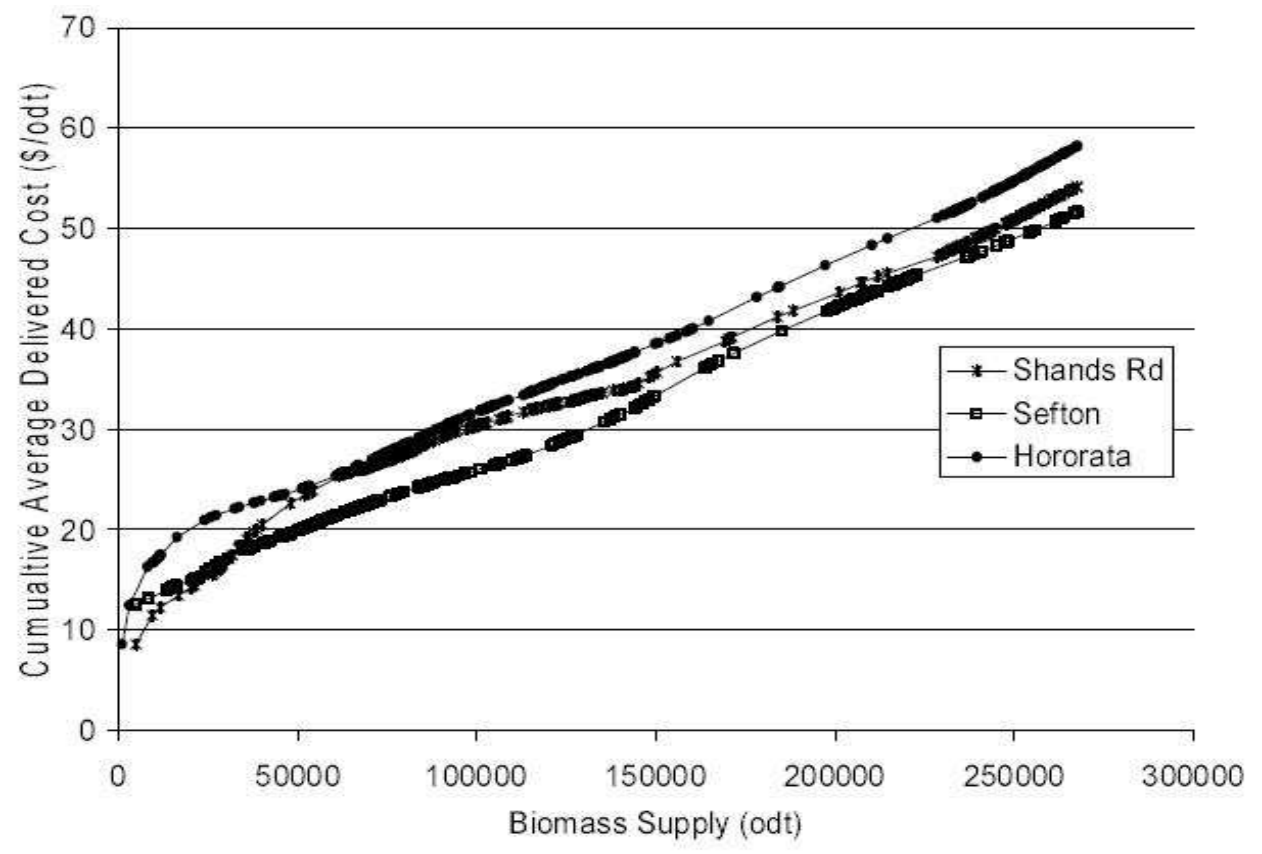

Figure 2: Biomass supply cost for the Canterbury region in oven dried tonnes (odt). (J. Li, 2008)

In the case of the LVL and sawmill setting approximately half of the biomass feed to the energy plant is comprised of residues assumed to be of little or no value. It should be noted the residues from a sawmill or LVL mill can supply enough biomass to meet their own energy needs (J. Li, 2008), however because of the high opportunity value of some of these products such as sawmill chip it is more sensible to sell this product 
and import lower value residues. The residues imported for the sawmill and LVL scenario have an approximate cumulative cost of \$20/odt resulting in an approximate biomass feed cost of \$10/odt for the scenarios.

Rather than attempt to justify wood cost in regards to the varying studies, the results section includes a sensitivity analysis (Section 6.2.1) of which wood cost is one of the factors. The reader can therefore extrapolate this sensitivity analysis to suit what they believe is an appropriate wood cost to their scenario. The cost in this section therefore can be considered a base, rather than an absolute value.

One also has to consider that although there are average figures as to the cost of residues, one would not build a plant based on average figures. A plant would likely be built in a niche scenario where there is a favourable wood resource. For example it would be logical to build a plant in an area outside of the economic working zone of a pulp mill in order to avoid competing for residues (Weir, 2008). This will be discussed in further detail in section 10.1 where the wood supply is compared with the power price by location.

\subsection{The Basic Power Scenario}

The electricity price used in the modelling is based on information sourced from the New Zealand Energy Data File 2007 (Dang \& New Zealand Ministry of Economic Development, 2007). For the base modelling scenario the prices are averages in the New Zealand context. Section 10 in the optimisation component of the thesis will investigate variations from average in the power price, based on both location and time of day.

The average price paid by the wood processing industry in New Zealand for electricity in 2006 was $10.46 \mathrm{c} / \mathrm{kWh}$. This is the price used for the economic analysis in this report. Also of importance is the buying vs. selling price of the electricity. The wood processing industry in 2006 had an average line charge of $1.44 \mathrm{c} / \mathrm{kWh}$ and this has been taken as the difference between the purchasing and selling price. This figure is an assumption as the actual selling price would be settled on a case by case basis, depending on the deal between the mill and the energy company. The price 
difference has an effect on the economics when internal electricity generation exceeds demand and the plant begins selling electricity back onto the grid.

\subsubsection{Future electricity price predictions}

Of importance to the study are future electricity prices. Figure 3 and Figure 4 show the historical electricity prices. Figure 3 is the nominal power price which is the actual price paid in $\mathrm{c} / \mathrm{kWh}$ while Figure 4 is the real price which has been corrected based on the consumer price index to give a more realistic interpretation of how the power prices have actually moved. Although the $\mathrm{c} / \mathrm{kWh}$ price of industrial electricity (Figure 3) has consistently increased over the past 30 years the real price once corrected has been relatively stable (Figure 4). Even the effects of deregulation in the late 1980's have not had a significant effect. Since approximately 2001 there has been a slight upwards trend in the industrial electricity price. This may be due to technological constraints coming into effect such as running out of generation and transmission capacity (Bodger, 2007), but it would be risky to extrapolate this slight upwards trend for the life of an energy plant as a basis for the economic study. It is, however, expected electricity prices will at the very least remain stable with the likelihood of increases. Therefore a conservative estimate of the electricity price for this economic study would be to use the 2006 figure as the continuous projection, with the understanding that the economics of an energy plant in this study are only going to improve with any electricity price increases.

Also likely to affect electricity prices within the next two decades is the New Zealand governments target of $90 \%$ renewable electricity by 2025 (Ministry of Economic Development, 2007b). As a general rule renewable based energy plants are more expensive than fossil fuel based energy plants. There will also be the cost of displacing and retiring fossil fuel plants which incurs a large investment. These factors increase the likelihood of power price rises. 


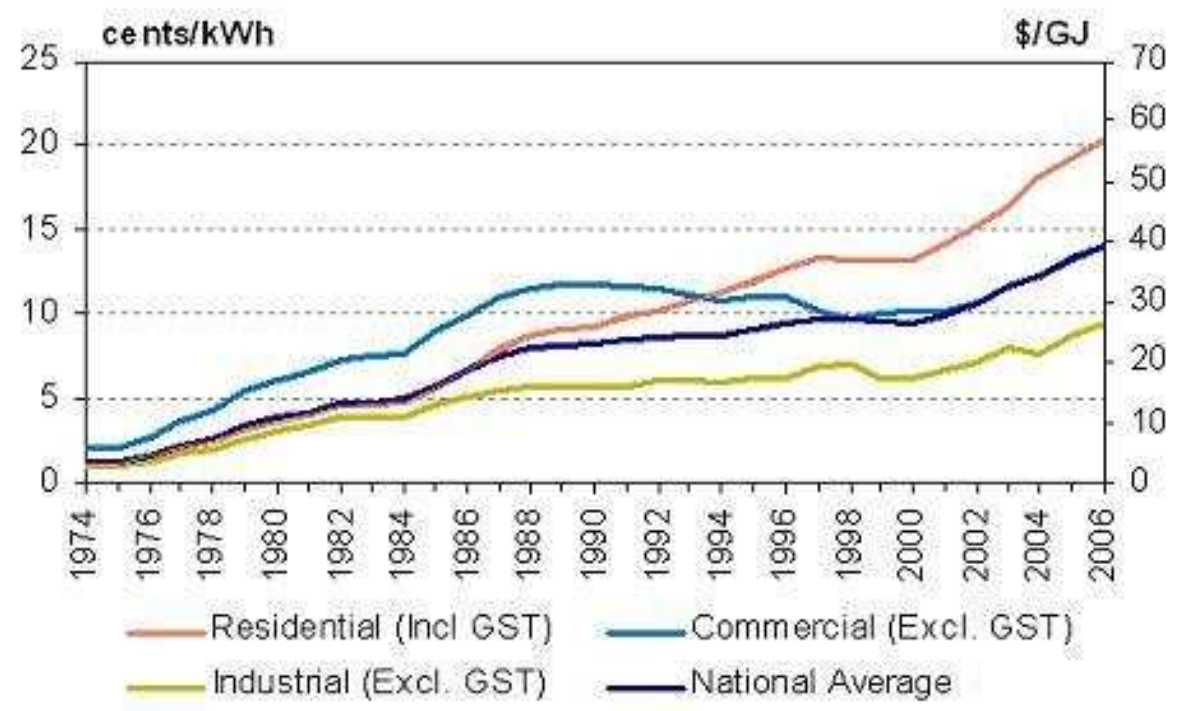

Figure 3: Historical electricity prices in New Zealand (Nominal). (Ministry of Economic Development, 2007a)

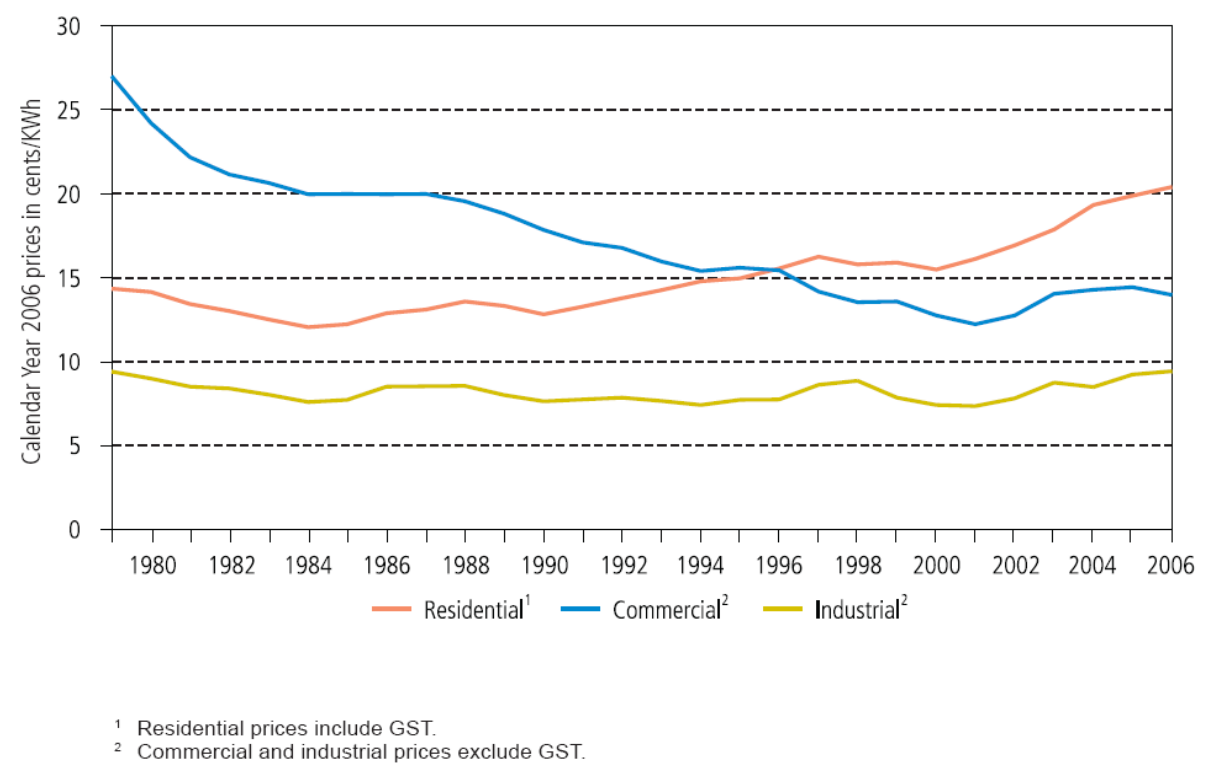

Figure 4: Historical electricity prices in New Zealand (Real). (Dang et al., 2007)

\subsubsection{Distributed Generation}

Currently distributed generation is not recognised widely in New Zealand. There are however a surprising number of distributed generators installed mainly as back-up generation. Distributed generation in New Zealand is somewhat of a niche market (CAENZ, 2003). The economics are dependent on many factors mainly influenced by the location of the installed generation. The fuel source and value, and the grid constraints and associated energy contracts need to be analysed on a case by case basis. 
For the scenarios in this thesis the energy plant will be situated in a mill supplying the power required by that mill. Even though the energy plant is able to supply the power requirements there is still the need to be connected to the grid as a backup if the energy plant fails. Under a normal scenario a user pays a line charge based on the peak load they draw. This is to cover capital and maintenance of the lines feeding the user. The issue with the scenarios in this paper is that while still connected to the grid there is still the liability for this cost whether power is being drawn through the lines or not. This obviously has a large influence on the economics. However, if there are grid constraints the associated lines company may come to an agreement with the generator to reduce this line charge, as local distributed generation may allow them to defer capital investment for that area (Bodger, 2007). This is an example of a niche market that would make the gasification plant more feasible. This scenario however is not particularly common place and can be the crippling hurdle for a distributed generation project. The government strategy (Ministry of Economic Development, 2007b) makes mention of continuing work to remove undue barriers to small scale generation and encourage development. What the actual tools are to promote this, however, is unclear at least in the current environment. Unless there is a relaxation or compensation in regards to the line charge it is unlikely there will be many economic opportunities for distributed generation in New Zealand other than niche opportunities where the grid constraints allow for a favourable contract because the generator has helped a lines company defer investment. For the purposes of this study the line charge has not been included in the calculations due to the potential for variability. One needs to assess how the line charge in a particular scenario would add or detract from the economics.

\subsection{Technology fit with government energy strategy}

The current government strategy is to work toward generation by $90 \%$ renewables by the year 2025 (Ministry of Economic Development, 2007b). The technology fits into this strategy for a number of reasons

- The process is renewable so doesn't contradict with the overall goal. Carbon released in the generation of energy is balanced by the carbon sequestered 
during the growth phase of the biomass. The process is therefore carbon neutral.

- The technology has the potential to provide extra employment and support in a local area, particularly remote areas with high unemployment.

- The CHP technology is very good base load. Other renewable technologies such as hydro and wind are dependent on nature and can't be relied upon to produce whenever needed. The CHP technology does not suffer from outside influences to the same extent making the technology good base load. One could argue that combined heat and power from biomass gasification is not THE technology rather it is a technology that is complementary to other forms of renewable electricity generation. In other words 'You shouldn't put all your eggs in one basket'.

Gasification also has the potential for more than combined heat and power applications. There is the potential for production of liquid fuels from the producer gas via the Fischer-Tropsch process. Installing the combined heat and power plants allows initial development and experience of the gasification technology. This experience provides a base for the development of liquid fuels from gasification. Government has announced the 'Biofuels Sales Obligation' of $3.4 \%$ of annual petrol and diesel sales by 2012 (Ministry of Economic Development, 2007b). Gasification has the potential to contribute towards this target. Gasification is therefore somewhat unique in that it can provide renewable heat, power, and liquid fuel all of which are complementary to the government's forward strategy.

Also raised in the strategy as an issue is visual impact. The strategy states some people believe wind farms have more impact on the environment than gas fired thermal plants (Ministry of Economic Development, 2007b). Gasification in a mill setting has very low visual impact. If installed on what is already an industrial site it is likely the public majority would not even realise an energy plant had been installed. A further benefit of the mill site in this respect is the fuel feed is in most cases predominantly, if not completely, provided as a residue from production. This minimises the necessity for extra transport of biomass to the site meaning very little extra truck loading on the roads. In the UK a survey of the public in an area where a 
gasification power plant was proposed showed very negative feelings towards such a plant with the biggest concern being the extra loading of trucks on the road (Upham \& Shackley, 2007). Gasification at an industrial wood processing site for the scale of plant discussed in this paper does not have this issue, as any extra truck movements necessary for supplying biomass would be a small fraction compared to the already existing truck movements to the site.

The New Zealand Energy Strategy (Ministry of Economic Development, 2007b) also comments that for industry there is the potential to greatly reduce emissions from industrial processes by improving efficiency, switching to lower carbon fuel sources 'from coal to gas or bioenergy' and increasing cogeneration. Gasification fits well with this goal as, if wide spread cogeneration is encouraged, there likely isn't enough large scale plants that could afford steam cycles due to the economies of scale required. Investment in smaller BIG-GE processes is potentially more feasible for the majority of smaller operators. 


\section{Base Economic Study Methodology}

\subsection{Introduction}

The purpose of this section is to create a model to predict the economic feasibility of a combined heat and power plant based on a BIG-GE system in both a sawmill and LVL mill. The methodology for creating the model is reviewed which is then applied in Section 5 and 6 to predict capital and operating costs. Results are discussed and comparison is made between the sawmill and LVL models as well as MDF from previous research (Rutherford, 2006).

\subsection{Overall Model}

The model developed to study economic feasibility uses a combination of Excel and HYSYS (heat and mass balance software).

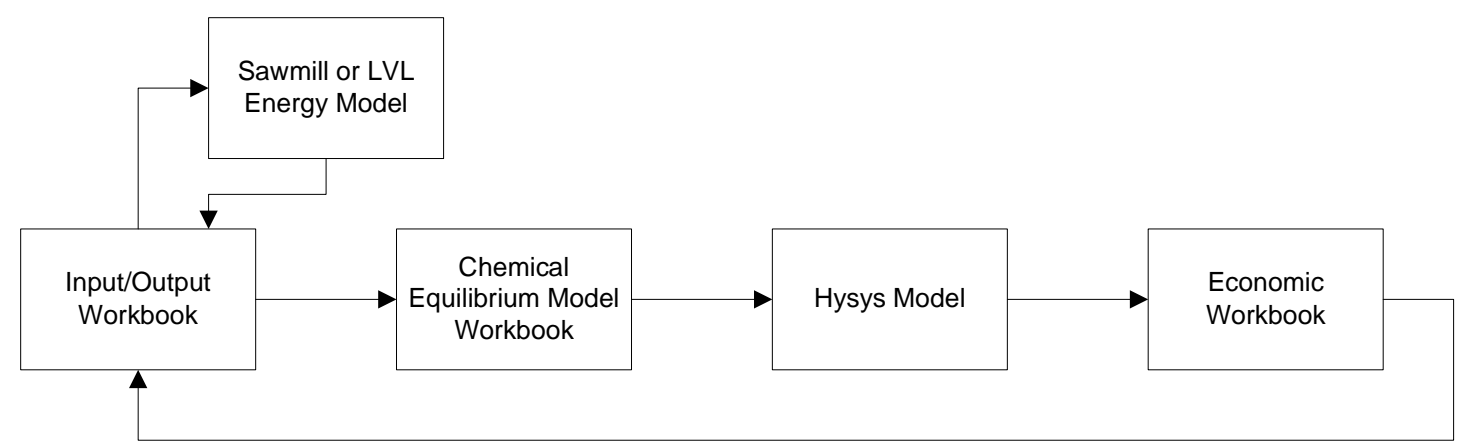

Figure 5: Flow diagram of economic modelling of gasification plant

As seen in Figure 5 the model can be broken up into four Excel workbooks, and one HYSYS model. The purpose, functionality and basis for each section is described below.

\subsubsection{Input/Output Workbook}

The Input/Output workbook is the main interface for the combined model. It is a means of collating the necessary information in a single sheet to feed to other workbooks in the model, as well as reporting back final results. 


\subsubsection{Chemical Equilibrium Model}

The chemical equilibrium model will not be explored in great detail in this report. The reason is that the model was originally developed by Rutherford and is described in detail in his thesis (Rutherford, 2006). A brief outline however is included for completeness. The chemical equilibrium model is used to predict gas composition and quantity from a gasifier based on user inputted parameters.

The model is based on the reaction

$\mathrm{N}_{\text {Wood }} \mathrm{CH}_{(\mathrm{H} / \mathrm{C})} \mathrm{O}_{(\mathrm{O} / \mathrm{C})}+\mathrm{N}_{\text {Steam }} \mathrm{H}_{2} \mathrm{O} \Leftrightarrow \mathrm{N}_{\text {Gas }}\left[x_{1} \mathrm{CH}_{4}+x_{2} \mathrm{CO}_{2}+x_{3} \mathrm{CO}+x_{4} \mathrm{H}_{2}+x_{5} \mathrm{H}_{2} \mathrm{O}\right]+\mathrm{N}_{\text {Char }} \mathrm{C}$

From this equation there are six unknowns that need to be solved for. Dalton's law and mass balances provide equations for four of the unknowns while using the $\mathrm{CO}$ shift reaction, and the steam methane reforming reaction the final two unknowns can be found.

CO Shift:

$$
\mathrm{CO}_{2}+\mathrm{H}_{2} \Leftrightarrow \mathrm{CO}+\mathrm{H}_{2} \mathrm{O}
$$

Steam Methane Reforming: $\mathrm{CH}_{4}+\mathrm{H}_{2} \mathrm{O} \Leftrightarrow \mathrm{CO}+3 \mathrm{H}_{2}$

To solve these equations it is necessary to have a value for an equilibrium constant. The constants are a function of temperature, which is in turn a function of composition therefore the model must be solved iteratively. The model uses Excel solver for convergence.

The model is based on several assumptions, chemical equilibrium being the most obvious one. However there are several other assumptions with the more important ones listed

- Uniform temperature in both the gasification and combustion columns.

- Temperature at which the reactions take place is equal to the gasifier temperature.

- The reactions modelled are representative of the reactions that are actually taking place in the gasifier. 
The model was applied by Rutherford both in the FICFB gasifier which has been constructed and tested at the University of Canterbury and an updraft gasifier which has been built by Page McCrae Engineering Ltd at a plywood mill. It was found that the model predicts the compositions of updraft gasifiers more accurately than that of FICFB gasifiers. The reason for this is that the gasification reactions in the FICFB have not reached equilibrium.

There is potential to develop the model further to try and account for the deviation from equilibrium, however for the purposes of this base economic study this development is not included. This is because the difference in the heating values between the actual and the predicted producer gases is minimal (Rutherford, 2006) and for an economic study the difference becomes insignificant. Also at the time of the economic study not enough consistent data from the lab scale gasifier was available to make valid modifications to the equilibrium model. Further discussion of equilibrium model modifications can be found in Section 8 .

The main inputs for the chemical equilibrium model as defined by the user are as follows

- Air preheat temperature

- Steam preheat temperature

- Char circulation fraction to circulating fluidised bed (CFB)

- Bubbling fluidised bed (BFB) temperature

- $\mathrm{CFB}$ temperature

The chemical equilibrium workbook has a worksheet linking the Excel models to the HYSYS model. The outputs of gas composition, flow, as well as other important parameters are imported into HYSYS to allow process modelling of the entire energy plant.

\subsubsection{Energy Demand Models}

For the economic modelling two energy demand models were used, one for the sawmill, the other for the LVL study. The energy demand models were built under Objective 3 of the BIGAS consortium (J. Li et al., 2006) so will also not be examined 
in detail here. The importance of the energy models in this context are the necessary inputs and outputs to allow the broader model to function.

\section{Inputs}

The energy demand models rely on inputs from the user for the following

\section{Sawmill}

- Production $\left(\mathrm{m}^{3} /\right.$ day)

- Log small end diameter (mm)

- Timber width (mm)

- Timber drying temperature $\left({ }^{\circ} \mathrm{C}\right)$

- Sawmill energy factor (somewhat of a rating of the age or advancement of the mill and whether the timber is planed or rough)

- Milling time per day (h)

\section{LVL}

- Production $\left(\mathrm{m}^{3} / \mathrm{y}\right)$

- Plant operating time of the LVL press both hr/day and days/year

- LVL density $\left(\mathrm{kg} / \mathrm{m}^{3}\right)$

- Log conditioning method - either vats or drive in chamber

- Heat source in press - either electricity or steam

\section{Outputs}

The outputs of the model are critical for the success of the broader modelling of the gasification plant. The important outputs of the model are as follows

\section{Sawmill}

- Log input required $\left(\mathrm{m}^{3} /\right.$ day $)$

- Wood waste generated ( $\mathrm{kg} / \mathrm{day})$

-Shiving

-Chip

-Sawdust

-Bark

- On production electrical load (MW) 
- Off production electrical requirement (MW)

- Thermal energy requirement (MW)

\section{LVL}

- Steam requirement $(\mathrm{kg} / \mathrm{h})$

- Electricity requirement (MW)

- Wood waste generated $(\mathrm{kg} / \mathrm{h})$

$$
\begin{aligned}
& \text {-Dry } \\
& \text {-Green } \\
& \text {-Bark }
\end{aligned}
$$

\subsubsection{HYSYS modelling}

The HYSYS model is used to solve for heat and mass flows in a candidate flow diagram. HYSYS also assists in the economic costing section of the model as it is used to size many of the unit operations.

It is possible to link between Excel and HYSYS which allows it to function within the broader model. The main inputs to the HYSYS model are

- Gas composition

- Gas flow

- Gas temperature

- Engine efficiencies

- Engine power required

- Steam required and steam loss

- Gasifier air and steam preheat requirements

The model assists in sizing much of the equipment such as heat exchangers and the boiler, and calculates flow rates of various working fluids in the process.

The heat exchanger sizing yields a UA (product of heat transfer coefficient and heat exchanger area). From data in literature of heat transfer coefficients $\left(\mathrm{U}-\mathrm{kW} / \mathrm{m}^{2} . \mathrm{K}\right)$ for each of the applications, an area can be generated for the heat exchangers which can be used in economic correlations to calculate cost. The boiler is sized in terms of $\mathrm{kW}$ output and this can be used directly with correlations to gain a capital cost. 


\subsubsection{Economic Modelling}

The economic model is the most important workbook in the broader model. The economic model predicts the capital cost of the plant based on the sizing parameters from the other workbooks. From the capital cost and other parameters an operating cost is calculated. This enables a cash flow analysis to be performed using NPV techniques to determine if the plant is economically feasible.

\subsubsection{Capital Cost}

The capital cost of the plant has been generated from various sources. Wherever possible available costs from manufacturers have been used, otherwise costing relationships have been predominantly based on data produced by the Society of Chemical Engineers New Zealand (SCENZ) (Bouman et al., 2005) and from Chemical Engineering Process Design and Economics (Ulrich \& Vasudevan, 2004). The costing relationship of the main equipment items is discussed with each item in section 5.1. The cost was estimated based on a bare module cost multiplied by an installation factor specific to the individual item. The installation factor is also discussed with each main plant item in section 5.1.

\subsubsection{Operating Cost}

The operating costs for the plant were calculated predominantly based on the guidelines of Ulrich and Vasudevan (2004). Where possible actual estimated costs were used rather than simple relationships in an attempt to improve the accuracy of the operating cost prediction. Important or significant items in the plant operating cost have been discussed below.

\subsubsection{Maintenance Costs}

A simple approach to maintenance costs has been employed based on a percentage of the fixed capital (total excluding working capital) investment spent per annum on maintenance. In this case 2\% was used (Ulrich \& Vasudevan, 2004). It should be noted this is at the lower end of the maintenance cost percentage range, however, it was deemed appropriate for the following reasons. 
- While the plant is technically novel in its totality the majority of the equipment is fairly common such as the feed system, boiler, heat exchangers, and gas engine.

- The gas engine is a significant part of the capital cost and Jenbacher claim long service intervals and maintenance friendly design (GE Jenbacher, 2005).

The overall maintenance figure is slightly higher compared to previous work by Rutherford, but it is deemed appropriate for the selected scenario.

\subsubsection{Operating Labour}

For operating labour it was estimated the plant would need two full time operators, one operator predominantly dealing with the front end of the plant ensuring wood supply to the gasifier, and another running the gasifier, engine, and boiler. In a sawmill situation it is common for the kiln operator to operate the boiler, therefore, there would be extra backup assistance when necessary. Also because an LVL plant is a $24 \mathrm{hr}$ operation, it is possible extra assistance would be available if required.

Common shift patterns are either a spare man per shift, or a spare shift. The extra person or shift is required to fill holidays, training, or sickness. The shift pattern chosen is that of a four on four off 12 hour shift with a spare shift. This requires four main shifts and a spare shift totalling 10 operators. This is more efficient than a spare man scenario which would require 12 operators. Operators are paid \$20 per hour. A simple gas engine/gas boiler system has labour cost advantages over a BIGCC process because of the steam pressures involved. BIGCC processes have high steam pressure requiring operators to hold a first class stationary engine drivers certificate (EECA, 2007). Operators with this qualification are sought after and therefore command a higher salary. 


\section{The Plant Design}

The purpose of this section is to outline the plant design, and then to review the main plant items including, in some cases, alternatives to those designs selected. Costing relationships will be incorporated in the discussion of each main plant item.

The following flow diagram (Figure 6) represents the process that has been modelled. This process is a BIG-GE arrangement. Note that the energy plant flow diagrams for sawmills and LVL plants are the same. This is because they both have requirements only for steam and electricity albeit in different ratios. The MDF plant studied previously varied from this as it had thermal oil and hot air requirements and the detail of the MDF energy plant can be found elsewhere (Rutherford, 2006). 


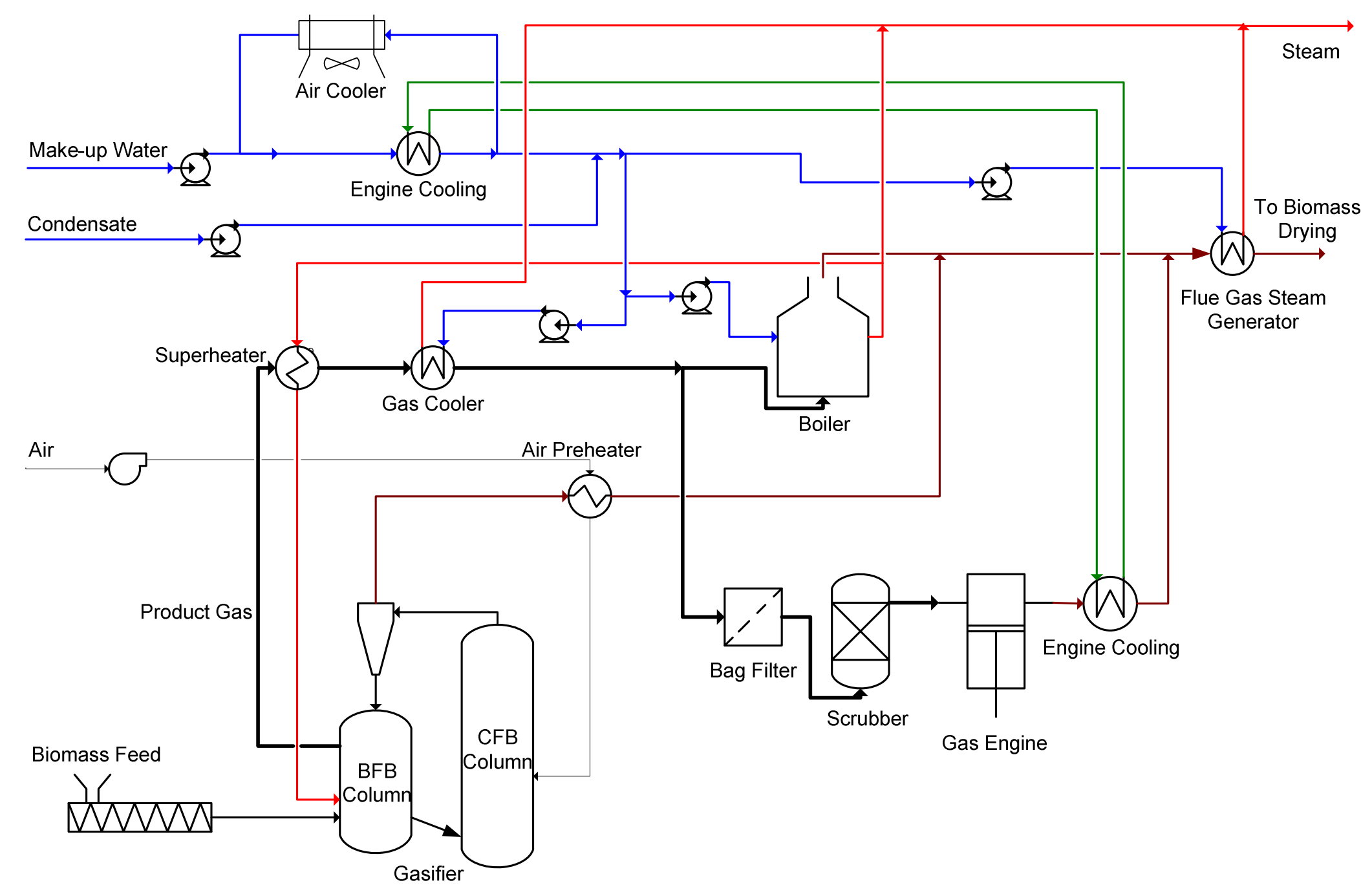

Figure 6: The BIG-GE process modelled in this study 


\subsection{Main Plant Items}

\subsubsection{Feed Handling}

The feed handling for a biomass gasification process is an area that is often not seen as a key part of the process. In typical flow diagrams found in literature wood is shown entering the gasifier with few details prior to this point, however, the feed handling is a very challenging part of the process. The reliability of a gasification process can be greatly affected by how well the handling system produces a consistent feed and is the Achilles heel of many plants. Biomass is inherently difficult to handle because it can vary in density, particle size, and moisture content. Depending on the source or method of hogging or size reduction the biomass may flow poorly and be very stringy (Ahrenfeldt \& Knoef, 2005). This makes the feed handling section a major consideration of any gasification plant. It also makes it very difficult to allocate a capital cost in a general economic study, because the complexity and therefore cost of any feed handling system is a function of the type of material, and the location. For example, a stand alone site using waste wood from landings would need much more equipment for processing than a sawmill where it is likely size reduction equipment and storage is already in place, at least to a limited extent.

For the purposes of this investigation, approximations of cost developed from personal communications between Rutherford and Brightwater Engineering (Rutherford, 2006) have been used to economically model the process. The feed handling system is based on generalisations of what would be required to feed systems of varying size and takes into account feed conveyors and storage.

\section{Costing Relationship}

From approximate costs by Brightwater Engineering for feed handling systems of various capacity the following relationship was formed

Installed Cost $(\$ N Z)=4 \times 10^{5} m^{0.60}$

Where $m$ is biomass flow in $\mathrm{m}^{3} / \mathrm{hr}$

Note that this is the total installed cost of the feed handling system therefore an installation factor is not applied. 


\subsubsection{Drying}

The drying step in a gasification plant is a significant unit operation in terms of both the influence on the process, and the associated capital cost. The moisture content of biomass from either sawmills or LVL mills has the potential to be quite high. For the modelling process green wood moisture content has been assumed to be $120 \%$ dry weight basis. This is a high value but it has been selected to be conservative in equipment sizing. Because the majority of the waste wood feeding the gasifier is green wood the drying process is critical for efficient operation of the gasifier. High moisture content will lower the gasification temperature increasing the production of tars, and give an overall lower quality producer gas and conversion efficiency (Brammer \& Bridgwater, 1999).

There are several types of dryer that may be suitable for an integrated gasification plant (Brammer \& Bridgwater, 1999)

- Batch through-circulation

- Continuous through-circulation

- Direct rotary

- Indirect rotary

- Fluid bed

- Pneumatic conveying

The two systems considered as most suitable for the purpose of this base study are that of batch through-circulation and direct rotary as they represent either end of the suitability vs. capital cost spectrum.

Batch through-circulation dryers in the context of biomass gasification are commonly in the form of bin dryers. This involves a bin with a perforated base through which hot gases are passed (Figure 7). The advantages of this system are that they have efficient heat and mass transfer, high capacity, suitability to use low grade heat, and simplicity hence lower capital cost. The main disadvantage of this system is the variation in moisture content produced throughout the bed, which will transfer moisture content fluctuations through to the gasifier. In spite of this disadvantage this 
method of drying can be found in some established gasification plants and is particularly suitable for small scale operations (Campion, 2006). It is suspected the main reason for choosing the batch through circulation method, despite its disadvantages, is the lower capital cost compared to other options.

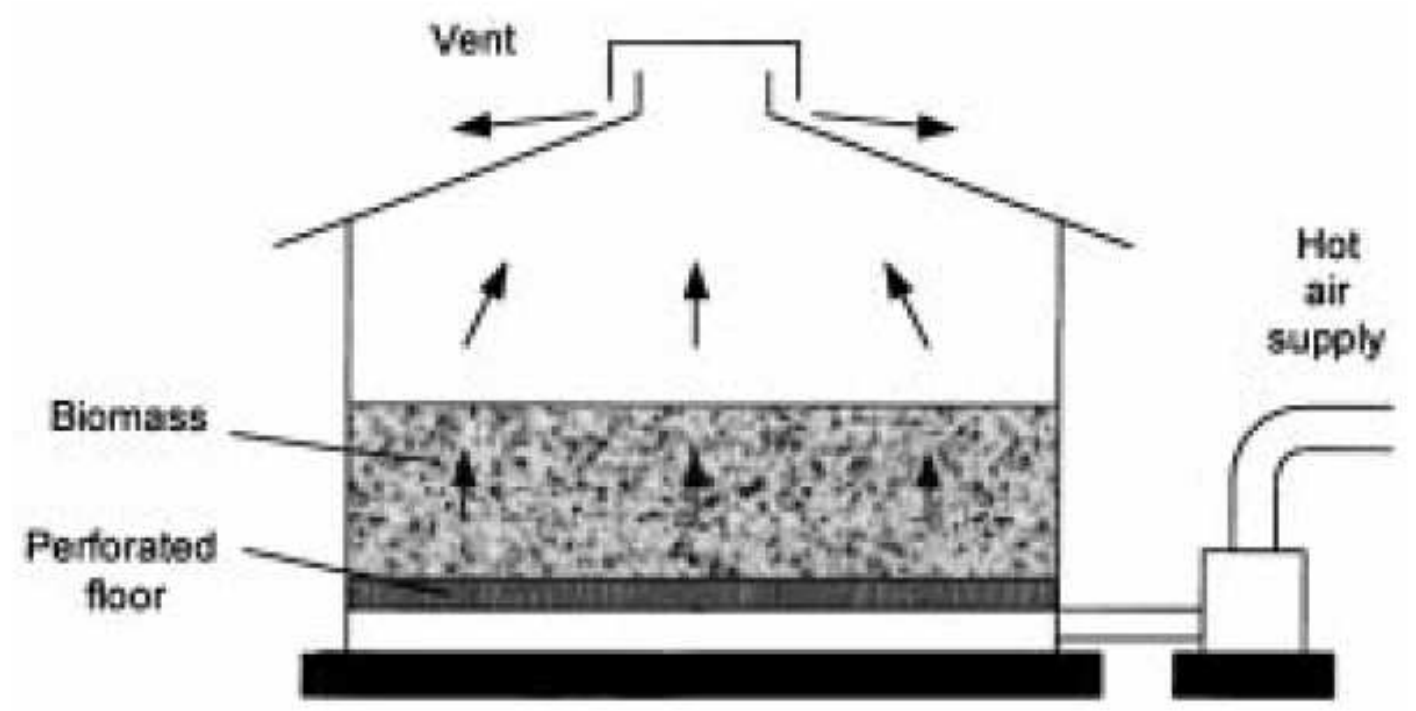

Figure 7: Example of a perforated floor bin dryer. (Brammer \& Bridgwater, 1999)

The direct rotary dryer is the most common system in existing large scale gasification plants (Brammer \& Bridgwater, 1999). It is a well understood technology and is therefore considered a low risk drying option. The main advantage of this system over a batch process is the consistency of moisture content, whereas the primary disadvantage is the higher capital cost.

The dryer itself is a cylindrical shell inclined slightly to allow travel of material through the dryer during rotation. In the case of a gasification plant flue/combustion gases can be used as the drying medium and are passed through the dryer in either a co-current or counter-current flow arrangement. In the cylinder lifting flights are used to lift the biomass and then cascade it through the drying gasses. The general arrangement can be seen in Figure 8 and Figure 9. 


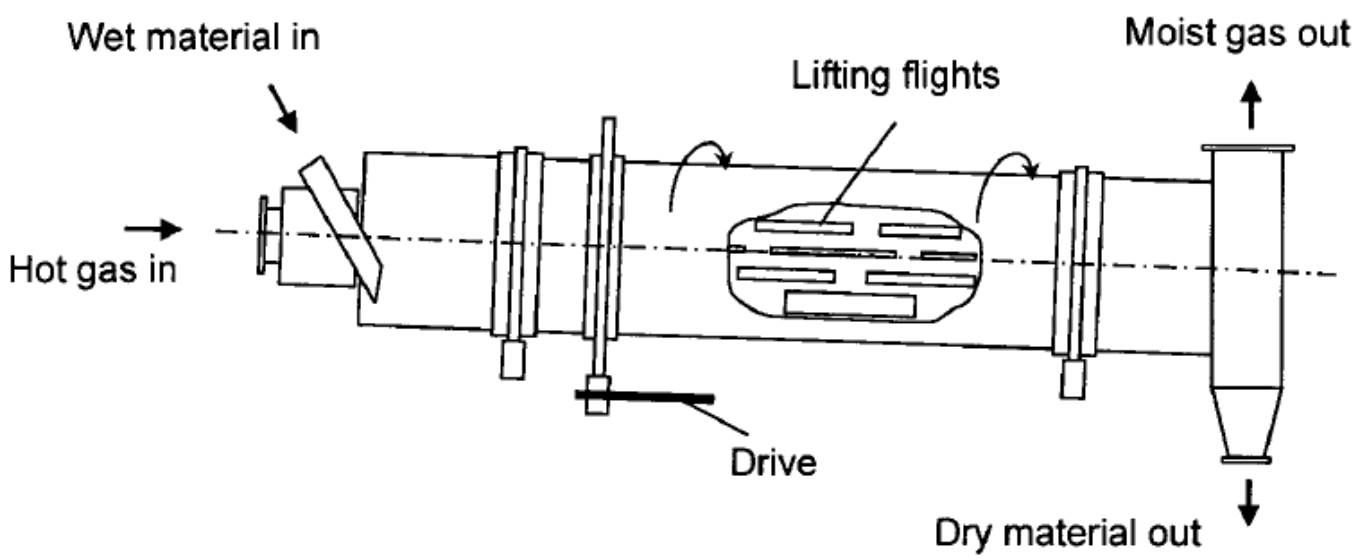

Figure 8: Example of a rotary cascade dryer. (Brammer \& Bridgwater, 1999)

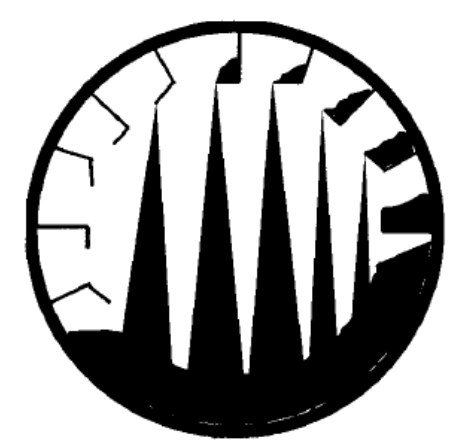

Figure 9: Flow pattern of material inside a rotary cascade dryer. (Brammer \& Bridgwater, 1999)

For the following reasons the method of drying chosen, as best suited to this study, is the direct rotary system.

- It is well understood, common for bigger gasification plants, and sizing and pricing information is available.

- The uniform moisture content achievable with a direct rotary drier is considered very important for the operation of the gasifier.

- The previous study into gasification plant at MDF mills (Rutherford, 2006) used this type of drying. Because the sawmill and LVL models will be directly compared against the MDF mill similar drying technology is incorporated into the plant.

It is a typical approach in initial design or case studies to start with the best technology for the required task, and then make concessions based on budget constraints as they are deemed necessary. Once the most feasible plant out of MDF, 
sawmills, or LVL plants is selected, further study may reveal where concessions are possible to make a gasification plant more economically viable. It is very likely the drying system would be one area of compromise due to the significant capital cost and availability of much cheaper alternatives, if the disadvantages of those alternatives can be managed.

\section{Costing Relationship}

The costing relationship for the rotary drum dryer obtained from literature (Brammer $\&$ Bridgwater, 2002) is represented below. This is the method used in previous work (Rutherford, 2006)

$\operatorname{MPIC}(\mathrm{k} \$ N Z)=15 *\left[\left(\frac{0.971}{x^{2}}-\frac{0.479}{x}+11.0\right) \frac{Q}{\Delta T}+k\right]^{0.863}$

Where MPIC is the main plant item cost

$\mathrm{x}$ is the mean biomass moisture content $(\%)$

$\mathrm{Q}$ is the heat transferred to the biomass $(\mathrm{kW})$

$\Delta \mathrm{T}$ is the mean temperature difference between the gas and biomass $\left({ }^{\circ} \mathrm{C}\right)$

$\mathrm{k}$ is a constant of 93.2

The installation factor selected for this drying system is 2 .

This relationship was recognised, however, as providing very high capital cost at higher biomass moisture contents. Communication with New Zealand manufacturers (Fernando, 2008) provided a much lower capital cost and is approximated by the relationship below.

Installed Cost $(\$ N Z)=3.5 \times 10^{5} x+3.5 \times 10^{5}$

Where $x$ is the total moisture removed during drying $(\mathrm{t} / \mathrm{hr})$

\subsubsection{Gasifier - FICFB}

The type of gasifier chosen for the study is a FICFB gasifier. The reasons for selecting this type of gasifier for the study are as follows: 
- A FICFB gasifier produces a gas with a higher calorific value than traditional air blown gasifiers which makes the producer gas more suitable for use in a combustion engine.

- There is an example in Austria where a pilot scale cogeneration plant has operated successfully for over 4 years with this type of gasifier (Rauch et al., 2004).

- There is a laboratory scale $100 \mathrm{~kW}$ gasifier running in the University of Canterbury Chemical Engineering Department, therefore data and experience is available for this gasifier design.

The main disadvantage of this type of gasifier is its complexity, which adds capital cost and operational challenges, but the advantages are seen to outweigh these.

The gasifier as shown in Figure 10 is made up of two main columns, the CFB (Circulating Fluidised Bed), and the BFB (Bubbling Fluidised Bed).

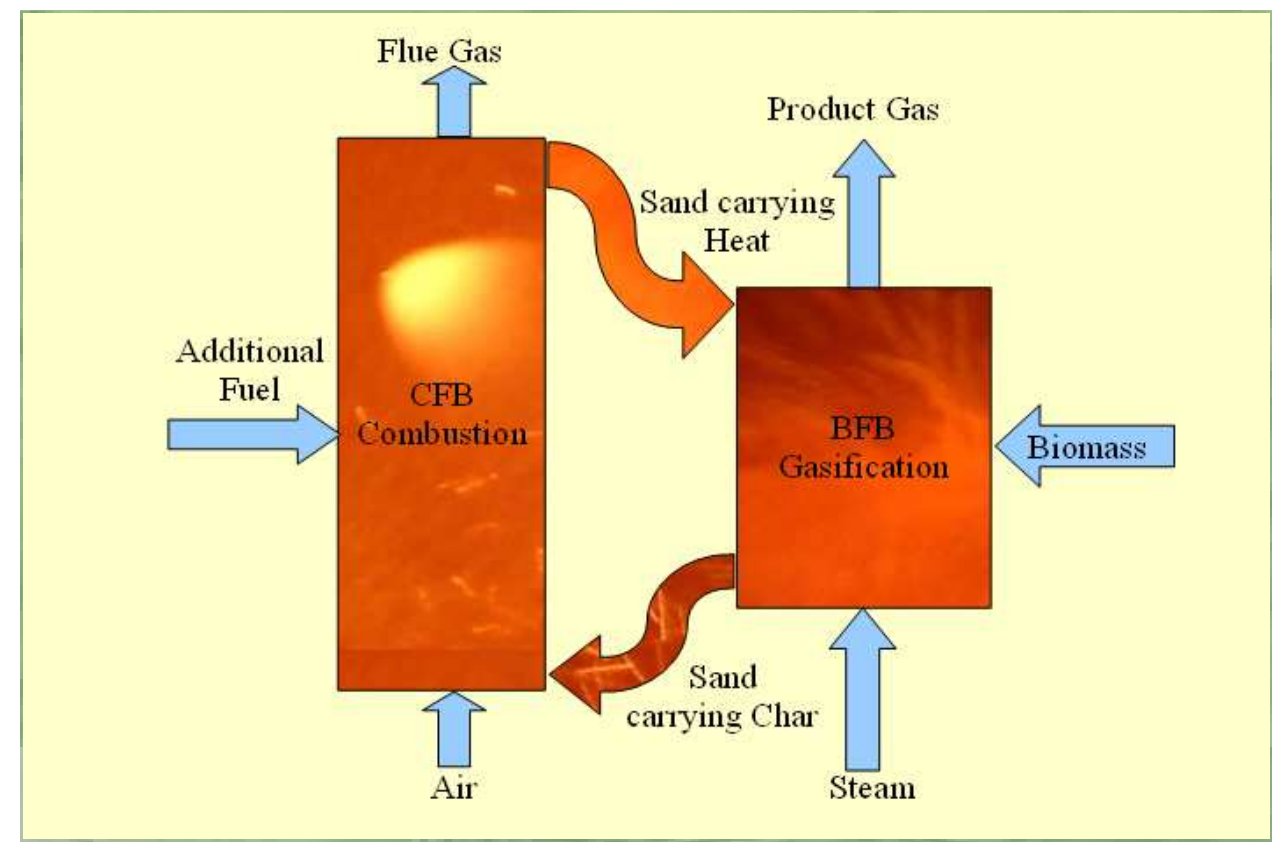

Figure 10: Layout of FICFB gasifier. (Rutherford, 2006)

Sand is circulated through the CFB where it is heated by combustion of char, and if necessary also by supplementary gas. The sand enters the CFB cyclone where the combustion gases are separated and the hot sand can enter the BFB. The BFB is where the gasification reactions take place. Wood is fed into the column near the 
bottom, and superheated steam is injected from the column base to aid the gasification reactions and fluidise the bed. Char and bed material flows through the chute back to the CFB to repeat the cycle.

\section{Costing Relationship}

The costing relationship used for the gasifier was the method developed previously (Rutherford, 2006). This was chosen primarily because the gasifier is such a novel part of the plant and solid costing data is not available. It is also less likely the consistency for comparison would exist if the gasifier costing was performed independent of previous research.

\section{Columns}

Steel \$NZ $=\left(3952 D_{r}+965\right) H_{r}{ }^{\left(0.9749-0.0518 D_{r}\right)}$

Refractory $\$ N Z=\frac{48}{25} M_{\text {hotface }}+\frac{28}{15} M_{\text {coldface }}$

Where $D_{r}$ is the diameter of the reactor (m)

$H_{r}$ is the height of the reactor (m)

$M_{\text {hofface }}$ is the mass of hot face refractory required $(\mathrm{kg})$

$M_{\text {coldface }}$ is the mass of cold face refractory required $(\mathrm{kg})$

Installation factor 6

\section{Cyclones}

Cyclone $(\$ N Z)=2330 \dot{q}_{c y c}{ }^{0.912}$

Where $q_{c y c}$ is the is the volumetric flow through the cyclone factored for the refractory lining $\left(\mathrm{m}^{3} / \mathrm{s}\right)$

Installation factor 6

\section{Blowers}

Blower $(\$ N Z)=771 \dot{q}_{\text {air }}+2.4 \times 10^{3}$

Pressure Correction factor $=0.2164 \ln \left(P_{\text {blower }}\right)+1$ 
Where $\dot{q}_{\text {air }}$ is the volumetric flow of air provided by the blower $\left(\mathrm{m}^{3} / \mathrm{s}\right)$

$P_{\text {blower }}$ is the blower operating pressure $(\mathrm{kPa})$

Installation factor 3

\section{Gas Burners}

\$NZ 12,000 each

Installation factor 2

\subsubsection{Gas Cleaning}

The major challenge with gasifiers is to clean the producer gas by removing particulates and tars. This is especially a problem when the gas is to be used in an engine. In this study a two-stage cleanup is used consisting of a filtration stage and a scrubbing stage. This is similar to that at the Guessing plant and also to that used in the previous study (Rutherford, 2006).

For the filtration stage a bag filter is used. At the Guessing plant the bag filter removed $99 \%$ of the particulates and between 20 to 30\% of the tar (Hofbauer, Rauch, Loeffler et al., 2002). The use of the bag filter is very simple from an economic modelling perspective as correlations are readily available.

The second stage of cleaning is a scrubber using bio-diesel as the scrubbing liquid. Liquid from the scrubber is purged off and burnt in the CFB. This means there are no liquid wastes from the gas cleaning stage. This is the arrangement used at Guessing where it achieves 98-99\% removal of the tar (Hofbauer, Rauch, Loeffler et al., 2002).

Cooling of the producer gas prior to the bag filter brings the temperature to 150$180^{\circ} \mathrm{C}$. Cooling in the scrubber itself yields a gas at approximately $40^{\circ} \mathrm{C}$ which is suitable to feed the gas engine (Rauch et al., 2004).

Currently progress on Objective 2 in the BIGAS Consortium is underway with a more novel design towards gas cleaning using a scrubbing and regeneration system. This is 
in early stages of development and testing, therefore, will not be used as the basis for this study.

\section{Costing Relationship}

Two separate costing relationships were used for the bag filter and the scrubber. Both were calculated based on equations fitted to graphical data (Ulrich \& Vasudevan, 2004).

Bag filter

$\operatorname{MPIC}(\$ N Z)=23355 \dot{q}^{0.6622}$

Scrubber

$\operatorname{MPIC}(\$ N Z)=22199 \dot{q}$

Where $q$ is the mass flow of gas $\left(\mathrm{m}^{3} / \mathrm{s}\right)$

The installation factor used was 4 for the bag filter and 6 for the scrubber.

\subsubsection{Heat Exchangers}

In general the heat exchangers selected for the plant were of shell and tube type. The reason for selecting this type is they are considered the most suitable for the application, while the capital cost is reasonable when compared to other types such as plate heat exchangers (Bouman et al., 2005). They are by far the most common heat exchanger configuration (Smith, 2005) and depending on the particular design can be used in most applications (Ulrich \& Vasudevan, 2004). They are generally accepted as being easy to maintain and clean and so are a logical choice for the plant.

\section{Costing Relationship}

The costing data (Bouman et al., 2005) is based on heat exchanger area. The HYSYS model produced provides a UA for the heat exchangers. Values from literature for $\mathrm{U}$ were obtained Table 2 for each scenario to allow an area to be calculated. 
Table 2: Heat Exchanger heat transfer coefficients (U). (Douglas, 1988)

\begin{tabular}{lc}
\hline Heat Exchanger & $\mathbf{U}\left(\mathbf{W} / \mathbf{m}^{2} \cdot \mathbf{K}\right)$ \\
BFB steam superheater & 56.8 \\
BFB steam generator & 78.5 \\
Waste gas steam generator & 78.5 \\
Engine cooling external exchanger & 284 \\
CFB air preheater & 56.8 \\
\hline
\end{tabular}

The costing relationship for heat exchangers in this study is

$\operatorname{MPIC}(\$ N Z)=15300 A^{0.566}$

Where $\mathrm{A}$ is the heat exchanger area $\left(\mathrm{m}^{2}\right)$

The installation factor used for heat exchangers was 2.

\subsubsection{Boiler}

The producer gas generated in the gasifier can be burnt within a typical gas fired boiler. The advantage of this is twofold. There is already a large base of existing technology and experience, and a gas fired boiler is considerably cheaper than an equivalent sized solid fuel boiler (Bouman et al., 2005). This helps offset some of the cost of a gasification front end. In fact it is widely agreed there are potential economic advantages to a gasifier/gas boiler system as a direct replacement to a conventional solid fuel boiler. This, however, would only apply to a simple gasifier such as an updraft. The simplicity lends itself to lower cost and improved reliability while tar content and gas heating value are not of such a concern in a boiler. There is no particular advantage to using a FICFB gasifier in a boiler only application.

In the case where steam supply is absolutely critical at very high operational efficiencies and the reliability of the gasifier is questionable during early development, a gas backup for the boiler would not be difficult. However, for the purpose of this study the gasifier is assumed to be reliable and a gas backup has not been incorporated into the capital cost.

\section{Costing Relationship}

The costing relationship (Bouman et al., 2005) based on a gas fired boiler is

$\operatorname{MPIC}(\$ N Z)=532 Q^{0.805}$

Where $\mathrm{Q}$ is the heating duty of the boiler $(\mathrm{kW})$ 
Installation factor 2

\subsubsection{Gas Engine}

The gas engine selected for the process is a Jenbacher engine. The reasons for selecting this type of engine are

- There are Jenbacher engines specifically designed for gaseous fuels with lower heating value.

- There are a variety of Jenbacher engine sizes and configurations available to suit the applications within this study.

- Specific examples are available of successful installation of Jenbacher engines in gasification plants (Hofbauer, Rauch, Bosch et al., 2002).

- It was the engine used in the MDF study previously (Rutherford, 2006) so will serve as a useful comparison.

- Jenbacher engines have high energy conversion efficiency for a gas engine.

Jenbacher engines employ lean burn technology where there is an excess of air over stoichiometric requirements. This technology yields higher efficiencies and lower emissions. Typical efficiencies for Jenbacher engines are $42 \%$ electrical efficiency and $43 \%$ thermal efficiency giving an overall energy utilisation efficiency of $85 \%$ (GE Jenbacher, 2006). This overall efficiency being realised, relies on having a use for the thermal energy. Some of this energy is low grade heat which has limited value in a sawmill or LVL plant.

The disadvantage of the Jenbacher engine is it's high capital cost. This is partly due to the small demand in the market. However as previously stated the normal practice is to initially price the best equipment available and make concessions from there. The alternatives are either a specific low calorific value gas engine from a lower priced manufacturer, or the budget option of a diesel engine either dual fuelled or converted to spark ignition. The latter is a suitable option for a simple demonstration plant where a manufacturing process is not critically linked to the reliability of the engine. 


\section{Costing Relationship}

Rutherford used the following costing relationship in his calculations (Rutherford, 2006). Because it is such a large capital cost the same relationship has been used for consistency allowing suitable comparison.

$\operatorname{MPIC}(\$ N Z)=839 P_{e}$

Where $P_{e}$ is the engine electrical output (kW)

The installation factor for the engine is 2 .

\subsubsection{Air Cooler}

Low grade heat is a by-product of the process from using a gas engine. In certain applications there is a sink for this heat such as district heating schemes. Unfortunately, except for heating boiler makeup water there is not a complete use for this heat in the process and other means of cooling for the engine are necessary.

The main options for cooling are either an air cooler or a closed or open water cooler. There are advantages and disadvantages of both and generally the non economic factors are balanced and the decision is made on cost (Ulrich \& Vasudevan, 2004). In this case an air cooler is chosen, because the disadvantages, such as a larger footprint and noise, are not of significant concern given their intended placement at an industrial site.

\section{Costing Relationship}

The cooler capital cost was calculated based on an equation fitted to graphical data from Gerrard (2000).

$\operatorname{MPIC}(\$ N Z)=6929 \ln \left(6.59 \times 10^{-2} Q\right)-3028$

Where Q is the heat load of the cooler $(\mathrm{kW})$

An installation factor of 2 was applied. 


\section{Results and Discussion for Base Economic Study}

\subsubsection{Capital Cost}

From the correlations and estimates outlined in section 3.1 capital costs have been estimated for sawmills and LVL plants. It is difficult to directly compare capital costs as each plant has different heat and power requirements therefore capital costs vary. However, it is beneficial to use a case study of an energy plant that will meet both heat and power requirements of a typical sized sawmill and LVL plant and compare the total capital costs. This will give an instant indication of the likelihood of a mill being able to invest in a plant.

For the initial capital and cash flow analysis the energy plants have been sized to meet the thermal and electricity demands of the associated wood processing plant. The reasons for sizing in this manner are

- Previous research (Rutherford, 2006) indicated that this is the most economic in an MDF setting, therefore it would likely follow suit for sawmills and LVL plants.

- It is logical and likely that a mill would size a plant to be energy self sufficient but not invest further capital for surplus generation.

- It is easier to show the breakdown of capital in a single case study for each scenario.

\subsubsection{Operating Cost}

While capital cost of the plants serves as a useful indicator it needs to be combined with the operating cost to truly gauge if it is economically viable.

In calculating operating cost the question arose as to whether the energy plant should be considered as a separate business entity. If the energy plant was not considered a separate business entity the taxation on the energy plant would be affected, depending on how the rest of the mill was performing economically. Because this will differ on a case by case basis it is more appropriate to treat the energy plant as a separate business entity, taxed in its own right. 
Using a typical profit and loss statement approach (see example in Table 36 Appendix A) for calculating the value of the plant, the revenue is calculated as the saving from not purchasing steam and electricity. The value of steam is taken as $\$ 8 / G J$ (East Harbour Management Services, 2005) and the cost of electricity as $10.46 \mathrm{c} / \mathrm{kWh}$ (Dang \& New Zealand Ministry of Economic Development, 2007). The electricity price was based on the average price paid by the wood processing industry for the 2006 March year. The costs of running the plant are used as the operating expense allowing a profit to be generated for use in cash flow analysis.

\subsubsection{Sawmill}

The size of the sawmill chosen for comparison is $103,000 \mathrm{~m}^{3} / \mathrm{yr}$ of sawn timber. The energy model is based on $300 \mathrm{~m}^{3} /$ day ( 8 hour milling, 24 hour drying) but an availability of $95 \%$ is assumed. This could be considered a larger than typical sawmill, but it is unrealistic to think a smaller sawmill could afford the capital cost of a cogeneration plant. The sawmill energy model from Objective 3 (J. Li, 2007) as described in section 2.1.3 was used to provide the energy values. For this size of sawmill the thermal requirement is $7.8 \mathrm{MW}$. The electricity requirement depends on whether the mill is on production at the time. In this case it is assumed that the sawmill runs for 8 hours a day while the drying runs continuously. On production electrical load is $1421 \mathrm{~kW}$. Capital cost breakdowns for the scenario are shown in Table 3 and Figure 11.

Table 3: Capital cost of a Gasifier - Gas Engine/Boiler process in a sawmill

\begin{tabular}{lc}
\hline Capital Item & Cost (\$NZ) \\
Biomass Drying & $1,295,630$ \\
Feed Handling & $1,403,030$ \\
Gasifier & $1,592,574$ \\
Gas Cleaning & 188,354 \\
Gas Engine & $2,457,768$ \\
Boiler & $1,102,458$ \\
Misc. & 138,219 \\
Contingency and Fee & $1,472,046$ \\
Working Capital & 965,008 \\
Total & $\mathbf{1 0 , 6 1 5 , 0 8 5}$ \\
\hline
\end{tabular}




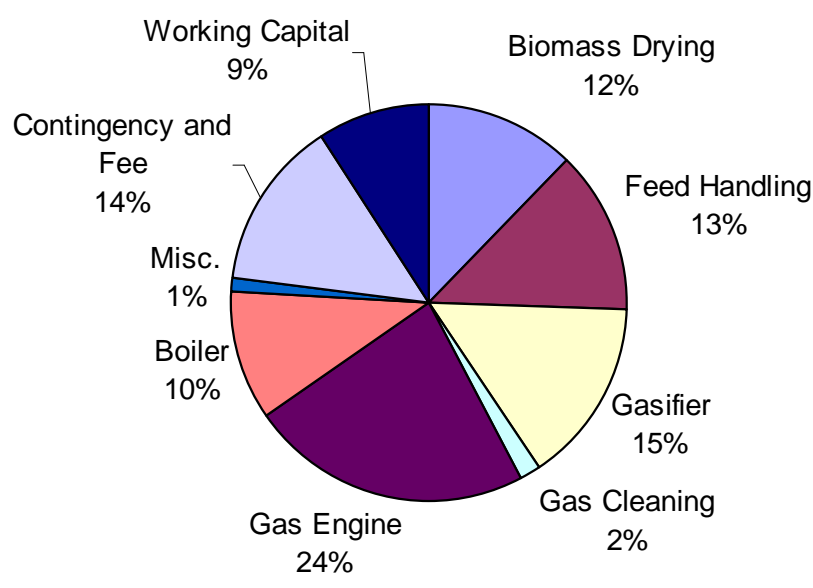

Figure 11: Capital cost of Gasifier - Gas Engine/Boiler process in a sawmill

Notable is the higher drying cost fraction for the sawmill compared to the other scenarios. The reason being the assumed moisture content of the wood supply. Unlike the LVL or MDF processes which have some dried wood waste it is assumed the sawmill has only green waste feeding the energy plant with an assumed moisture content of $120 \%$. Drying this to $25 \%$ in a rotary drum drier is capital intensive as sizing and costing is based on the quantity of water removed.

Although capital cost is a worthwhile indicator of economics the cash flow and payback potential of a plant gives a better insight into its viability. Figure 12 shows the cash flow analysis for the sawmill at varying discount factors.

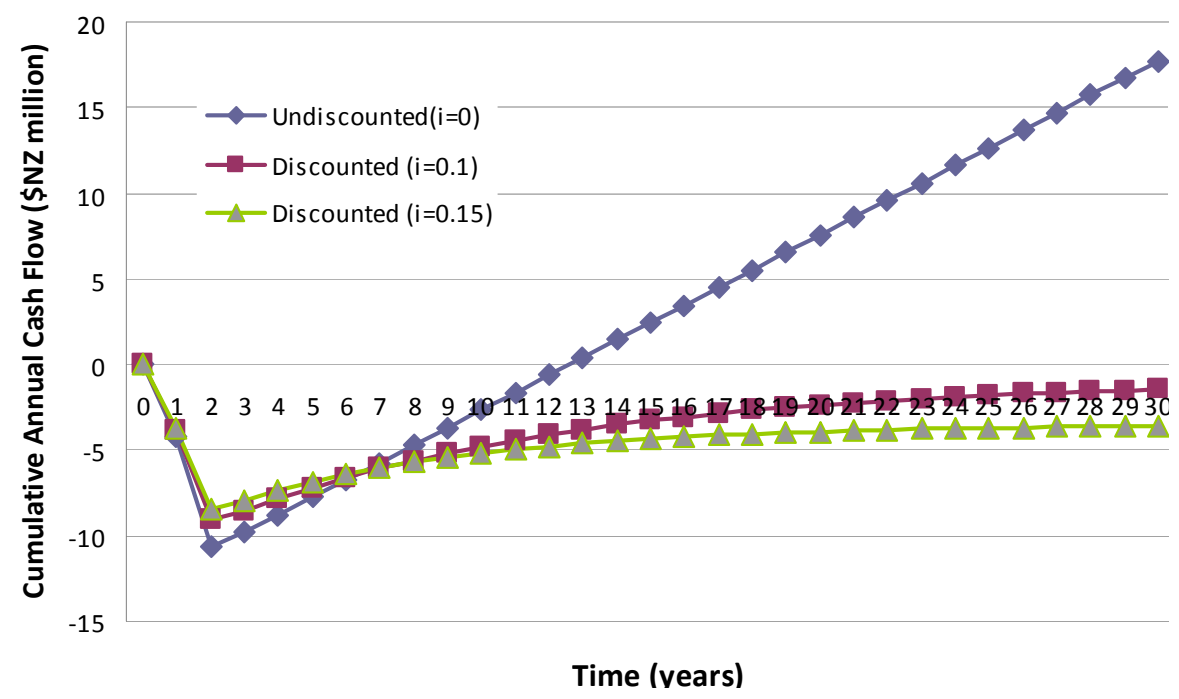

Figure 12: Cash flow analysis of sawmill energy plant showing capital payback period 
The cash flow profile for this size of plant is not positive based on current electricity prices. At a discount factor of 0.1 the plant never pays back the capital, and is therefore a poor investment in this size and plant configuration in the current economic environment. There is, however, a definite economy of scale in increasing the size of the energy plant (Figure 13). The graph is based on varying the electrical generation while keeping the thermal generation constant to meet the mill requirements. The wood feed and gasifier size are increased with the surplus producer gas fed to an upsized engine to increase electrical generation while still providing the same thermal output. The breakeven price is the electricity value that returns zero NPV (Net Present Value) at 30 years with a discount factor of 0.1. At around 2000 to $3000 \mathrm{kWe}$ generation capacity the breakeven price is approaching the price of electricity used in the modelling. However a 30 year payback is very long and represents the expected lifetime of the plant. Therefore, the breakeven price needs to be significantly below the current electricity price of $10.46 \mathrm{c} / \mathrm{kWh}$ to be considered a worthwhile economic venture. When electrical generation meets the mill requirement of $1421 \mathrm{~kW}$ the breakeven electricity price is $11.6 \mathrm{c} / \mathrm{kWh}$.

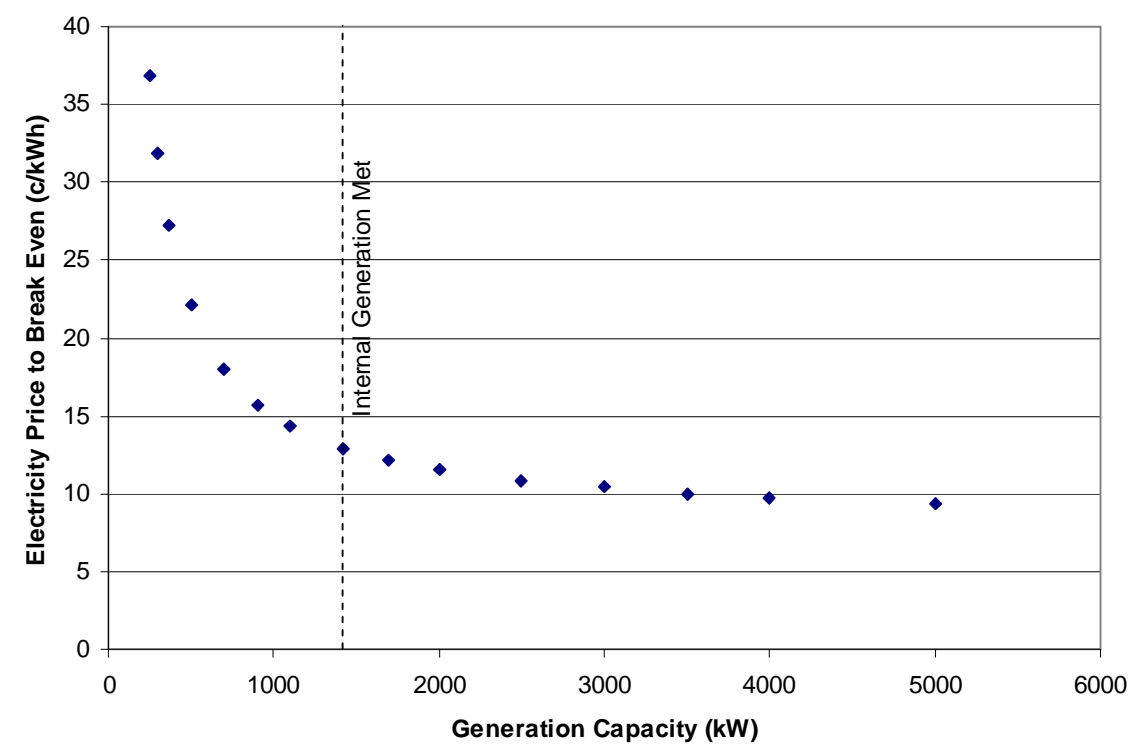

Figure 13: Electricity price required for sawmill energy plant to break even based on a 30 year payback period 


\subsubsection{LVL}

The size of the LVL plant chosen is $80,000 \mathrm{~m}^{3} / \mathrm{yr}$ of production. This is typical of a New Zealand LVL plant (J. Li \& Pang, 2006). The LVL plant differs from the sawmill in that it is a continuous operation and typically runs 23 hours per day and 330 days per year (J. Li \& Pang, 2006).

The thermal and electrical demand compared to production rate differs between LVL plants due to differences in log conditioning and press heating. In this case the capital cost will be compared for mill LVL A and mill LVL B.

Mill LVL A uses hot water vats and drive in chambers as the log conditioning method and electrical heating in the press. The thermal load for this mill is $10 \mathrm{MW}$ and the electrical load is $5118 \mathrm{~kW}$.

Mill LVL B uses drive in chests with a hot water spray as the log conditioning method and steam heating of the press. The thermal load for this mill is 11.9 MW and the electrical load is $3469 \mathrm{~kW}$.

The capital cost breakdown of LVL A and LVL B is outlined in Table 4 and Figure 14 and Figure 15. Figures show the capital cost is considerably higher for LVL A than LVL B even though the two mills have the same production capacity. This is due to the generation capacity necessary to supply the extra electrical needs of the mill. Electrical energy is significantly more expensive to provide than thermal energy, which is demonstrated in Figure 14 and Figure 15 with the gas engine being $41 \%$ of LVL A's capital compared to $33 \%$ for LVL B. In addition because the electrical energy cannot be generated as efficiently as the thermal energy there is the need for higher feed rates for LVL A which in turn increases the drying and feed handling costs. The only areas in which LVL A has an advantage over LVL B in terms of capital items is in the cost of the boiler due to less thermal requirements, and the miscellaneous section which includes heat exchangers for recovering more thermal load. 
Table 4: Capital cost breakdown of Gasifier - Gas Engine/Boiler process for LVL mills

\begin{tabular}{lcc}
\hline Capital Item & LVL Mill A (\$NZ) & LVL mill B (\$NZ) \\
Biomass Drying & $1,500,002$ & $1,392,272$ \\
Feed Handling & $1,976,602$ & $1,899,477$ \\
Gasifier & $1,901,985$ & $1,838,438$ \\
Gas Cleaning & 595,039 & 456,122 \\
Gas Engine & $8,719,494$ & $5,932,065$ \\
Boiler & $1,444,026$ & $1,648,116$ \\
Misc. & 158,529 & 161,884 \\
Contingency and Fee & $2,933,222$ & $2,399,107$ \\
Working Capital & $1,922,890$ & $1,572,748$ \\
Total & $\mathbf{2 1 , 1 5 1 , 7 8 7}$ & $\mathbf{1 7 , 3 0 0 , 2 2 9}$ \\
\hline
\end{tabular}

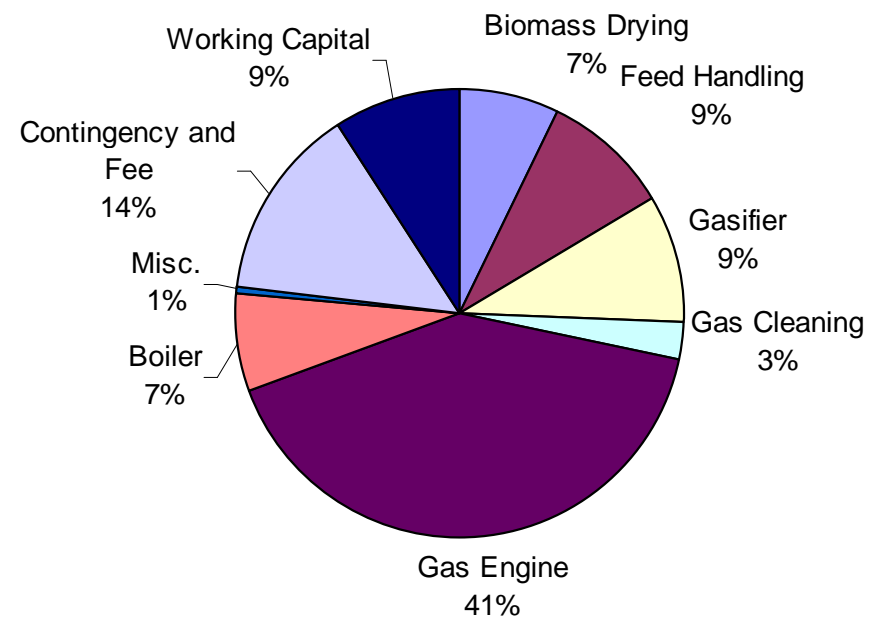

Figure 14: Capital cost of Gasifier - Gas Engine/Boiler process in LVL Mill A

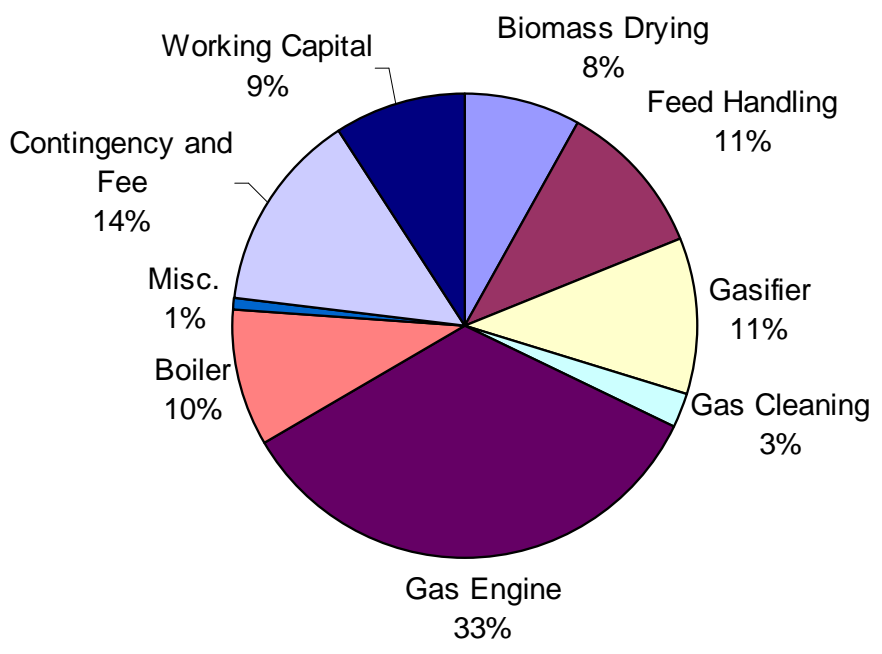

Figure 15: Capital cost of Gasifier - Gas Engine/Boiler process in LVL Mill B 
In spite of the extra capital cost and the inefficiencies of LVL A the cash flow profiles for both mills are similar and have a breakeven of approximately 19 years for LVL A and 17 years for LVL B. This is achieved due to the fact that although the investment is larger for LVL A the value added from greater electrical generation assists in offsetting the additional capital.

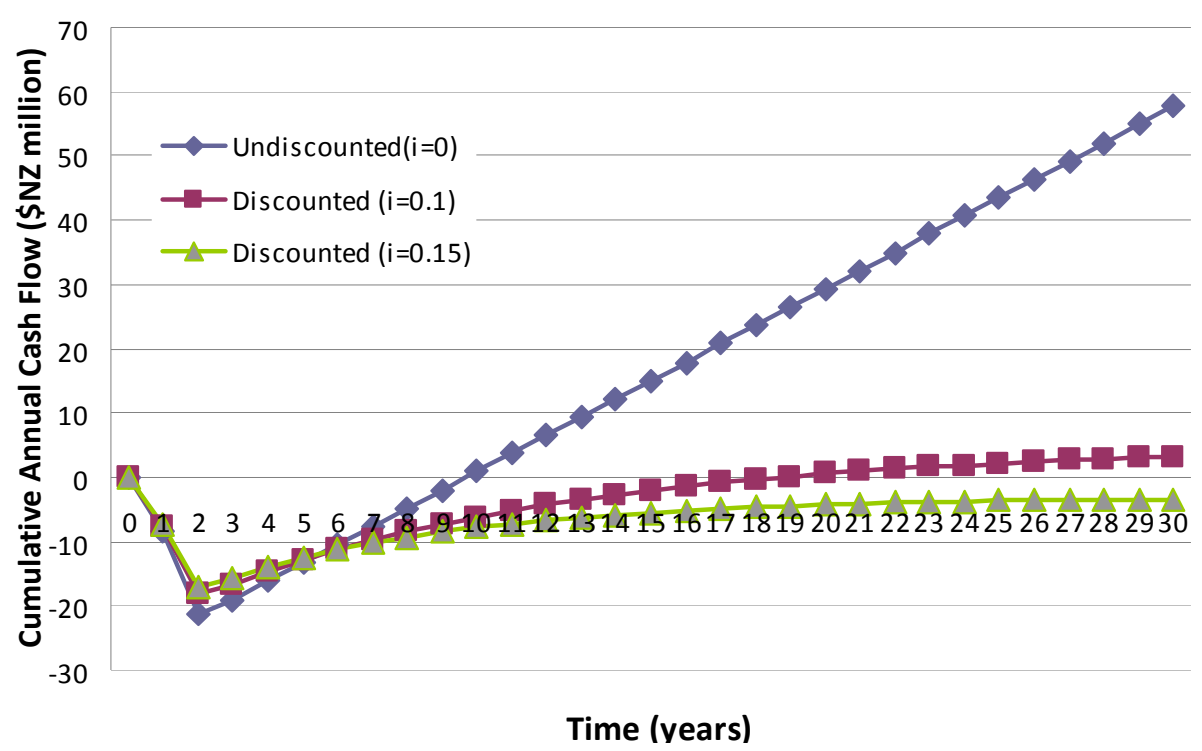

Figure 16: Cash flow analysis of LVL Mill A energy plant showing capital payback period

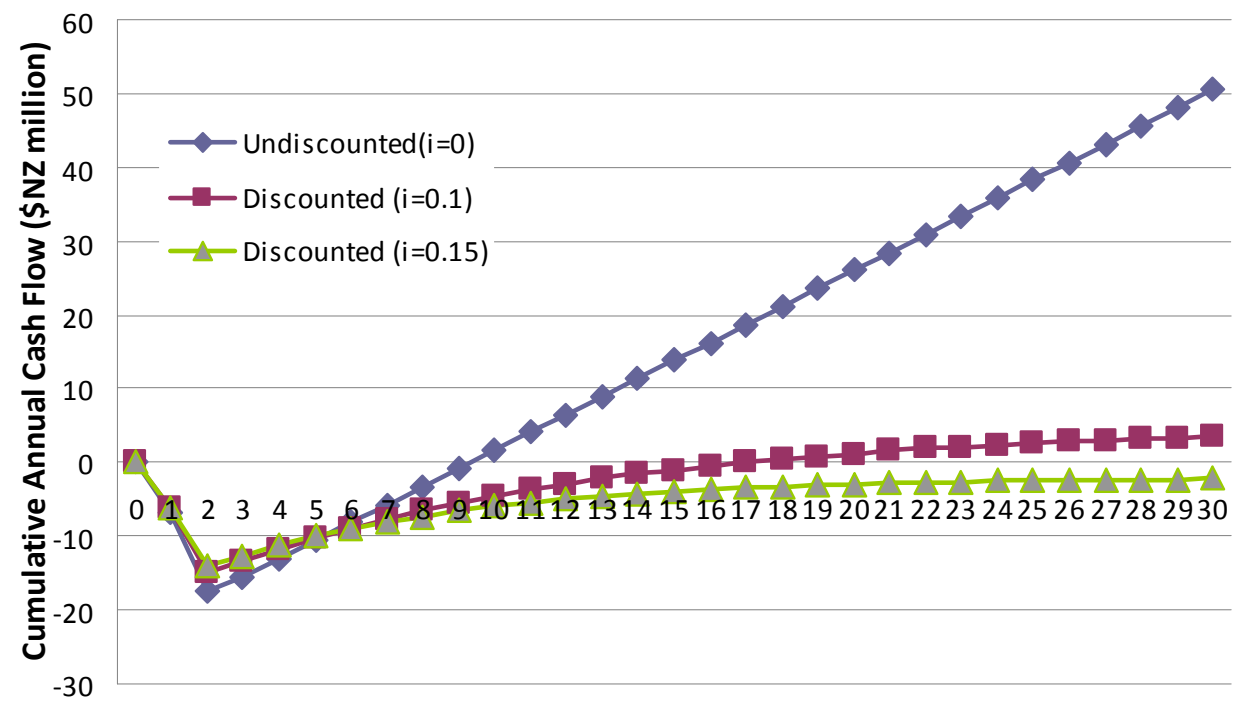

Time (years)

Figure 17: Cash flow analysis of LVL Mill B energy plant showing capital payback period

Graphs of breakeven electricity cost (Figure 18 and Figure 19) yield some very interesting results. The graphs do not show a typical economy of scale relationship as with the sawmill (Figure 13), rather the breakeven price increases with increasing 
electrical generation capacity. The gradient does however fall away rapidly showing an economy of scale relationship taking over. Notable is the change in the trend after the point at which the mills electrical demand is met. After this point any surplus electricity is sold at the lower selling price, which attributes to the small rise in breakeven cost. This confirms that a logical sizing for a CHP plant in a mill is where the electrical demands are just met. The graph also indicates it is economic to invest only in thermal generation, however the electrical generation breakeven price is still below the average purchase price of $10.46 \mathrm{c} / \mathrm{kWh}$ so it is worthwhile for a mill to also invest in electrical generation capacity.

The variations in the LVL breakeven graphs compared to that of the sawmill (Figure 13) are also due to the different electrical requirements of the mills. The sawmill only requires peak electrical load for eight hours out of twenty-four each day. This allows the majority of the electricity to be sold, therefore, in the sawmill scenario there is no obvious variation in the trend at the point where peak load is met.

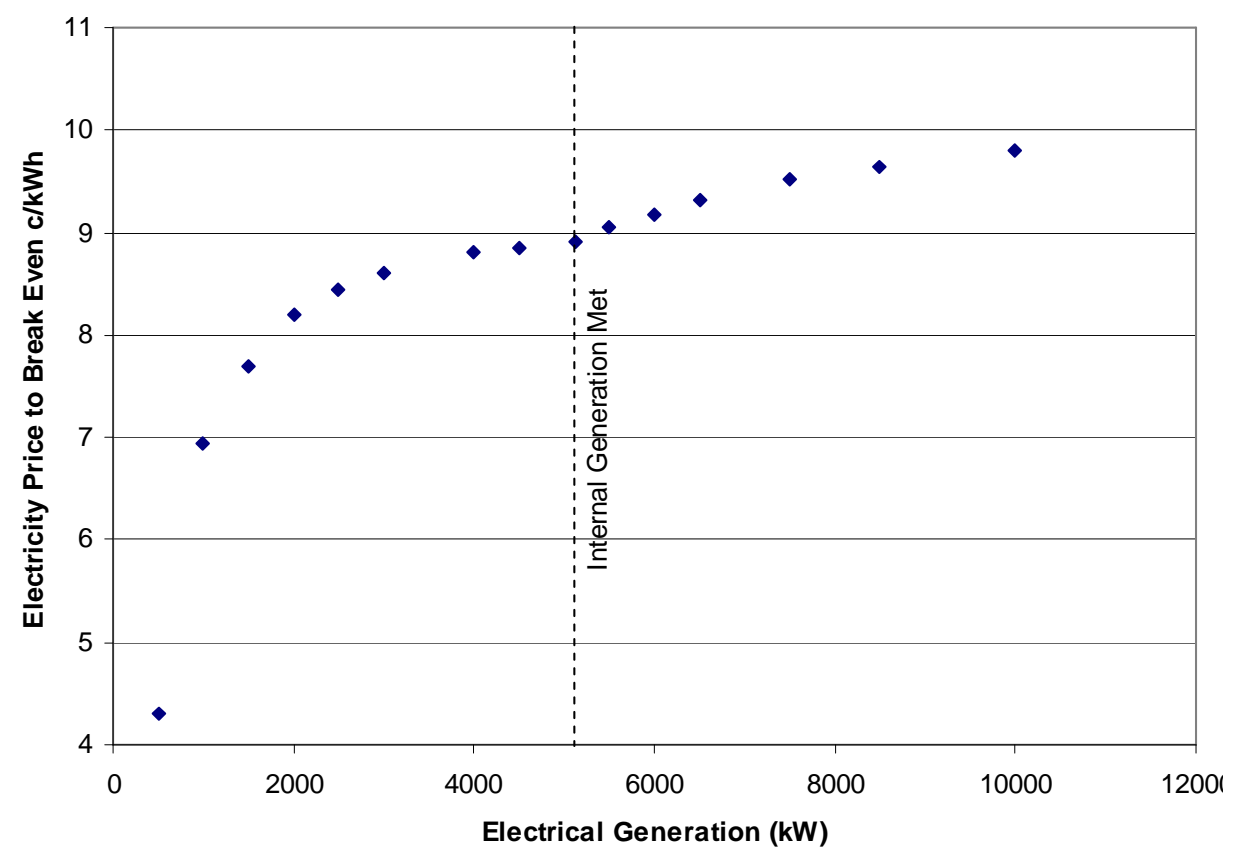

Figure 18: Electricity price required for LVL Mill A energy plant to break even based on a 30 year payback period

LVL B has a slightly different profile than LVL A with a much flatter graph with the notable similarity being the change around the point where the electrical demands for the plant are met. The difference between the two mills arises because LVL B has a 
higher thermal demand than LVL A. Therefore before electrical generation is considered there is more economy of scale in the plant. Therefore the breakeven price is not nearly as high in the lower electrical generation range. The breakeven electricity cost of $7.9 \mathrm{c} / \mathrm{kWh}$ for LVL B is lower than for the sawmill and LVL A scenarios.

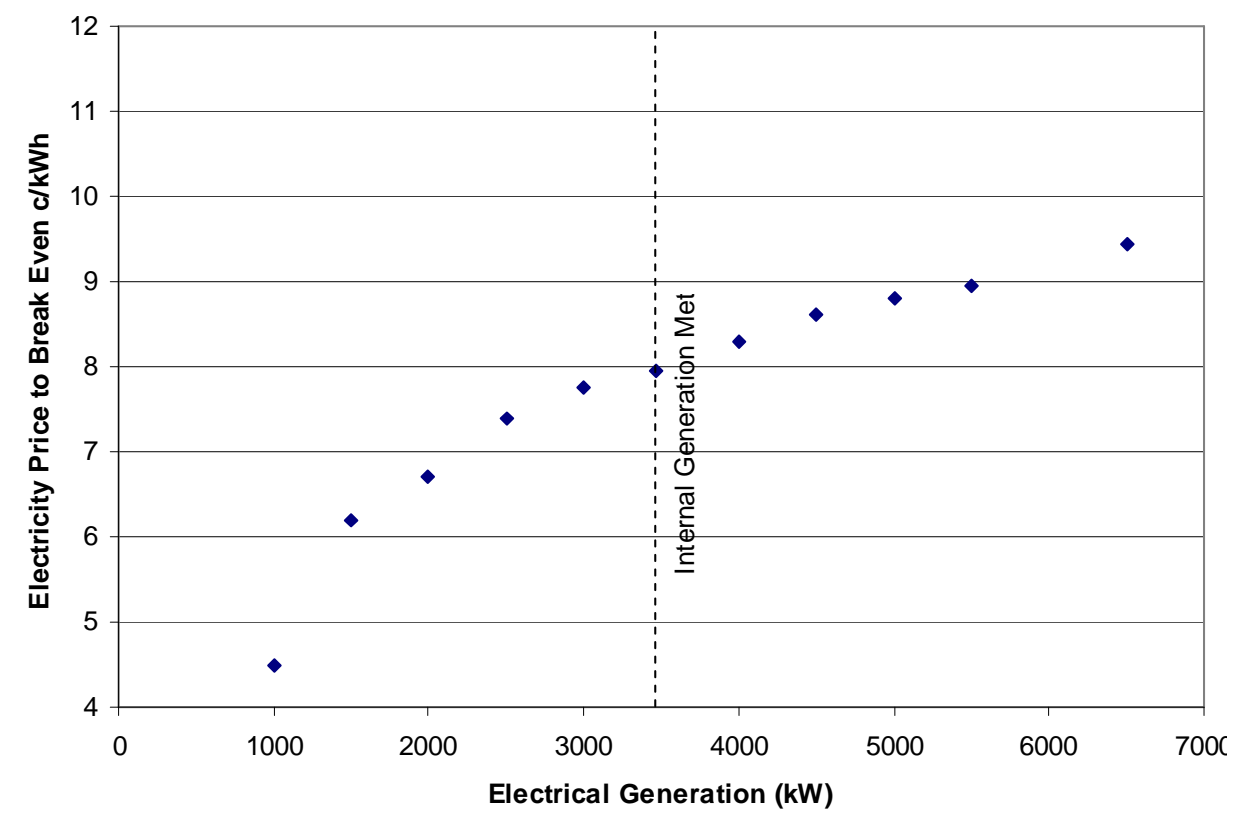

Figure 19: Electricity price required for LVL Mill B energy plant to break even based on a 30 year payback period 


\subsubsection{Comparison to MDF}

For means of comparison the data from Rutherford (Rutherford, 2006) for capital cost of a plant that will meet a typical MDF mill heat and electrical demand has been included. The plant produces $120,000 \mathrm{~m}^{3} / \mathrm{yr}$ of MDF and requires $19 \mathrm{MW}$ of thermal energy and 4.79 MW of electrical energy. The capital cost breakdown is shown in Table 5 and Figure 20 below.

Table 5: Capital cost of Gasifier - Gas Engine/Boiler process in a MDF plant

\begin{tabular}{lc}
\hline Capital Item & Cost $\mathbf{( \$ N Z )}$ \\
Biomass Drying & $2,036,201$ \\
Feed Handling & $2,173,866$ \\
Gasifier & $2,288,560$ \\
Gas Cleaning & 321,561 \\
Gas Engine & $7,059,154$ \\
Boiler & $4,562,235$ \\
Misc. & 131,773 \\
Contingency and Fee & $3,343,203$ \\
Working Capital & $2,191,655$ \\
Total & $\mathbf{2 4 , 1 0 8 , 2 0 8}$ \\
\hline
\end{tabular}

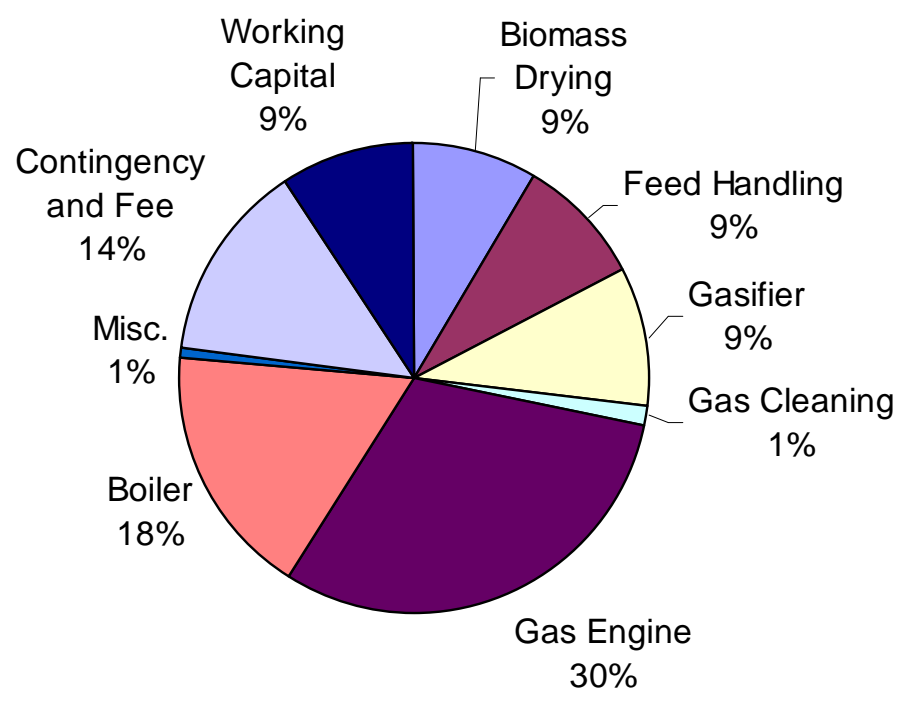

Figure 20: Capital cost of Gasifier - Gas Engine/Boiler process in a MDF plant 


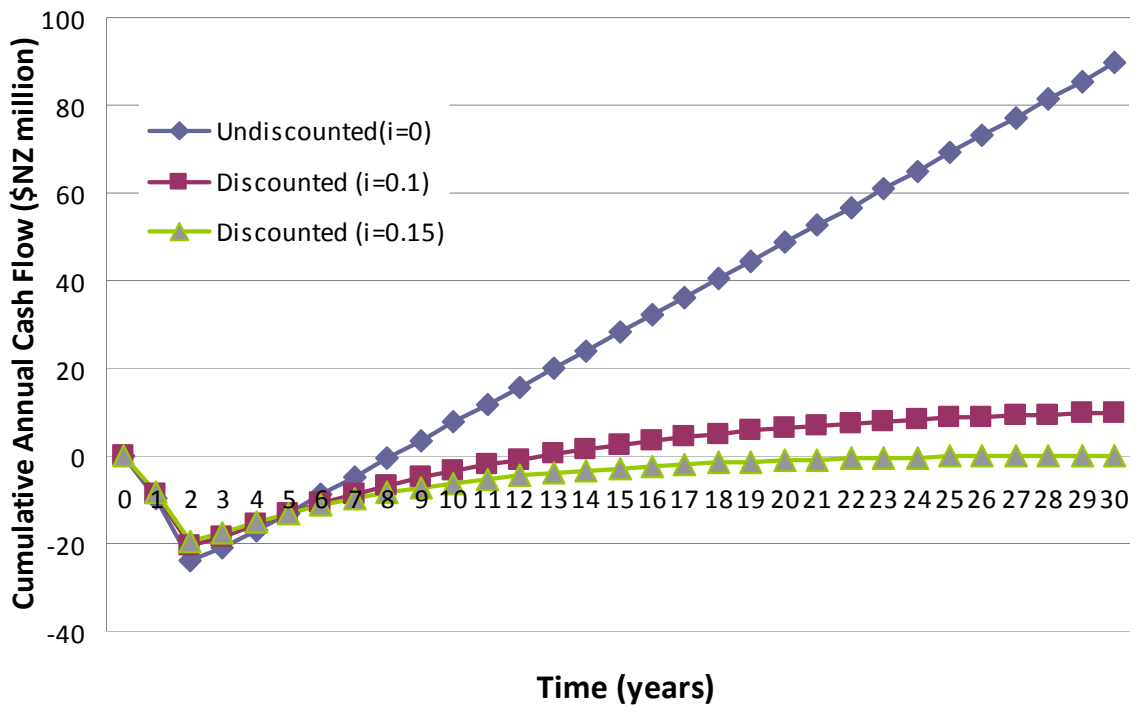

Figure 21: Cash flow analysis of MDF energy plant showing capital payback period

From Table 5 and Figure 20 and Figure 21 it can be seen the MDF mill is by far the most economic. This is primarily due to the amount of process heat the energy plant is 'selling' for a given capital cost compared to the other three scenarios. The MDF plant has a need for hot gases in the tube drier. There is little capital cost in delivering this thermal requirement in comparison to steam, although the energy supplied was valued at $\$ 8 / \mathrm{GJ}$ as for steam. Therefore, the capital cost for an MDF energy centre providing $19 \mathrm{MW}$ of thermal energy is not significantly more than one providing 10 MW of thermal energy. This gives an obvious advantage from an economic perspective - effectively being able to 'sell more product' for the same investment.

The breakeven profile (Figure 22) for MDF (Rutherford, 2006) is comparable to the LVL mills in terms of the trend being contrary to expected economy of scale relationships. Because of the value generated from the tube drier heat the graph is even more distinct. In fact from the graph it can be concluded that for this scenario the most economic approach may actually be to just meet the thermal demands of the plant. This opens another issue in the choice of gasifier style. In this case a simpler updraft would be more suitable as it has lower capital cost while still achieving the same result. This will not be investigated further in this section but is noted for completeness. 


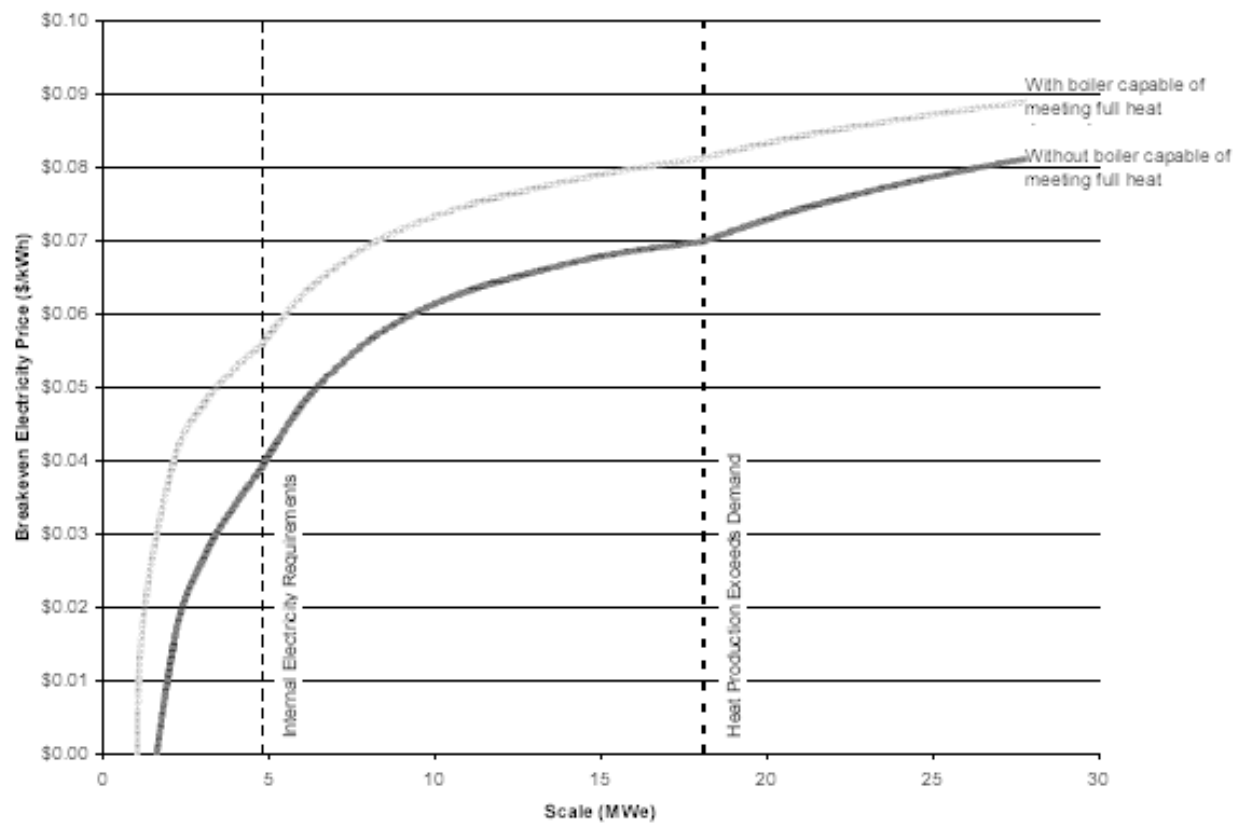

Figure 22: Electricity price required for MDF energy plant to break even based on a 30 year payback period. (Rutherford, 2006) 


\subsection{Base Economic Study Comparisons}

\subsubsection{Sensitivity Analysis}

Figure 23 to Figure 26 show the effect on NPV of a percentage change from the base case for the capital cost, electricity price and the wood cost. The graphs have been compared together in this section so the effects of different thermal and electrical requirements can be clearly seen. The base case for each is that the electrical and thermal needs for the associated mill are met as discussed previously in Section 6.

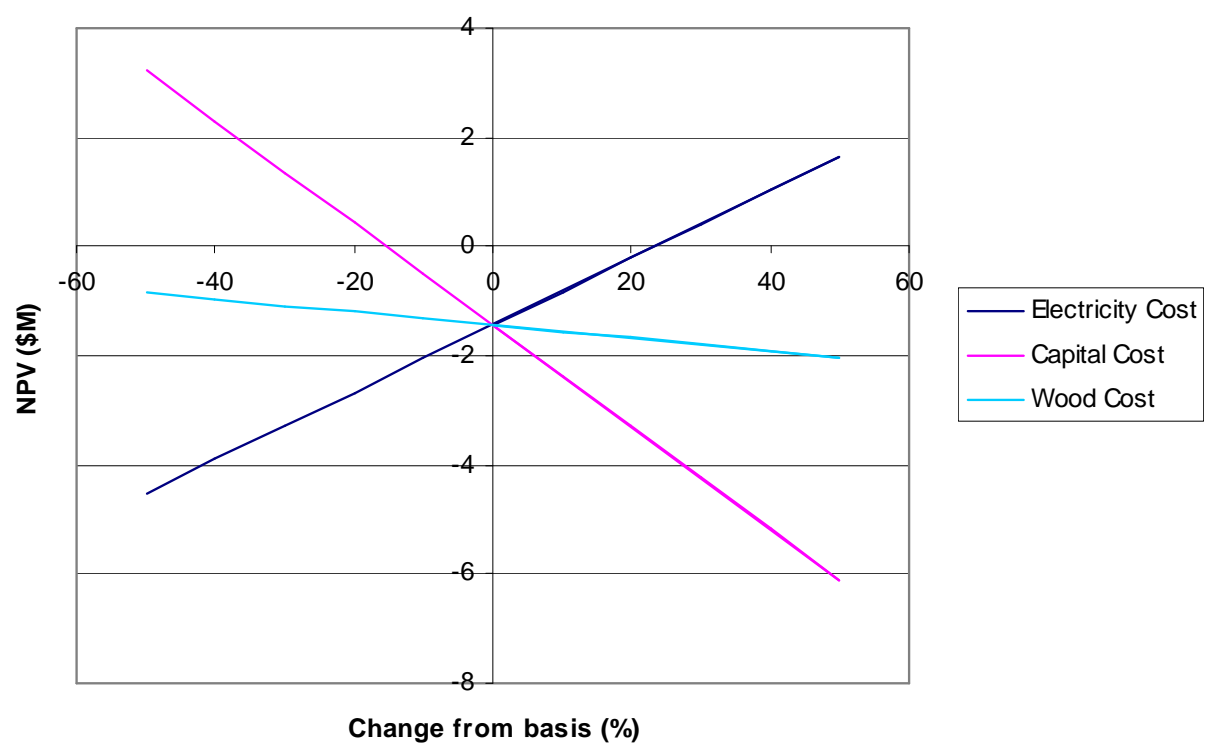

Figure 23: Sensitivity analysis for sawmill energy plant

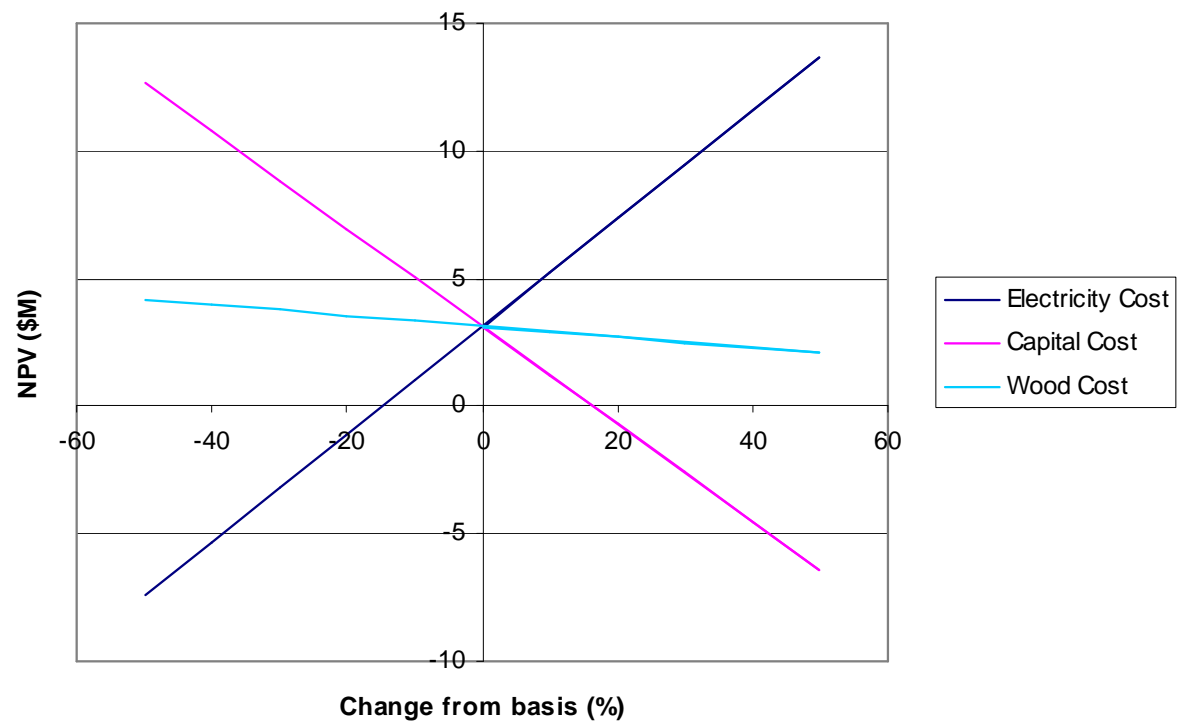

Figure 24: Sensitivity analysis for LVL Mill A energy plant 


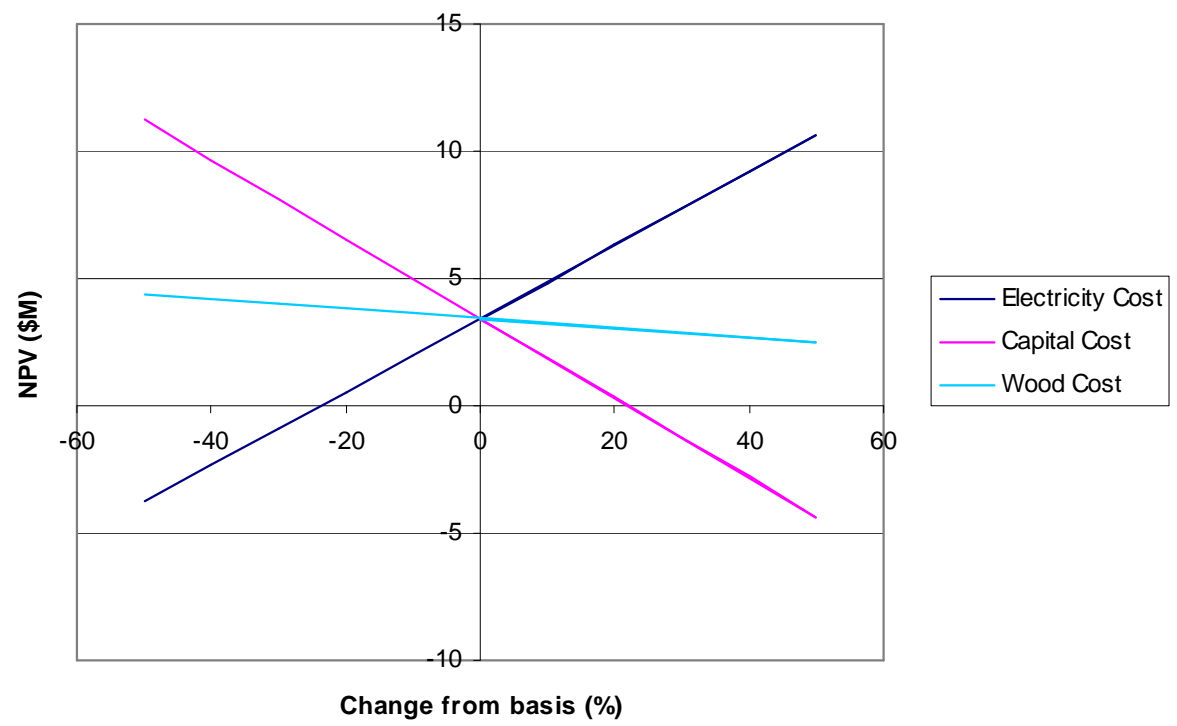

Figure 25: Sensitivity analysis for LVL Mill B energy plant

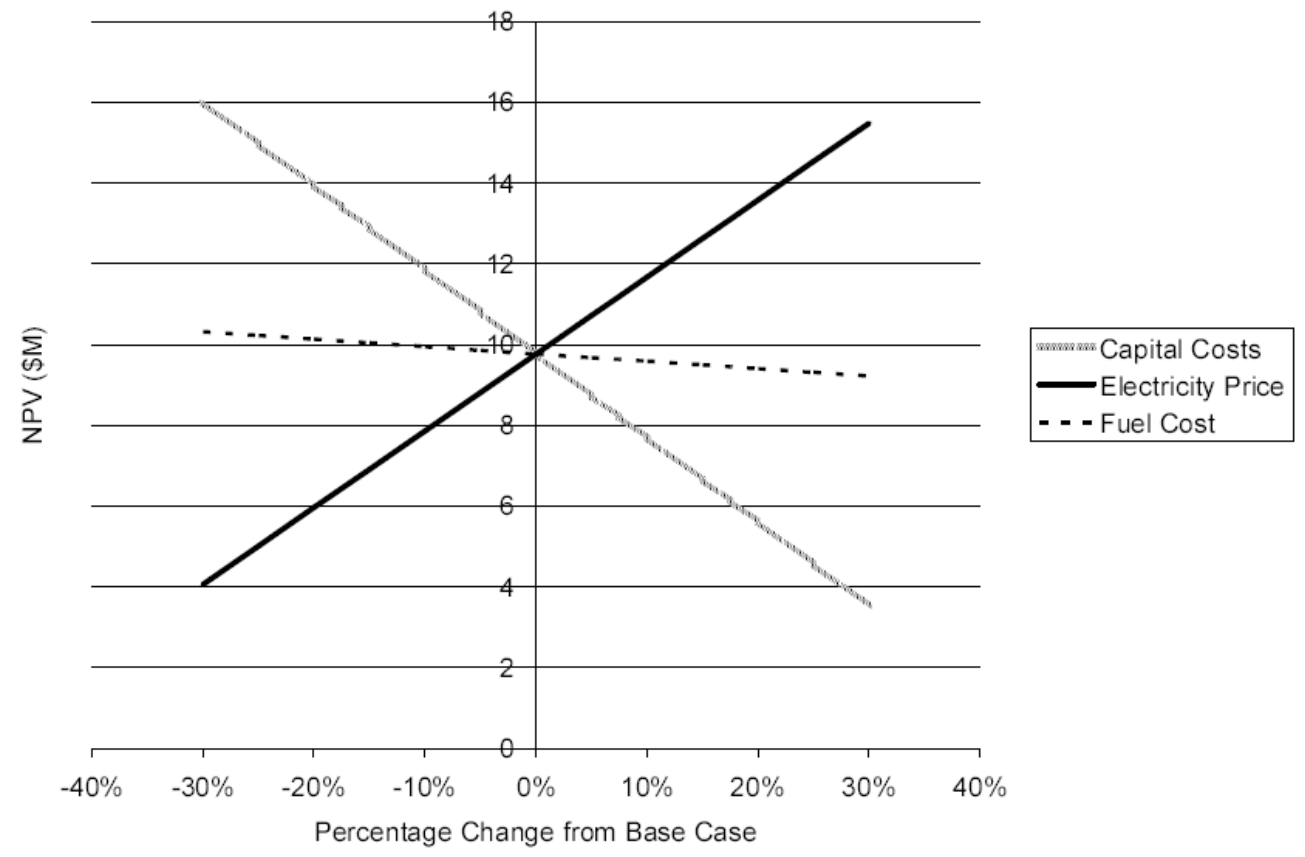

Figure 26: Sensitivity analysis for MDF energy plant (Rutherford, 2006)

All the graphs show similar trends in relation to the wood price. Wood price has the least effect on the economics of the plant and can change significantly without affecting the economics by an appreciable amount. It should be noted there is the potential for the wood cost to vary significantly depending on the base assumptions of mill location and residue availability. The capital cost and electricity price, however, do have a significant effect. Notable, is that the sawmill is not as sensitive to 
electricity price changes as the other plants due to the sawmill's lower requirement of 1.4 MW of electrical generation compared to over $5 \mathrm{MW}$ for the LVL A mill.

The sensitivity of the economics to the electricity price is beneficial and encouraging. Based on the reasoning in section 3.2.1 it is very unlikely power prices will fall so this sensitivity will not have a negative effect on plant economics, rather a very positive impact if the power prices do in fact rise.

\subsubsection{Plant Efficiency}

As with the sensitivity analysis the plant efficiencies have been grouped to allow easy comparison and are shown in Figure 27 to Figure 30. The efficiency is based on either the electrical output or thermal and electrical output over the gross calorific value of the wood entering. For efficiency analysis the electrical generation is increased while the thermal energy provided to the mill remains constant.

The common trend for all graphs is that with generation capacity increase there is an increase in electrical efficiency, but a decrease in total efficiency (electrical + thermal efficiency). The increase in electrical efficiency occurs due to the fact that as the gas engine increases in size it receives a greater fraction of the gas generated in the gasifier. The total efficiency decreases with increasing generation capacity due to the difference between the conversion efficiencies of the thermal and electrical components in the plant. Electricity cannot be generated as efficiently as steam and with increasing electrical generation the fraction being produced at this lower conversion efficiency increases thus lowering the overall efficiency. 


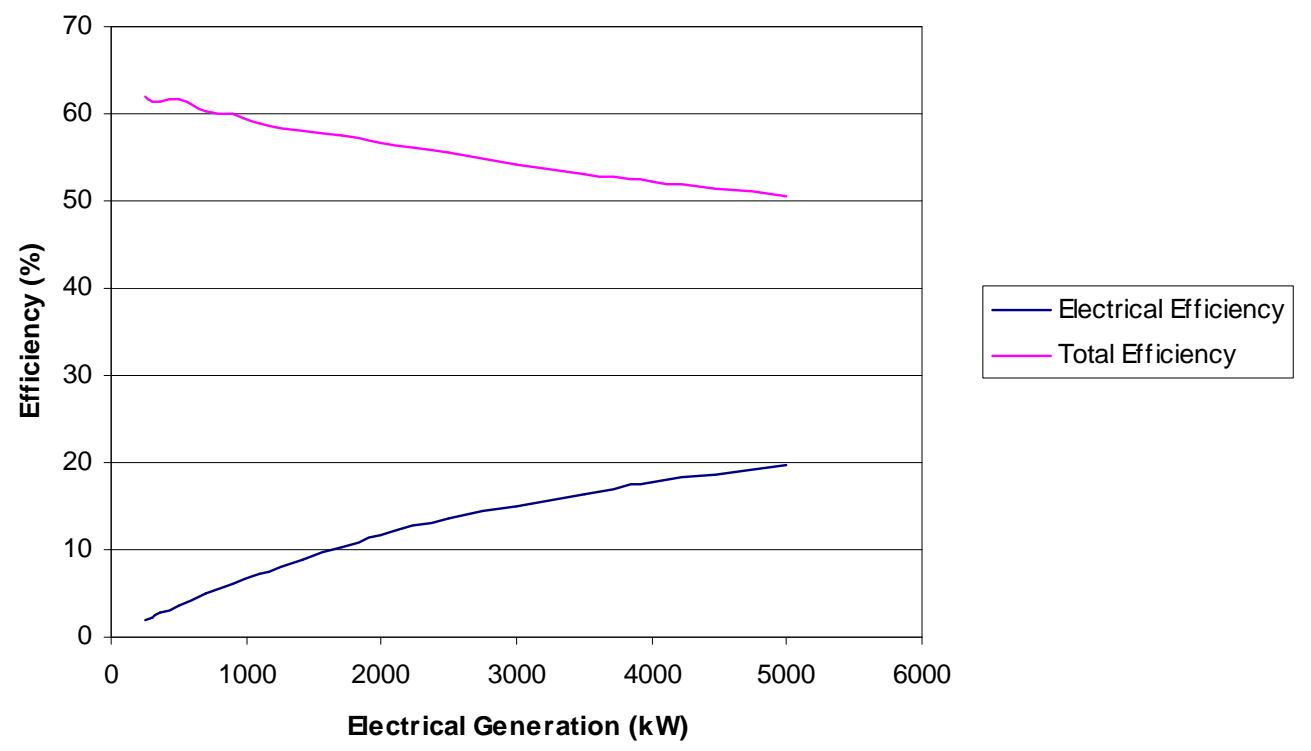

Figure 27: Sawmill energy plant fuel efficiency showing electrical efficiency and total efficiency (electrical + thermal) vs. electrical generation

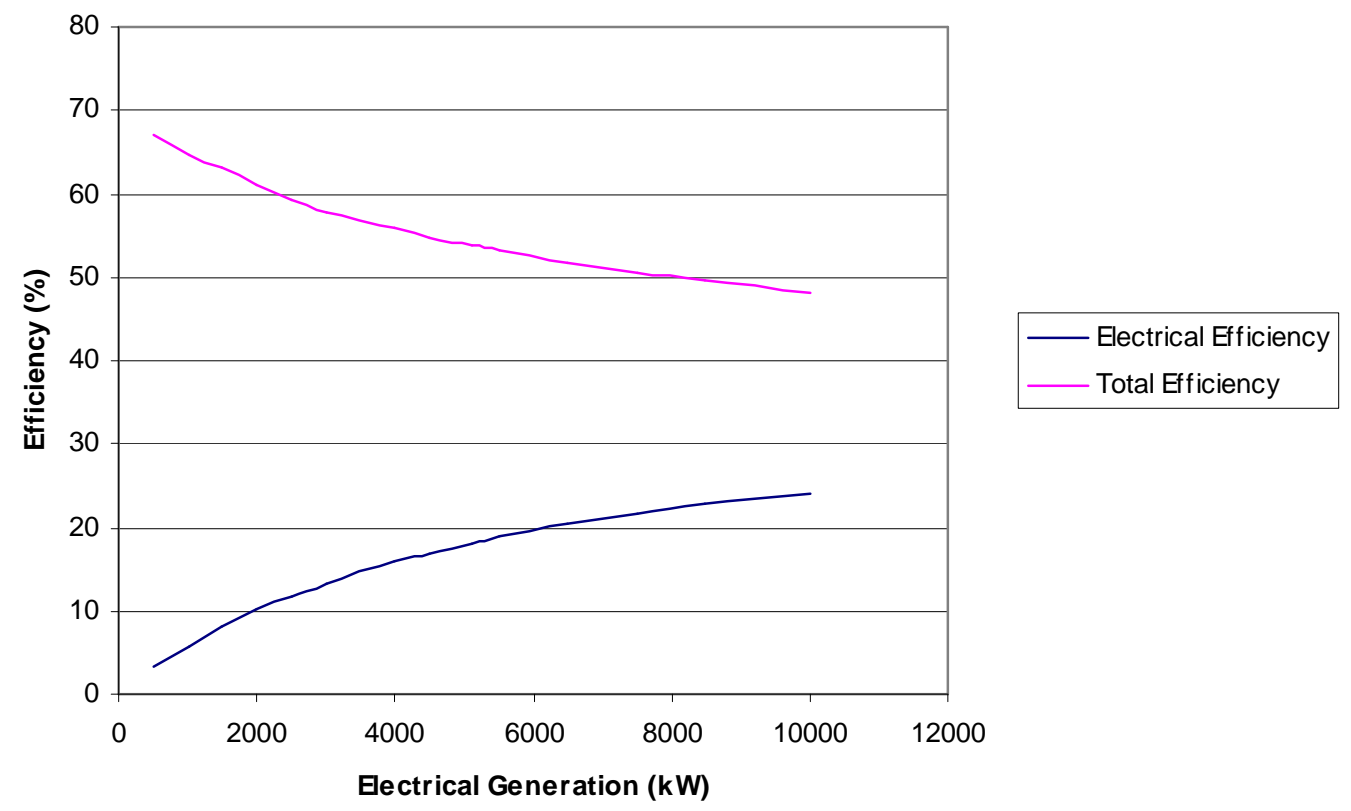

Figure 28: LVL A energy plant fuel efficiency showing electrical efficiency and total efficiency (electrical + thermal) vs. electrical generation 


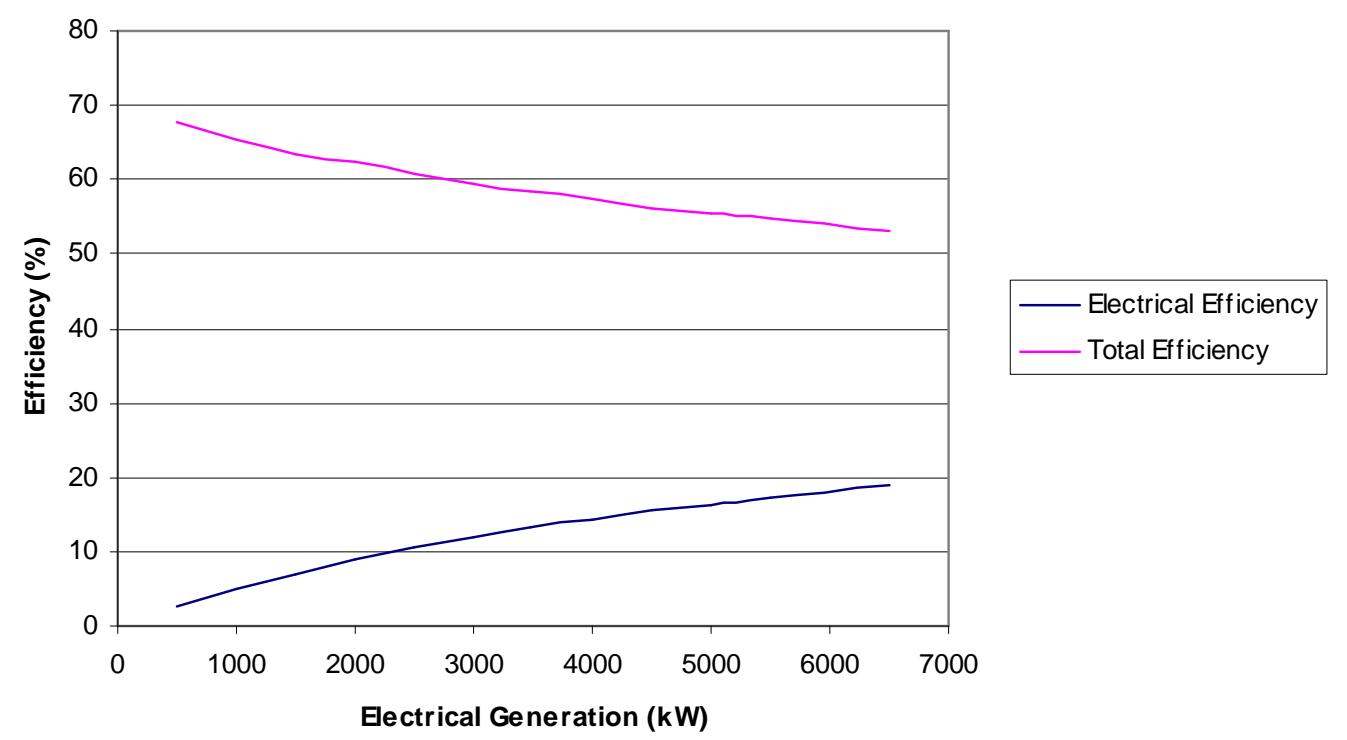

Figure 29: LVL B energy plant fuel efficiency showing electrical efficiency and total efficiency (electrical + thermal) vs. electrical generation

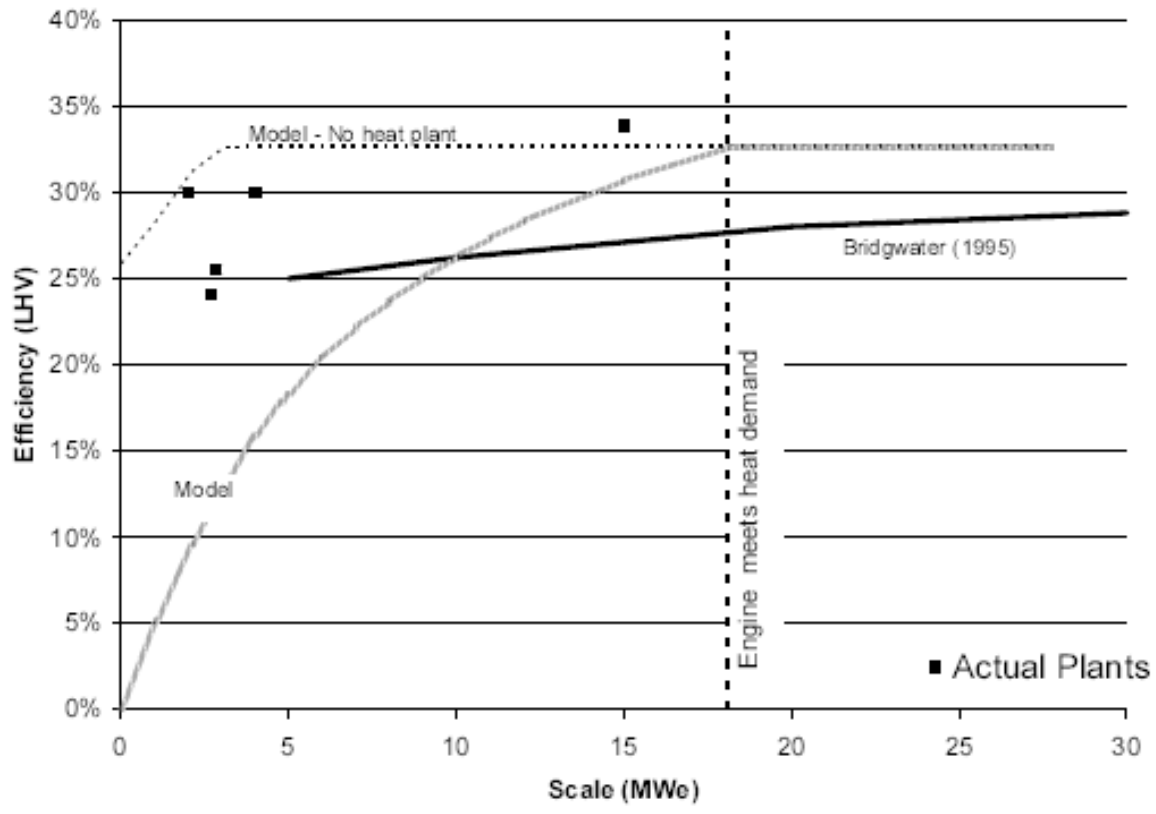

Figure 30: MDF energy plant electrical efficiency vs generation capacity. (Rutherford, 2006)

\subsubsection{Comparison to other gasification based installations}

For completeness this section compares the cost per unit output to literature. Care, however, must be taken when reading into the comparisons as efficiency and cost per unit output depends significantly on the split between heat and power. Most existing plants are designed with power generation predominantly in mind with the heat 
generated being a by-product. Literature tends to reflect this with total plant costs being quoted as a price per kWe (Ahrenfeldt \& Knoef, 2005). The scenarios in this thesis depend both on heat and power in varying ratios more so than many other contexts.

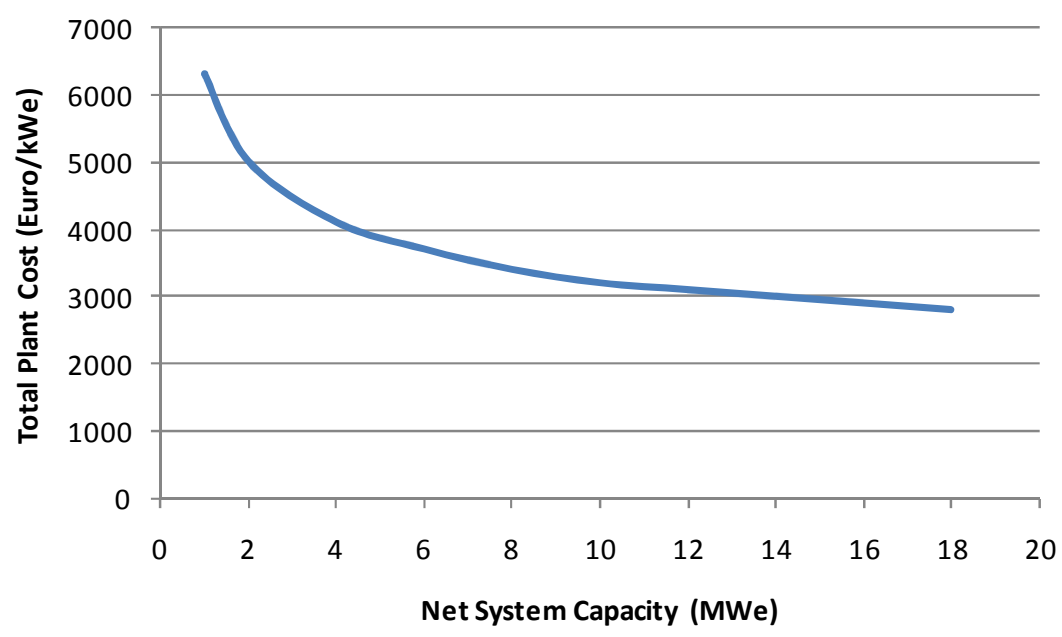

Figure 31: Typical total installed capital cost of a gasifier + gas engine plant based on cost per kWe. (Ahrenfeldt \& Knoef, 2005)

Figure 31 is an example of reported figures in literature. For an approximate comparison a plant generating $5 \mathrm{MWe}$ as in the LVL A scenario would cost 3800 Euro/kWe which in turn is $€ 19 \mathrm{~m}$. This is in comparison to the LVL A cost calculated in this study of \$NZ $21.1 \mathrm{~m}$. The LVL A scenario has additional cost related to the heat generation, although not substantially above an electrical generation focussed plant, as such a plant still needs to process the heat generated. It is noted that when the cost per $\mathrm{kWe}$ from literature is converted from Euro to $\$ \mathrm{NZ}$ there is disparity between the costs predicted in the study. The New Zealand plant being lower cost is justified by the relative cost of building such a plant in the two locations. Unless the New Zealand plant is mostly comprised of European equipment it is likely the plant could be built relatively cheaper than in the European context. For example the rotary drum drier was originally priced using European data and the capital cost was approximately 2.5 times the cost of one manufactured in New Zealand. It is expected many other items in the plant would follow suit. 


\subsection{Conclusions of Base Economic Study}

It can be concluded that the most economic scenario is the MDF plant, followed by LVL Mill B then Mill A respectively, with the sawmill being the least economic. The reasons for this order of economic feasibility are

- The sawmill has a higher drying requirement for the biomass used by the plant which has an effect on capital. Also because the overall requirements for heat and power are lower there are no advantages gained from economies of scale compared to the other plants.

- LVL Mill A and B are economically similar. They perform better than the sawmill mainly due to economies of scale but also because having dry wood feed stock reduces the drying requirement.

- The MDF plant is the most economic attributed mainly to the revenue generated from waste heat supplying the tube drier, which carries little capital cost. Without this factor it is likely it would be no more economic than the LVL models.

While current economic conditions show the results for the MDF and LVL mills to be relatively competitive with other technologies, the future economic environment will likely only serve to increase the feasibility of the technology. While caution needs to be taken in predicting future electricity prices the technological constraints on the New Zealand electricity network, and the target of $90 \%$ generation by renewables by 2025 (Ministry of Economic Development, 2007b) indicates that it is likely the power prices will at the very least remain constant if not rise. As seen in section 4.4.1 the economics are very sensitive to electricity price, therefore any rise will have a very positive effect on the economics. In addition a significant advantage to the technology is that being renewable it is in line with the government's forward strategy.

As a comparison the planned renewable generation projects for New Zealand are primarily based around geothermal, hydro, and wind. Figure 32 gives future price predictions of generation in New Zealand including these three sources. Gasification compares well with a breakeven price ranging from 4-8.9 c/kWh for MDF and LVL, 
with sawmills following behind at $11.6 \mathrm{c} / \mathrm{kWh}$. The graph also indicates that the cost of renewables is predicted to increase in line with extra capacity.

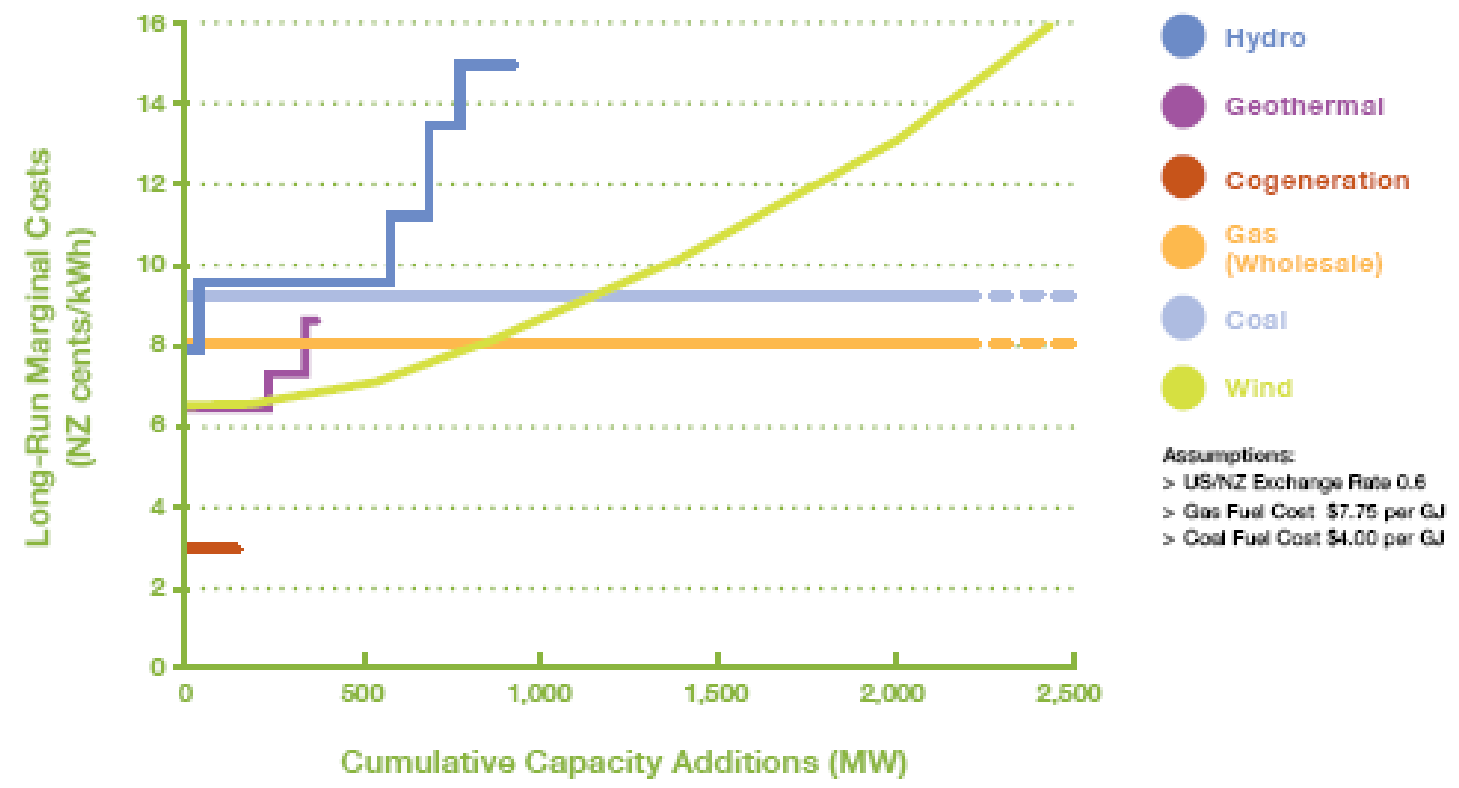

Figure 32: New plant generation costs assumed in base case to 2015. (Ministry of Economic Development, 2006)

The economics of the plant are predictably very dependent on capital cost. From the capital cost breakdown the gas engine makes up a considerable percentage of the overall cost, particularly in LVL A where it represents $41 \%$ of total capital. The drying and feed handling areas are also recognised as high cost items that have potential alternatives. The cost of these items also has a flow on effect as the contingency and fee and working capital are based on a percentage of the base capital cost. Therefore, from these conclusions the thesis will target optimisation of the areas that will be most economically beneficial. Capital cost alternatives and localised power prices are considered in Sections 9 and 10 respectively, while novel methods of integration to further reduce capital and operating cost are investigated in Section 11. 


\section{Comparison to Existing Combustion Based Technology}

Of considerable interest is the comparison between gasification based combined heat and power and the traditional combustion/boiler/steam turbine CHP process for heat and electricity generation. While much conjecture is made about the advantages and disadvantages of each it is not common to find a direct economic comparison especially in the New Zealand wood processing industry context. Literature suggests (Thumann \& Mehta, 2001) that the practical lower limit of steam turbine based cogeneration is $1000 \mathrm{~kW}$. The sawmill scenario in this study is not far above this, but rather than simply assume the steam based cogeneration will not be appropriate technology it is better to perform a directly comparable economic study. Therefore, in this section several different arrangements of traditional combustion based combined heat and power plants will be investigated.

The comparisons made are

- Scaling of an Energy for Industry study (Energy for Industry, 2005) to provide thermal output close to sawmill requirements, and an excess of electricity. A gasification plant is sized to the same electrical output for comparison. The reason for performing this investigation is it allows comparison with feasibility studies from other parties and highlights differing base assumptions. This scenario will be discussed in more detail due to the base assumption differences.

- A 60 bar steam process with an extracting steam turbine. This represents the higher end of efficiency but also the higher end of capital cost as will be discussed.

- A 40 bar steam process with an extracting steam turbine. This system incorporates lower capital cost due to the lower steam pressures but suffers somewhat in efficiency.

- A 30 bar steam process analysed with both an extracting and a fully condensing steam turbine. This process was investigated as a lower capital cost but lower efficiency alternative but also because the fully condensing scenario is similar in design to the Blue Mountain Lumber Sawmill cogeneration plant currently in operation (BANZ, 2007). 


\subsection{Energy for Industry Comparison}

Energy For Industry has compiled a report in conjunction with EECA evaluating opportunities for distributed electricity generation in New Zealand (Energy for Industry, 2005). One of the processes studied serves as a useful comparison as it produces electricity and also steam at a pressure consistent with that of the sawmill based gasification scenario. The system is based on a boiler and extraction/condensing steam turbine as shown in Figure 33.

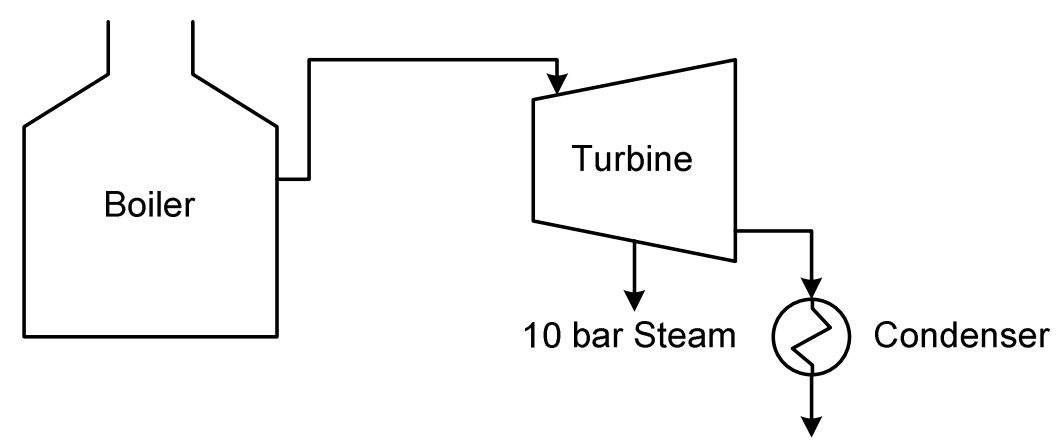

Figure 33: Basic flow schematic of extraction/condensing steam turbine

The basic system specifications for the combustion based plant are -

- Boiler
$52.4 \mathrm{t} / \mathrm{h}$ steam
60 bar steam pressure

- Turbine

8.3 MW electrical generation

$25 \mathrm{t} / \mathrm{h}$ steam exiting turbine for plant use

10 bar steam exit pressure

The scale, however, is larger than that required by the sawmill, mainly in terms of electricity generation. The system will rely heavily on being able to sell significant amounts of power onto the grid. The requirements of the sawmill scenario used in the gasification analysis are-

- Electrical demand $1421 \mathrm{~kW}$

- Thermal demand $\quad 7786 \mathrm{~kW} \quad(13.9 \mathrm{~T} / \mathrm{hr}$ steam approximately)

The plant needs to be scaled down to be a direct comparison to the gasification system. The first scenario analysed will be to halve the scale of the plant to 
approximate the steam flow rate required by the sawmill. Therefore the plant specifications will be as follows

- Boiler $20 \mathrm{MW}$

$26.2 \mathrm{t} / \mathrm{h}$ steam

60 bar steam pressure

- Turbine 4.15 MW electrical generation

$12.5 \mathrm{t} / \mathrm{h}$ steam exiting turbine for plant use

10 bar steam exit pressure

Correlations for capital cost vs. scale need to be employed to estimate the new capital cost. Power law estimating has been used based on Equation 18 (Gerrard, 2000).

Capital Cost $=C_{r}\left(\frac{S}{S_{r}}\right)^{n}$

Where $\mathrm{C}_{\mathrm{r}}$ is the reference or original capital cost

$\mathrm{S}$ is the new dimension in this case taken as $\mathrm{kW}$

$\mathrm{S}_{\mathrm{r}}$ is the reference or old dimension

$\mathrm{n}$ is the scale exponent

For this scenario the typical value for $\mathrm{n}$ of 0.6 is used. While this factor does seem a very generic application of the 6/10 rule (Gerrard, 2000) it is considered appropriate for this scenario. Full plants are typically in the order of 0.66 (Gerrard, 2000) therefore slight variations within this band have little effect on the comparisons in this chapter given the accuracy level of capital cost prediction. The $\mathrm{kW}$ output of the boiler and the turbine have both been halved. The new capital cost is therefore \$NZ $21 \mathrm{~m}$.

\subsubsection{Operating Cost}

The Energy for Industry study performed base estimates of operating costs and revenues based on values for steam, electricity and biomass as follows

- Biomass feed \$2/GJ

- Steam value $\$ 16 / \mathrm{T}$

- Electricity value $8 \mathrm{c} / \mathrm{kWh}$ 
There were also labour and maintenance charges. The maintenance will be applied as a percentage of the capital cost, while the labour will remain the same as the operational requirements are not expected to change even though the plant is halved in size.

For the purposes of comparison the values for biomass, steam, and electricity as applied to the gasification scenario will be applied. They are as follows

- Biomass feed

$\$ 10$ per dry tonne

- Steam Value $\$ 8 / \mathrm{GJ}$

- Electricity value $10.46 \mathrm{c} / \mathrm{kWh}$ used on site, $9.02 \mathrm{c} / \mathrm{kWh}$ sold

The gross calorific value of wood is taken as $20.1 \mathrm{MJ} / \mathrm{kg}$ to convert between $\$ / \mathrm{T}$ and $\$ /$ GJ. It can be seen there is a large difference in the base assumption of the wood cost. The EFI study used $\$ 40 / \mathrm{T}$ for the wood. While this may be an average cost it is unlikely someone would venture to build an energy plant under this scenario, therefore the lower value is assumed to be suitable as it is likely a case study would only be performed at a plant that does not have a significant market for its residues.

Both scenarios have independently assumed an availability of $95 \%$ or 8322 hours running per year. The operating costs and revenues are calculated for the combustion based scenario which allows a cash flow analysis to be performed (Figure 34).

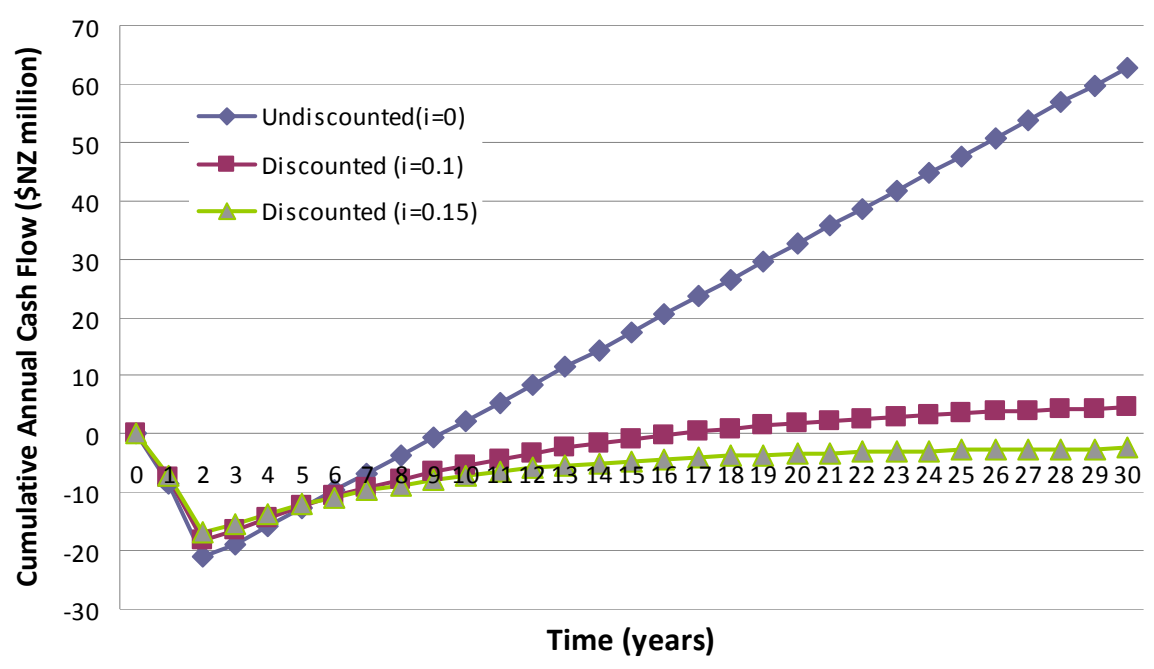

Figure 34: Cash Flow Analysis of Combustion based Cogeneration Plant 
As a comparison to the combustion based scenario a gasification plant has been modelled that meets the heat needs of the process but also generates $4.15 \mathrm{MW}$ of electrical energy to match the combustion based plant. The economics of this are shown in Table 6 and Figure 35.

Table 6: Capital cost of gasification based comparison to combustion technology

\section{Capital Item}

Biomass Drying

Feed Handling

Gasifier

Gas Cleaning

Gas Engine

Boiler

Misc.

Contingency and Fee

Working Capital

Total

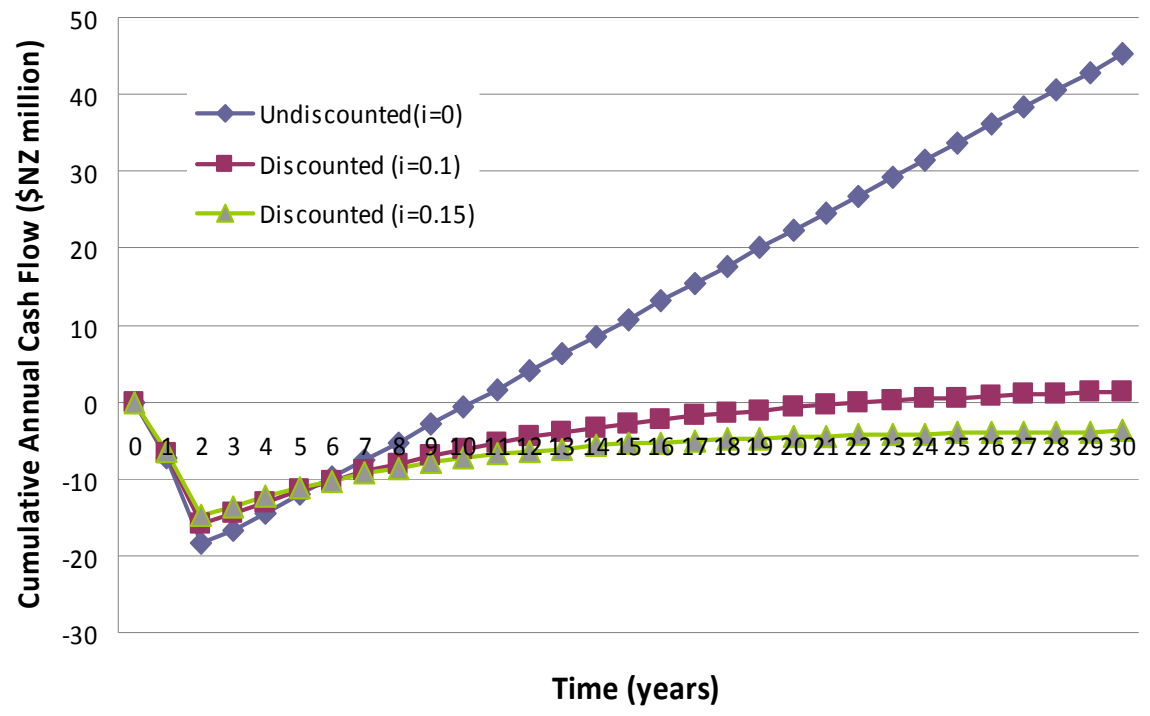

$1,714,580$

$1,747,730$

$1,981,363$

435,589

$7,083,587$

$1,103,858$

147,740

$2,558,601$

$1,677,305$

$18,450,353$

Figure 35: Cash flow analysis of gasification plant with 4.15 MW of electrical generation 
Table 7: Comparison of economics between combustion and gasification scenarios

\begin{tabular}{lcc}
\hline Economic Parameter & Combustion & Gasification \\
Capital Cost (\$NZm) & 21 & 18.5 \\
Operating Cost (\$NZm per annum) & 1.4 & 2.4 \\
Revenue (\$NZm per annum) & 4.9 & 4.9 \\
Annual Profit After Tax (\$NZm per annum) & 0.92 & 0.45 \\
Cash Flow (\$NZm per annum) & 3.0 & 2.3 \\
Return On Investment (based on cash flow) (\%) & 14.4 & 12.4 \\
Breakeven Electricity Price (c/kWh) & 7.8 & 10.3 \\
\hline
\end{tabular}

Table 7 shows a direct comparison between the economic parameters of both scenarios. While the capital cost for the combustion plant appears considerably higher, the actual difference is only $10 \%$. Given that the method of estimation employed in this thesis typically carries an error of $\pm 30 \%$ it could be said the capital cost differences between the two plants are negligible and a decision to build either design of plant would depend on factors other than the capital cost in this scenario.

The greatest disparity between the two scenarios is the operating cost, with the combustion based scenario being nearly half that of the gasification scenario. Part of this difference is from the $\$ 512,000$ per annum biodiesel use in the tar scrubber but a significant proportion of the difference is a product of different assumptions made in the operating costs.

The gasification plant includes a more detailed analysis of the labour and maintenance component, however, this may have caused the costs to have been overestimated. It is unlikely labour costs would be significantly higher for the gasification system. Although it is a more complicated system the size of the boiler required and the steam pressures make the gasification system more favourable. The greatest consideration is whether the gasification plant can be controlled well enough to enable limited operator input. This would allow job sharing between other personal such as the kiln operator. According to regulations (Department of Labour, 2004) there is the possibility that the system in the gasification scenario may be able to be controlled by a 'responsible person' rather than a qualified operator, as may be necessary for the combustion based CHP system. The boiler in the combustion system would likely remain within the same hazard category as prior to it being scaled down so it is likely there is still the requirement for the same level of monitoring even though the boiler is 
half the size (Standards Australia, 2005). This justifies the same labour cost as before the plant was scaled. It is assumed the high pressure boilers in this study are installed and certified as attended boilers (Blower, 2008).

In the gasification system two operators were allocated to run the plant. Comparing real life scenarios and other comparisons this could be considered an overestimation. At the most it should take only one operator to control the plant, or simply job sharing with the kiln operator would potentially make it $0.5-0.8$ of a person, as the boiler is easier to set up as a limited attendance boiler. In the gasification scenario the overhead calculated may also be excessive being more indicative of a standalone site.

The maintenance is another area of difference. In this case the gasification based maintenance is cheaper. This recognises the difference between the difficulties of maintenance of the two plants. While the gasification plant is novel in concept, the majority of the equipment for servicing is not. In comparison the combustion based cogeneration system utilises high pressure boiler systems requiring more rigorous maintenance regimes due mainly to the more complicated control systems necessary to operate such a boiler safely (Blower, 2008).

Of interest to the comparison is the relative efficiencies of both plants. Table 8 shows the efficiencies of the combustion and gasification scenarios generating the same heat and power outputs.

Table 8: Comparison of efficiency between combustion and gasification

\begin{tabular}{lcc}
\hline & Combustion & Gasification \\
Wood Feed Power (MW) & 33.4 & 22.9 \\
Electrical Efficiency (\%) & 12.4 & 18.1 \\
Thermal Efficiency (\%) & 21.0 & 34.0 \\
Total Efficiency (\%) & 33.4 & $\mathbf{5 2 . 1}$ \\
\hline
\end{tabular}

Table 8 shows the gasification plant requires less wood to generate equivalent heat and power, resulting in much higher overall plant efficiencies. While the combustion plant is more economic in this analysis (primarily due to the base assumptions made in operating costs), the gasification scenario has advantages in terms of wood supply cost. The scenario where this would be most beneficial is if there is an increasing 
cumulative cost to supply wood to the plant. This is likely to be a situation in many plants as the cheap feedstocks such as sawdust are consumed first. Therefore the combustion scenario is likely to have a higher $\$ / T$ wood feed cost.

\subsection{0 bar steam and extracting steam turbine process}

The first scenario analysed consists of a boiler raising superheated steam to 60 barg and $450{ }^{\circ} \mathrm{C}$. The steam turbine has a steam pass out pressure of $10 \mathrm{barg}$ and also partially condenses to allow generation of the required amount of electricity. The sawmill is sized consistent with the rest of the thesis so it requires 7.8 MW steam and 1.4 MW of electrical generation.

In performing the analysis several assumptions had to be made

- It is assumed the shaft work available for electrical generation from the steam turbine is $75 \%$ of the ideal isentropic scenario.

- The electrical conversion efficiency from shaft work is $85 \%$.

- The steam that condenses does so to 0.1 bara

- The efficiency of the boiler in raising steam is $60 \%$ of the fuel input due to the assumed high moisture content of the biomass

- No biomass drying

- The feed handling system carries the same capital cost as that of the gasification scenario

Because of the boiler pressures involved the boiler is a field erected type which carries significantly more cost than a packaged boiler (Ulrich \& Vasudevan, 2004). The boiler cost correlation used is that for a coal fired boiler due to the solids handling necessity of the biomass (Ulrich \& Vasudevan, 2004). The capital cost for the system is shown in Table 9. 


\begin{tabular}{lc}
\hline Capital Item & Cost $\mathbf{( \$ N Z )}$ \\
Feed Handling & $1,661,972$ \\
Boiler & $12,359,897$ \\
Steam Turbine & $1,260,000$ \\
Contingency and Fee & $2,292,280$ \\
Working Capital & $1,757,415$ \\
Total & $\mathbf{1 9 , 3 3 1 , 5 6 4}$ \\
\hline
\end{tabular}

It can be seen in Table 9 the combustion based process at $\$ \mathrm{NZ} 19.3 \mathrm{~m}$ is considerably more expensive than the gasification process at $\$ N Z 10.6 \mathrm{~m}$. This much higher cost is attributed predominately to the boiler. This indicates that high pressure boilers at such small scale carry very poor economies of scale.

In order to calculate the operating costs with appropriate comparability to the gasification scenario the same assumptions are made and the same cost factors are applied. Therefore operating labour, maintenance, overheads and other parameters are all applied in the same manner. The breakeven electricity cost in this scenario is $25 \mathrm{c} / \mathrm{kWh}$. The overall efficiency of this process is $42.9 \%$ (compared to $58 \%$ for the gasification scenario). The high breakeven electricity cost reflects the significant cost of the high pressure boiler pushing the overall capital costs much higher than the gasification and other combustion scenarios. In Appendix A profit and loss statements are shown for both the gasification and a combustion scenario to show in detail the cost differences.

\subsection{0 bar steam and extracting steam turbine process}

The second scenario is that of a boiler generating 40 barg steam at $400^{\circ} \mathrm{C}$ for use in the steam turbine. The advantage of this scenario as opposed to the previous $60 \mathrm{barg}$ scenario is a packaged boiler can be used rather than a site erected boiler. The difference in capital cost is significant. Table 10 shows the capital cost breakdown. 
Table 10: Capital cost estimate for 40 bar scenario

\begin{tabular}{lc}
\hline Capital Item & Cost $\mathbf{( \$ N Z )}$ \\
Feed Handling & $1,711,910$ \\
Boiler & $4,421,657$ \\
Steam Turbine & $1,260,000$ \\
Contingency and Fee & $1,109,035$ \\
Working Capital & 850,260 \\
Total & $\mathbf{9 , 3 5 2 , 8 6 1}$ \\
\hline
\end{tabular}

While lowering the pressure and temperature of the process has a detrimental effect on efficiency (reduced to $40.8 \%$ ) the capital saving far outweighs any efficiency disadvantage.

Applying the same assumptions towards operating costs gives a breakeven electricity price of $9.8 \mathrm{c} / \mathrm{kWh}$. This is lower than the gasification scenario $(11.6 \mathrm{c} / \mathrm{kWh})$. The reason for this is twofold. Firstly the capital cost is slightly lower than the gasification scenario, and secondly the combustion based plant does not have the expense of biodiesel. The gasification system does, however, gain on the combustion based scenarios (especially in the lower pressure systems) in terms of wood cost due to the efficiency.

\subsection{0 bar steam and extracting/fully condensing process}

The third process is broken into two scenarios. The first is an extracting turbine with partial condensing to allow sufficient generation. The second is a fully condensing turbine where all the steam entering the turbine is reduced to 0.1 bara as shown in Figure 36.

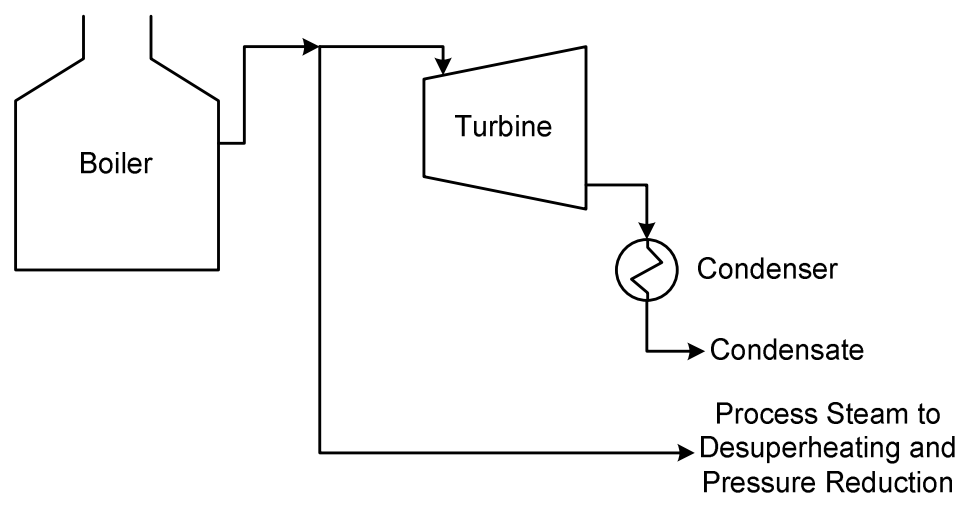

Figure 36: Fully condensing turbine flow diagram 
This fully condensing scenario is investigated because it is similar to Blue Mountain Lumber's cogeneration plant (BANZ, 2007) and serves as a useful 'real world' comparison. The estimated capital costs for the two scenarios are shown in Table 11.

Table 11: Capital cost estimate of 30 bar scenarios

\begin{tabular}{lcc}
\hline Capital Item & \multicolumn{2}{c}{ Cost (\$NZ) } \\
& Extracting & Fully Condensing \\
Feed Handling & $1,757,890$ & $1,987,770$ \\
Boiler & $3,349,215$ & $3,845,527$ \\
Steam Turbine & $1,260,000$ & $1,260,000$ \\
Contingency and Fee & 955,066 & $1,063,994$ \\
Working Capital & 732,217 & 815,729 \\
Total & $\mathbf{8 , 0 5 4 , 3 8 8}$ & $\mathbf{8 , 9 7 3 , 0 2 0}$ \\
\hline
\end{tabular}

From the operating cost analysis the breakeven electricity price of the extracting scenario is $7.9 \mathrm{c} / \mathrm{kWh}$ with an efficiency of $39.1 \%$ where the fully condensing scenario is $10 \mathrm{c} / \mathrm{kWh}$ with an efficiency of $31.8 \%$. The fully condensing scenario is by far the least efficient of all the scenarios.

\subsection{Sensitivity Analysis Comparison}

Because of the difference in efficiency between the gasification and combustion scenarios a sensitivity analysis has been performed on the wood cost between all scenarios and is shown in Figure 37.

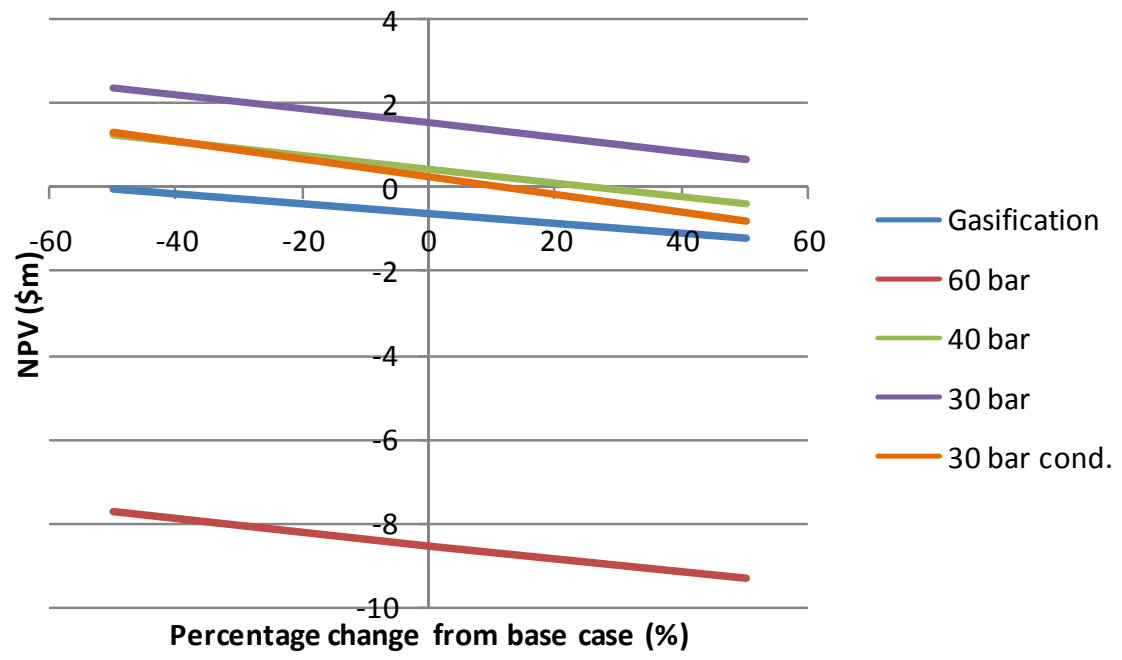

Figure 37: Sensitivity analysis for change in wood per tonne price for gasification and combustion scenarios 
The combustion plants are all less efficient than the gasification scenario (hence more biomass requirement) therefore wood cost has a greater effect on the economics. The sensitivity analysis shows that if the wood cost were to increase significantly more than $60 \%$ the NPV of some of the combustion plants would be similar to the gasification scenario. What the analysis doesn't take into account, however, is the cumulative additional cost of having to use higher value feedstocks due to higher wood usage. Because the lowest value feedstocks would be used first the plant that consumes the least wood for a given output due to a higher efficiency would have the lower overall \$/tonne wood cost. This is an advantage for the gasification scenario and could work towards offsetting the slightly poorer economics. For clarity an example is shown in Figure 38 of the cumulative cost of biomass. The example assumes there is $10,000 \mathrm{odt} /$ annum of sawdust available at no value which is used first, followed by 4,000 odt/annum of bark at \$10/odt, 20,000 odt/annum of chip at $\$ 25 /$ odt with the remainder being imported wood to the mill at $\$ 40 /$ odt. The wood use for the gasification scenario is plotted on the graph, as is the 30 bar condensing turbine combustion scenario. It can be seen in this example the requirement for extra wood for the combustion scenario nearly doubles the wood cost per tonne.

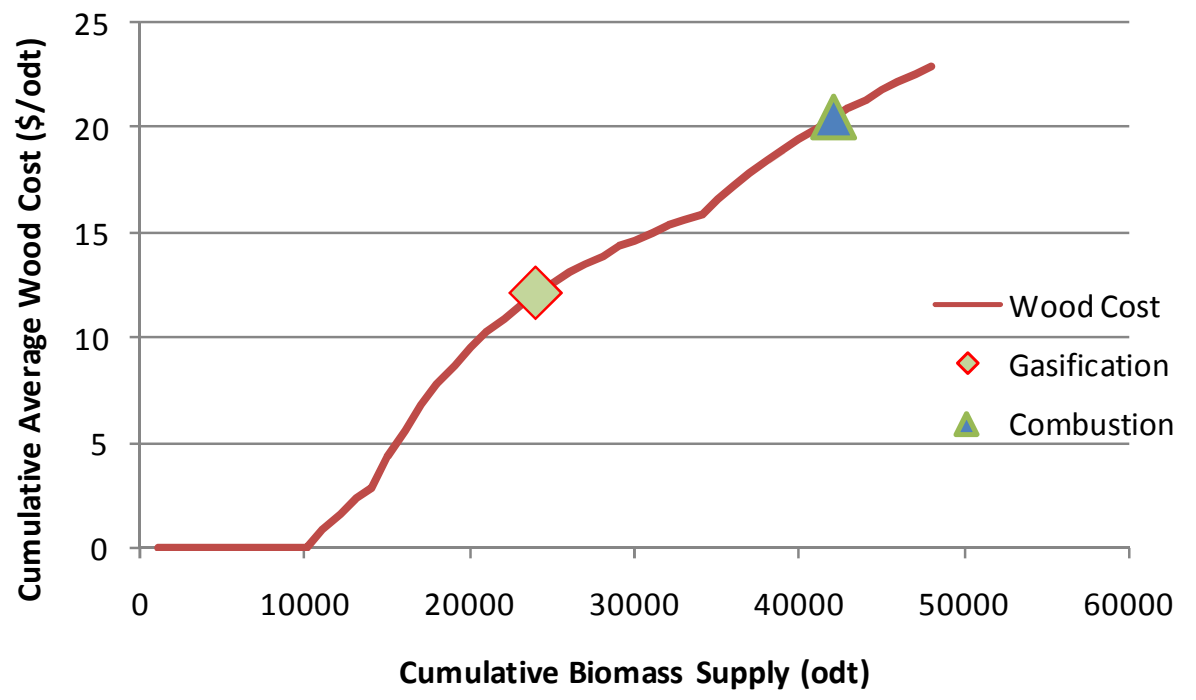

Figure 38: Example of effect of cumulative biomass use with varying cost of feed components 


\subsection{Conclusions of comparison to combustion based combined heat and power}

Based on this study the gasification system is not as economic as the combustion based scenarios. This is attributed to, in part, the assumptions that formed the basis of the study. It is possible that due to the more detailed capital costing of the gasification process, by comparison the estimate of the combustion based process may be somewhat light on capital cost. It is, however, expected any difference would not be significant and it is assumed the analysis is thorough enough for this general study. The gasification scenario does have the significant advantage of greater efficiency hence reducing the wood feed requirements. As stated previously if the wood price per tonne increased with greater biomass usage which is likely, the gasification plant could equal the economics of some of the combustion based scenarios. Rather than conclude the gasification scenario is poor in economics compared to the combustion scenarios this analysis creates a driver to find lower capital cost alternatives and novel opportunities to take advantage of the flexibility of gasification. Including some of these alternatives, which are examined in later sections, makes the gasification scenarios comparable to or better than the economics of a combustion based cogeneration plant. Another advantage of the gasification system is the potential for liquid fuels which is a current and very topical driver for the development of the gasification technology. A combined heat, power, and liquid fuels plant is a very effective way of utilising the available energy. 


\section{Chemical Equilibrium Model Modification}

Previous research (Rutherford, 2006) developed a chemical equilibrium model for use in the economic modelling of the gasification plants. The model was accurate in predicting the producer gas composition when adapted to an updraft gasifier, however the model was not accurate when compared to FICFB gasification. One should refer to Rutherford's thesis as the equilibrium modelling sections provide a basis for reading this section.

The equilibrium model over predicts hydrogen and carbon monoxide and under predicts carbon dioxide and methane (Rutherford, 2006) based on the original results from the CAPE (Chemical and Process Engineering - University of Canterbury) FICFB gasifier. However at that time data from only two runs was available.

The CAPE gasifier had considerable downtime while it was rebuilt and rewired amid safety concerns. However, in the latter half of 2007 and through 2008 there have been numerous runs of the gasifier which have yielded adequate data for analysis.

\subsection{Improving the accuracy of the equilibrium model prediction}

Further runs on the gasifier show the trend is consistent in regards to the over prediction of hydrogen and carbon monoxide, and under prediction of carbon dioxide and methane. Of interest also, is the very high moisture content (approximately 50 mol\%) that is certainly not in line with the equilibrium model, and the presence of higher hydrocarbons (ethane and ethene) which are not considered in the model.

It is apparent the gasifier is not reaching equilibrium at the gasification temperature measured. There are two potential reasons for this

- The gasification temperature measured is not representative of the actual temperature at which the reactions are taking place

- The reactions are kinetically limited

Due to the nature of fluidised beds which provide even heat distribution, the significant number of temperature probes in the gasifier reading similar temperatures 
and examples in literature of similar behaviour (Prins et al., 2007), kinetic limitation is the more accurate assumption.

Workers in the literature take several approaches to allocate for this difference to equilibrium to create what is often termed a 'quasi' or 'phenomenological' equilibrium model. A common and simple method is to allow for an 'approach' temperature (Dupont et al., 2007; Prins et al., 2007). This involves solving the chemical equilibrium model at a lower temperature (refered to as a 'quasi' equilibrium temperature) to represent the gasification reactions not reaching equilibrium. Equations 21 and 22 show the relationship between temperature, equilibrium constants and composition which forms the basis of the model.

CO Shift:

Steam Methane Reforming:

$$
\begin{aligned}
& \mathrm{CO}_{2}+\mathrm{H}_{2} \Leftrightarrow \mathrm{CO}+\mathrm{H}_{2} \mathrm{O} \\
& \mathrm{CH}_{4}+\mathrm{H}_{2} \mathrm{O} \Leftrightarrow \mathrm{CO}+3 \mathrm{H}_{2}
\end{aligned}
$$

The iterative nature of the model solves for a $\mathrm{k}$ value based on

$$
\ln k=-\frac{\Delta G^{0}}{R T}
$$

The $\mathrm{k}$ value is then used to calculate the compositions based on

$$
k=\left[\sum x_{i}^{v_{i}}\left[\frac{P}{P_{0}}\right]^{\sum v_{i}}\right.
$$

Work by Li (2004) found this approach temperature to be $250^{\circ} \mathrm{C}$ below the measured gasification temperature. Other work (Prins et al., 2007) has split these approach temperatures into the various reactions. Interestingly, it has shown that for gasifier operating temperatures in the range of $740-910{ }^{\circ} \mathrm{C}$ the much lower 'quasi' equilibrium temperatures appear to be independent of process temperature in this range (Prins et al., 2007). This appears to be an indirect means of stating that with variation in the gasification temperature (within reason) there is very little variability in the gas composition produced. This is very representative of the CAPE gasifier as the gas composition varies little with variations in temperature (in the normal operational range of 680 to $750{ }^{\circ} \mathrm{C}$ ). In fact it can be said the gas composition is somewhat 
independent of most process conditions such as feed rate and steam to biomass ratio when operating in the normal temperature range.

To demonstrate the effects of an approach temperature the equilibrium model has been solved for a range of temperatures lower than typical gasification temperature (around $720{ }^{\circ} \mathrm{C}$ ) and is shown in Figure 39. It should be noted that the experimental data is not plotted or compared with the modelled data until Section 8.1.3 (shown in Table 12). This is because until the component variation corrections are developed in Sections 8.1.1 to 8.1.2 comparison is somewhat meaningless.

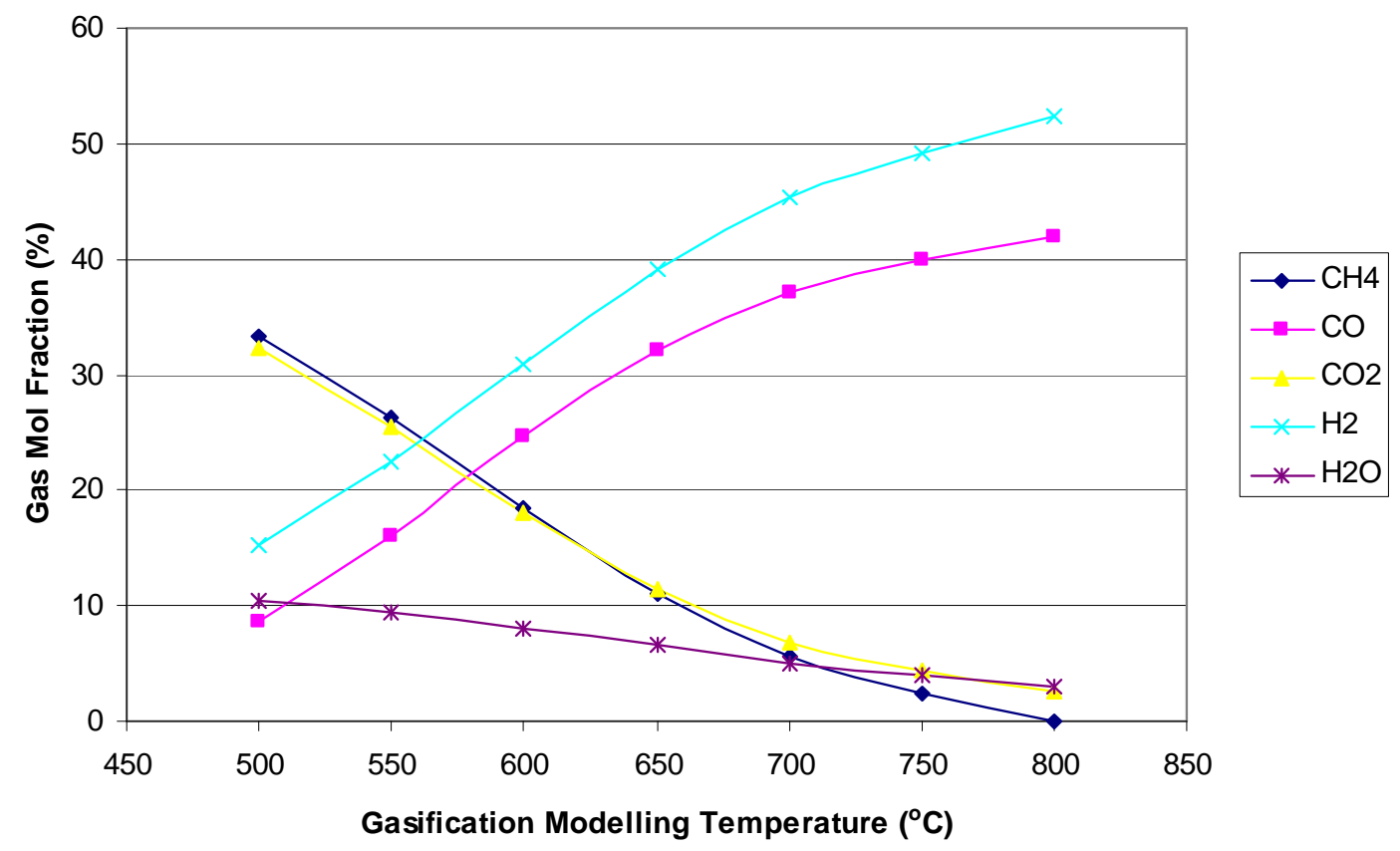

Figure 39: Demonstration of the effects of varying gasification temperature in the equilibrium model

As Figure 39 shows, lowering of the gasification temperature in the model has a significant effect on the gas composition. Modelling a lower temperature assists to reduce the over prediction of hydrogen and carbon monoxide, and the under prediction of methane and carbon dioxide. While this is an improvement in prediction the molar fractions of the individual components show considerable deviation from the experimental data. For example in the experimental data there is a higher fraction of carbon monoxide than hydrogen. This may be indicative that the $\mathrm{CO}$ shift reaction 
is tending closer towards equilibrium than the steam methane reaction due to differing kinetic limitations of the two reactions.

The temperatures have, therefore, been split into the two reactions in order to take account of the differing kinetic limitations. As an example the model has been solved for a range of 'quasi' equilibrium temperatures, however, there is a $200{ }^{\circ} \mathrm{C}$ offset (approach temperature) between the $\mathrm{CO}$ shift and methane reforming reactions and is shown in Figure 40.

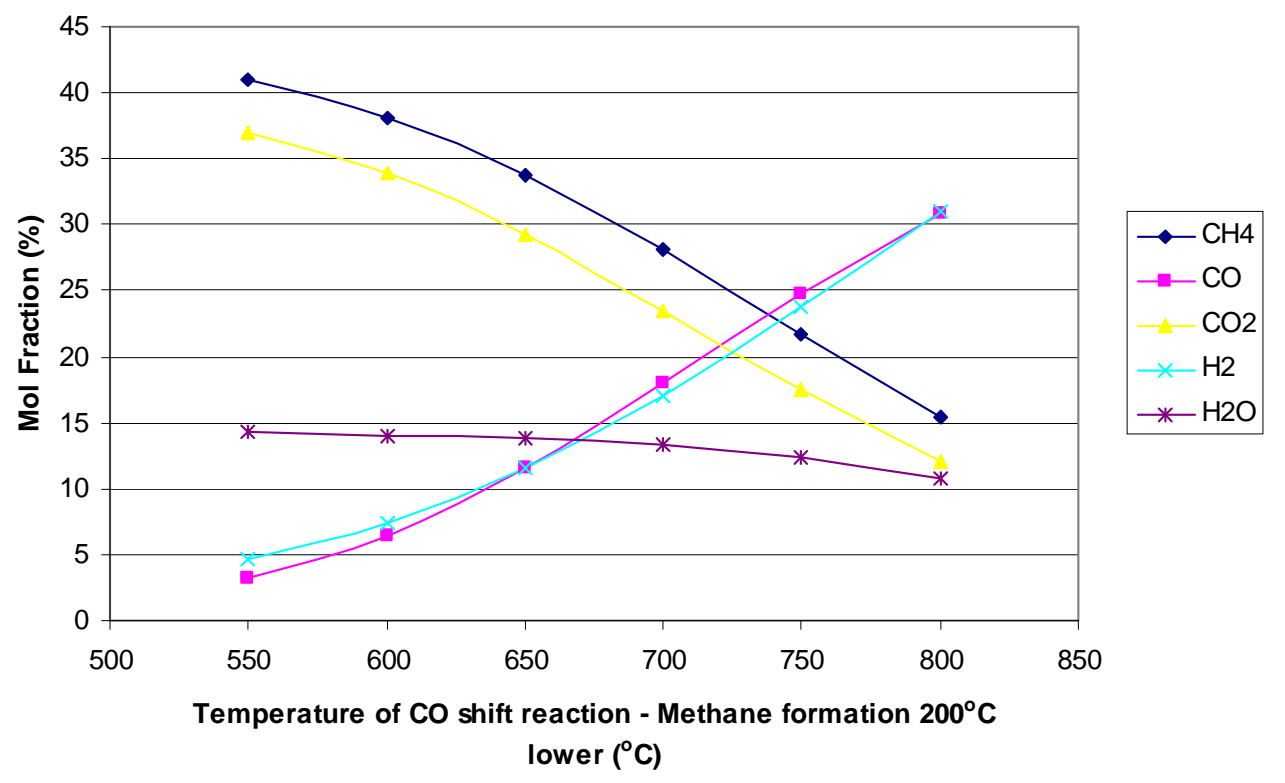

Figure 40: Variation of equilibrium model temperature with the methane formation reaction having a $200^{\circ} \mathrm{C}$ approach to equilibrium

Figure 40 shows that certain components in the gas trend closer towards the experimental data. However, the model is still significantly different from the actual data both in terms of moisture content and higher hydrocarbon production. An understanding of the mechanisms and a method to take these parameters into account is necessary before optimisation of the 'quasi' equilibrium temperatures.

\subsubsection{Higher hydrocarbon production}

While the model does not account for any longer chain hydrocarbons than methane, the actual plant data shows production of ethane and ethene. In the data used in this 
analysis the average fraction of ethane and ethene was $0.74 \mathrm{~mol} \%$ and $4.27 \mathrm{~mol} \%$ respectively (dry basis).

The question is how to allocate for the production of these longer chain hydrocarbons without having to build significant extra complexity into the equilibrium model. Two options are considered.

- Remove the quantity of carbon and hydrogen in the ethane and ethene from the initial biomass into the gasifier. This would effectively increase the steam/biomass ratio, and likely have little other effect other than the results of a higher steam/biomass ratio.

- Consider the ethane and ethene as a replacement for methane. The reactants that would have formed methane have partly formed longer chain hydrocarbons instead as a result of incomplete cracking of pyrolysis products (X. T. Li et al., 2004).

It is considered that the second option is a far more realistic representation. Based on the typical fraction of ethane and ethene the product could be considered to be $\mathrm{C}_{2} \mathrm{H}_{4.3}$ overall. An appropriate assumption is that this makes up 5\% molar volume of producer gas as this has been consistent across most recent gasification tests.

To approximate within reasonable accuracy it is considered that the ethane/ethene mix replaces methane in a 2:1 ratio. For example if the equilibrium model predicts $25 \%$ methane, the adjusted model will give $15 \%$ methane and $5 \%$ ethane/ethene. For the hydrogen component, a conversion of $10 \%$ methane to $5 \%$ ethane/ethane mix will give a hydrogen surplus of $9.25 \%$. This hydrogen excess will be added to the hydrogen component solved by the equilibrium model. The effect of this is the model will need to solve for a low hydrogen content.

\subsubsection{High moisture content}

There is a large discrepancy between the moisture content of the producer gas as predicted by the equilibrium model ( $<10 \%$ molar volume) compared to that measured on actual gasifier runs (typically 50\% molar volume or more). 
It is suspected a significant amount of steam in the system used mainly for fluidisation of the BFB is not taking part in the gasification reactions due to kinetic limitations and is bypassing to the producer gas. This would in effect lower the real steam/biomass ratio in the equilibrium calculations. Figure 41 gives a graphical representation of the suggested water flows in the gasification column.

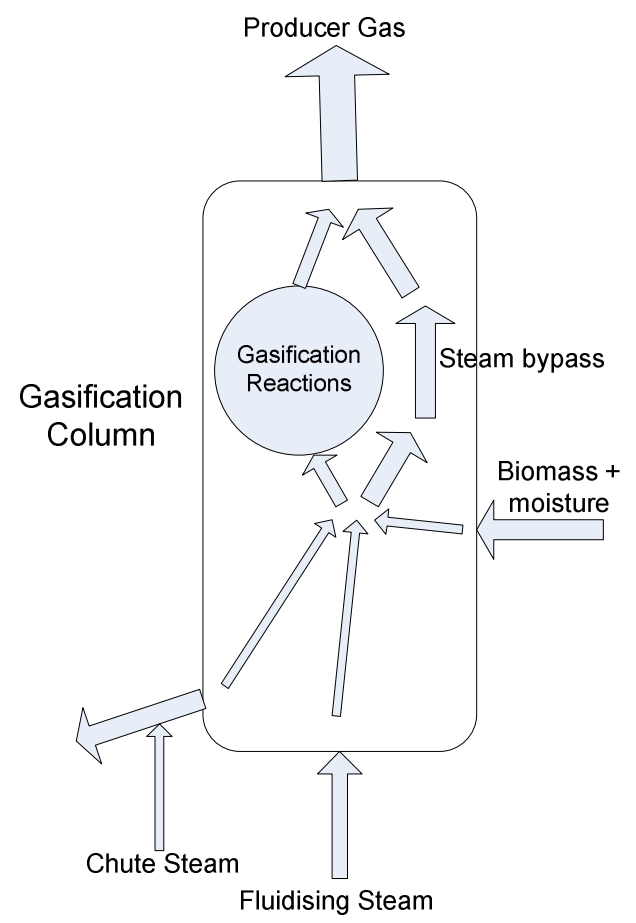

Figure 41: Visual representation of steam bypassing gasification reactions

Because of this observation, the steam/biomass ratio as calculated based on steam and moisture entering the gasifier should not be taken as the quantity of steam taking part in the reactions. The steam/biomass ratio in the model, rather, has been considered a variable open to change in order to optimise producer gas composition prediction. Figure 42 shows the effect of a change in steam/biomass ratio. Of particular interest is the crossover of carbon monoxide and hydrogen fractions at lower steam/biomass ratios. This is consistent with experimental data supporting the assumption the steam/biomass ratio taking part in reactions is lower than that predicted by steam and biomass flows entering the gasifier. 


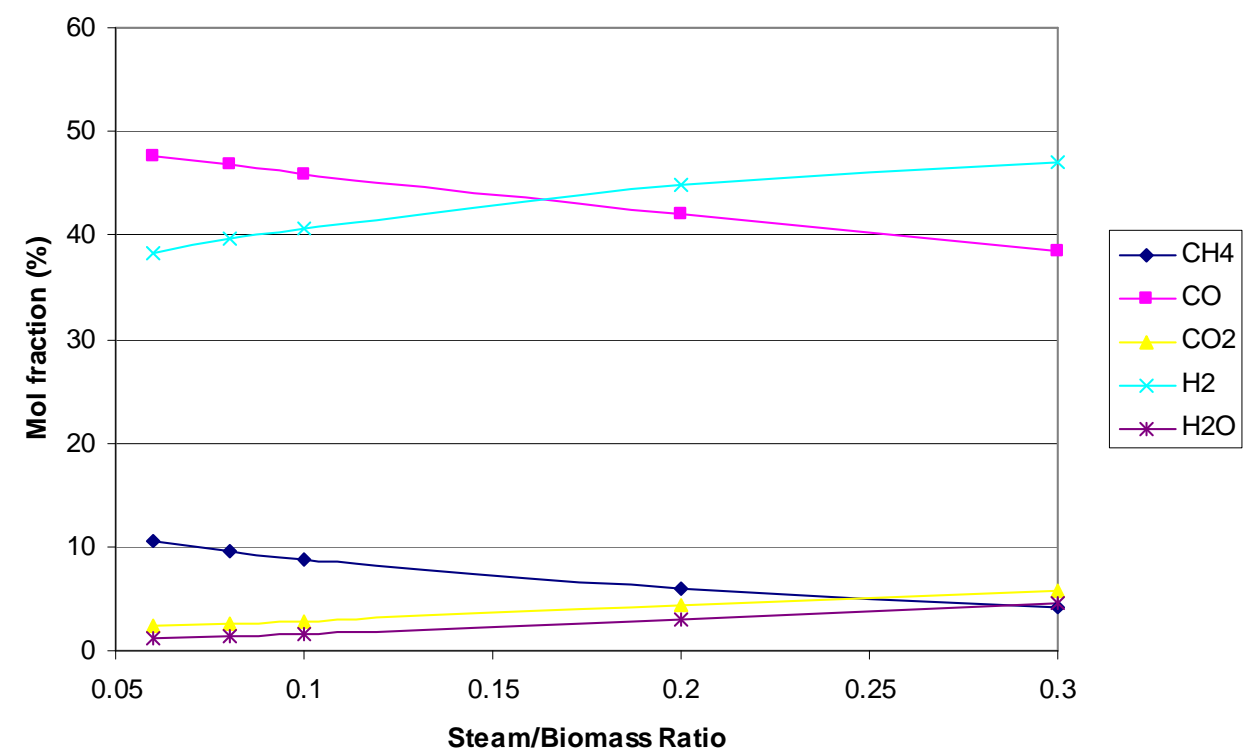

Figure 42: Modelled producer gas composition as a function of variation in steam/biomass ratio based on original equilibrium model at $720^{\circ} \mathrm{C}$

\subsubsection{Optimisation of the model to reflect experimental data}

The factors discussed above need to be combined and optimised to reach an accurate prediction of the producer gas composition. Unfortunately because of the functionality of the model using macros and solver in Excel, iterations need to be performed manually to find the optimum parameters. The sum of squared errors between the lab data and the modelled data was used as an indication of the accuracy of the prediction. The experimental data used as a comparison was the average of several runs of data. As a base to gauge the improvement of the model, the experimental data is compared with the equilibrium model solved at $720^{\circ} \mathrm{C}$ for both reactions with a steam/biomass ratio of 0.3 . These are typical parameters for the gasifier operation. The higher hydrocarbon adjustment would have been included in the model to aid comparison but this drove the methane component negative therefore the higher hydrocarbon component is set to $0 \%$. Results are shown in Table 12 which includes a sum of squared error calculation for comparability and the calorific value of the actual and predicted producer gas. $\mathrm{Nm}^{3}$ refers to gas volume at 'normal' conditions taken to be atmospheric pressure and $20^{\circ} \mathrm{C}$. The sum of squared error is calculated as shown in Equation 23.

Sum of squared error $=\sum_{i=1}^{n}\left(x_{m i}-x_{a i}\right)^{2}$ 
Where $\mathrm{x}_{\mathrm{mi}}$ is the modelled component

$\mathrm{x}_{\mathrm{ai}}$ is the actual component

Table 12: Comparison of experimental to unmodified model producer gas results

\begin{tabular}{lccc}
\hline Component & Actual & & Mol Fraction (\%) \\
$\mathrm{CH}_{4}$ & 14.6 & \pm 0.5 & Modelled \\
$\mathrm{CO}$ & 36.7 & \pm 1.4 & 4.4 \\
$\mathrm{CO}_{2}$ & 18.7 & \pm 1.5 & 40.3 \\
$\mathrm{H}_{2}$ & 24.7 & \pm 1.8 & 6.0 \\
Ethane/Ethene & 5.2 & \pm 0.4 & 49.4 \\
Sum squared error & & & 0.0 \\
Calorific value $\mathbf{M J} / \mathbf{N m}^{3}$ & $\mathbf{1 4 . 2}$ & & $\mathbf{9 2 0}$ \\
\hline
\end{tabular}

Table 12 shows the sum of squared errors is 920. After manipulation of the parameters the optimum results achieved are shown in Table 13. This includes allocation for higher hydrocarbons, split reaction 'quasi' equilibrium temperatures and modified steam/biomass ratio.

Table 13: Comparison of experimental to optimised model producer gas results

\begin{tabular}{lccc}
\hline Component & Actual & & Mol Fraction (\%) \\
$\mathrm{CH}_{4}$ & 14.6 & \pm 0.5 & Modelled \\
$\mathrm{CO}$ & 36.7 & \pm 1.4 & 18.5 \\
$\mathrm{CO}_{2}$ & 18.7 & \pm 1.5 & 34.8 \\
$\mathrm{H}_{2}$ & 24.7 & \pm 1.8 & 15.1 \\
Ethane/Ethene & 5.2 & \pm 0.4 & 26.9 \\
Sum squared error & & & 4.8 \\
Calorific value $\mathbf{M J} / \mathbf{N m}^{3}$ & $\mathbf{1 4 . 2}$ & & $\mathbf{3 6 . 7}$ \\
\hline
\end{tabular}

Table 13 shows the sum of squared error has been reduced to 36.7. Encouraging is the small difference in overall calorific value of the two predictions of only $7 \%$. This calorific value appears high but it excludes dilution from nitrogen and helium. The parameters at which this occurred are shown in Table 14.

Table 14: Parameters for optimised model

\begin{tabular}{lr}
\hline CO shift 'quasi' equilibrium temperature $\left({ }^{\circ} \mathrm{C}\right)$ & 700 \\
Steam methane 'quasi' equilibrium temperature $\left({ }^{\circ} \mathrm{C}\right)$ & 560 \\
Steam to biomass ratio & 0.07 \\
\hline
\end{tabular}


The results show the 'quasi' equilibrium temperature of the $\mathrm{CO}$ shift reaction to be $700^{\circ} \mathrm{C}$. This temperature indicates the $\mathrm{CO}$ shift reaction has reached or at least is close to equilibrium, while the steam methane reforming reaction at $560^{\circ} \mathrm{C}$ is far from equilibrium. This is consistent with literature (Dupont et al., 2007) in which the water gas shift reaction (the reverse of the $\mathrm{CO}$ shift) is asserted as being at equilibrium at 800 to $1000^{\circ} \mathrm{C}$ while the steam methane reaction is kinetically limited. The steam to biomass ratio of 0.07 indicates, as expected, a kinetic limitation reducing the steam taking part in the reaction, leading to high moisture contents in the producer gas.

\subsection{Gas Production Rate}

Of equal importance to composition is the gas production rate. This is because the composition and hence calorific value of the fuel per $\mathrm{m}^{3}$ multiplied by the flow rate of the gas gives the energy available for use from the gasifier. Of particular relevance is how the equilibrium model used in the base economic study compares in terms of predicting energy available from the gas for the combined heat and power plant, compared to use of the experimental producer gas data. Based on the modelling conditions in the economic study the energy in the producer gas is equivalent to 22.5 MJ per kg of dry wood fed to the gasifier. By comparison the experimental data gives a value of $23.3 \mathrm{MJ}$ of gas per $\mathrm{kg}$ of dry wood feed. This is only a $3 \%$ difference, which in terms of the overall expected error in the economic study is very minor. This gives confidence that the use of the equilibrium model in the base economic study is a fair representation of actual performance even if the gas composition is not particularly accurate.

However, as the model has been further developed for gas composition since the base study it is important to compare the effect the developments have had on gas production rate. As the model is pulled further back from equilibrium using the 'quasi' equilibrium temperatures the gas production rate decreases. At the conditions where the gas composition is predicted most accurately, the gas output is equivalent to 16.2 MJ of gas per $\mathrm{kg}$ of dry wood feed. This is $31 \%$ lower than the experimental results. The further the model is from equilibrium the lower the overall gas production rate. Unless this is corrected for, the original equilibrium model is in fact more accurate than the developed model in terms of overall energy production. As 
with the other 'quasi' equilibrium model factors an adjustment can be made by comparing with experimental data. The simplest method is to directly apply the average gas production rate from the experimental data. While this may appear very simplistic the average is consistent with a gas production of $1.7 \pm 0.2 \mathrm{Nm}^{3}$ per $\mathrm{kg}$ of dry wood feed over the range sampled. Applying this flow rate, although empirical, is an accurate method of predicting the gas production rate.

\subsection{Conclusions of the chemical equilibrium modelling modification}

When performing modification of the equilibrium model to improve composition prediction the ultimate goal of the modelling must be kept in mind. While initially the intention is to provide an accurate model for the CAPE gasifier the broader aim is to generate a model that assists in process design to allow predictable scale up of the technology. The model has moved from being a completely theoretical prediction of the gases to a model which contains a significant set of empirical relationships based on the gasifier. While there are examples in literature of other 'phenomenological' models to suit individual gasifier operations (X. T. Li et al., 2004), this method is also criticised as being very 'dead end' and restricted to the studied system (Dupont et al., 2007). However, experimental results on the CAPE gasifier show the operating parameters have little effect on gas composition and it is more a factor of the plant design. It is important, therefore, to compare the modelled data with a different gasifier of the same design outside of the particular laboratory gasifier used as the basis to validate the model's ability to predict composition. Results from the Vienna University of Technology $100 \mathrm{~kW}$ gasifier (TUV, 2008) compared to modelled data is shown in Table 15.

Table 15: Comparison of modelled data to the Vienna University of Technology $100 \mathrm{~kW}$ gasifier operating at $850^{\circ} \mathrm{C}(\mathrm{TUV}, 2008)$

\begin{tabular}{lcc}
\hline Component & Modelled & Mol Fraction (\%) \\
$\mathrm{CH}_{4}$ & 9.7 & TUV 100kW \\
$\mathrm{CO}$ & 26.7 & 10.2 \\
$\mathrm{CO}_{2}$ & 18.1 & 27.1 \\
$\mathrm{H}_{2}$ & 40.6 & 21.0 \\
Ethane/Ethene & 4.8 & 38.9 \\
Sum squared error & & 2.8 \\
Calorific value $\mathbf{M J / \mathbf { N m } ^ { 3 }}$ & $\mathbf{1 2 . 8}$ & $\mathbf{1 5 . 4}$ \\
\hline
\end{tabular}


The modelling conditions for the Table 15 data are shown in Table 16.

Table 16: Parameters for model compared to the TUV $100 \mathrm{~kW}$ gasifier

\begin{tabular}{lr}
\hline CO shift 'quasi' equilibrium temperature $\left({ }^{\circ} \mathrm{C}\right)$ & 750 \\
Steam methane 'quasi' equilibrium temperature $\left({ }^{\circ} \mathrm{C}\right)$ & 570 \\
Steam to biomass ratio & 0.4 \\
\hline
\end{tabular}

As can be seen in Table 16 the parameters have been changed from those used for the CAPE FICFB gasifier. The temperature of the $\mathrm{CO}$ shift reaction was increased to $750^{\circ} \mathrm{C}$ to take into account the normal operating region of $750-900^{\circ} \mathrm{C}$ for the TUV gasifier. The steam/methane reaction was set at $570^{\circ} \mathrm{C}$ assuming the kinetic limitations still apply. The steam/biomass ratio was increased due to research by the TUV suggesting water conversion increases with increasing temperature (TUV, 2008). The difference between the heating values of the modelled vs. actual TUV gasifier is $8.5 \%$.

In conclusion the modified equilibrium model allows significantly increased accuracy of prediction of the gas composition of FICFB gasifiers compared to a pure equilibrium model. More important is the prediction of calorific value of the gas to within $7 \%$ accuracy. However, sensible application of model parameters including 'quasi' equilibrium temperatures and steam to biomass ratio is necessary to yield accurate prediction. 


\section{Capital Item Alternatives and Economic Effects}

\subsection{Introduction}

One of the greatest difficulties in the justification of a gasification based plant is the necessity for high cost capital items. Initially in the economic modelling higher range equipment was selected for use, as is normal for an initial study. However, the cost of certain capital items is very high and it was concluded there may be room to make concessions. The question, however, is whether selection of lower capital cost equipment for the same tasks will affect reliability and stability of operation to a point where it would have been better to spend more money initially. The old adage 'The bitterness of poor quality is remembered long after the sweetness of a good price' needs to be kept in mind when selecting alternatives and examples can be found where using lower priced equipment results in the need for re-engineering (Waldheim, 2006).

The main capital items that need to be reviewed as identified in the base economic study are the

- Feed handling

- Biomass dryer

- Gas engine generator set

\subsection{Feed Handling}

The feed handling component in the basic study was based on some very general rule of thumb correlations. They are, however, potentially more applicable to a greenfield site where there is no existing waste material handling. One needs to assume within a sawmill or LVL plant that there are either two scenarios

- An existing fuel feed and storage system if there is an existing combustion based energy plant.

- An existing system for moving around and storing biomass for it to be on-sold or sent to landfill. 
By this rationale there is already a certain amount of useful equipment in an existing plant. Also the correlations provided by the material handling specialist company may prove to be more expensive than other companies that can also provide materials handling equipment. However, because of the likelihood of inconsistencies between mills in terms of existing plant, and the long term experience of the company making the cost estimates the feed handling cost will not be modified. If the price predicted is higher than what the system could actually be built for then this provides a conservative economic buffer in estimating capital cost for the overall system.

\subsection{Biomass Dryer}

For the initial costings in the base economic study a rotary drum dryer was employed. The rotary drum dryer was chosen as it is a suitable and effective means of drying biomass to a consistent moisture content. Selecting alternatives is not seen as simple as the gas engine. With an engine the basic principles are the same and the alternatives are simply to find different manufacturers and engines of different ages. The drying method differs from this in that different technologies are available, as well as various manufacturers of the same technology. Consideration is made, however, of the balance between reduction in capital cost and the negative effects on the plant operation.

There are several alternatives when investigating a lower cost method of drying.

- Find a low cost manufacturer of rotary drum dryers

- Find a suitable second hand rotary drum dryer

- Use a semi batch type dryer typical within the grain industry

- Use a bin dryer

- Another more cost effective continuous method

- An original novel method

A rationalisation of this list is necessary for further investigation.

- Pure batch drying such as bin drying should be eliminated. While this may be a low capital cost method the effects on the operation from variations in moisture content are considered to be too risky. While the actual effects are not quantified, for the purposes of this study it seems prudent to avoid 
installing any equipment that will make operation of a new and novel technology more difficult.

- Trying to look for low cost manufacturers of the same equipment is somewhat fruitless. The rotary drum dryer can be bought for a very good price in New Zealand when compared with Europe. It is unlikely a significantly lower cost manufacturer could be found that doesn't sacrifice build quality.

- Thoughts should be given to alternative continuous methods that will still produce an even moisture content.

Therefore the types of dryer that will be investigated further are

- A suitable second hand rotary drum dryer

- An adaption of a dryer as used in the grain industry

\subsubsection{Second Hand Rotary Drum Dryer}

Because the equipment is fairly specialised it will not be common to find second hand rotary drum dryers. A search has been made and a dryer located that can be used as a comparison (Asset Disposals Ltd, 2008). The dryer, however, is only designed for $250-500 \mathrm{~kg} / \mathrm{hr}$. For example the sawmill scenario needs to process $2.8 \mathrm{~T} / \mathrm{hr}$ of dry biomass. Therefore the dryer would need to be approximately 6 times the size. The cost of the dryer is \$AUD 46,000 plus \$AUD 2000 shipping. This total converted to $\$ N Z$ is approximately $\$ N Z 58,000$. For general comparison a power law scale up factor of 0.6 is applied to the dryer to obtain an approximate price for a scale suitable for the sawmill scenario. The resultant bare module cost is $\$ N Z 170,000$. Because this price is considerably lower than the new rotary drum dryer it is not sensible to apply an installation factor as the work required for installing the second hand dryer is comparable with the new dryer. The new dryer installation cost is around $\$ 300,000$ (Fernando, 2008) making the installed second hand dryer \$NZ 470,000.

While this is a reasonable capital cost and a method worth pursuing for economic reasons the only second hand rotary drum dryer available that could be found needed to be scaled up considerably for this analysis, confirming a lack of second hand availability. 


\subsubsection{Multi-Deck Turbo Dryer}

An alternative drying system quoted by a New Zealand manufacturer is a multi-deck turbo dryer (Openshaw Plant Machinery Ltd, 2008). The dryer itself is a second hand unit, with all new peripheral equipment. The dryer consists of three decks with each deck having four sweep arms fitted with paddles to transfer the material being dried across the deck area. A schematic of a multi deck dryer is shown in Figure 43. This is not identical to the dryer investigated but gives a visual representation of the functionality.

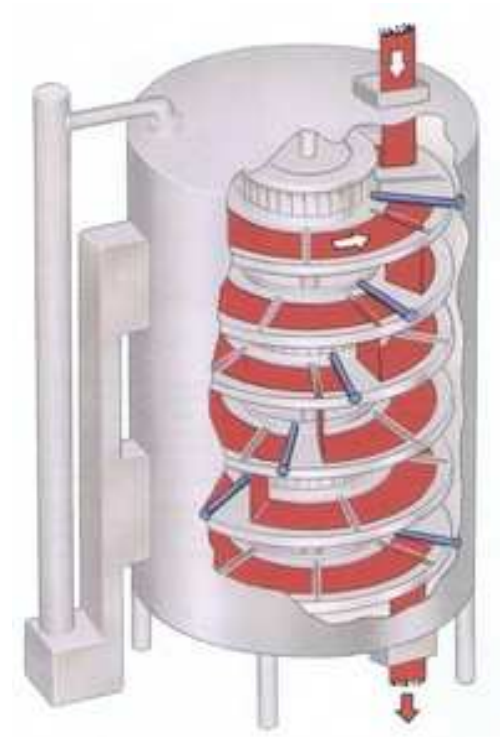

Figure 43: A schematic of a Multi-deck Dryer

The dryer provides continuous movement of the material being dried which is beneficial for high moisture content materials. The dryer is designed to process 1750 $\mathrm{kg} / \mathrm{hr}$ of dried material. For the benefit of this study it will be assumed that two drying units will be needed as the sawmill scenario needs $2800 \mathrm{~kg} / \mathrm{hr}$ of dried biomass, as well as an extra conveyor feeding and discharging from the extra dryer. The quoted prices for the remainder of the equipment will be increased by a scaling factor of 0.6. It should be noted the equipment is predominantly designed to process sawdust, which is likely to be a major component of the biomass feed. Details of specifications and costs of the equipment can be found in Appendix B.

It is unlikely the hammer mill is a necessity but will be left in the quote to be conservative, as it may help even particle sized feed to the gasifier especially if chip or hogged forest residues are a potential feedstock. The heating system has been 
scaled back as it is assumed hot gas will provide the heat for drying rather than any form of burner and heat exchange. The pricing for the dryer system modified to suit the scenarios in this thesis is included in Table 17.

Table 17: Estimated capital costs for multi-deck turbo dryer

\begin{tabular}{|c|c|c|c|c|c|}
\hline Item & $\begin{array}{l}\text { Price } \\
\$ N Z\end{array}$ & $\begin{array}{l}\text { Size Increase } \\
\text { by factor }\end{array}$ & $\begin{array}{l}\text { Upsized Cost } \\
\text { \$NZ }\end{array}$ & Quantity & $\begin{array}{l}\text { Total Cost } \\
\text { \$NZ }\end{array}$ \\
\hline Intake hopper & 6,580 & 2 & 9,973 & 1 & 9,973 \\
\hline Transfer belt conveyor & 11,370 & 1 & 11,370 & 2 & 22,740 \\
\hline Multi deck turbo dryer & 48,425 & 1 & 48,425 & 2 & 96,850 \\
\hline Rotary valve & 4,080 & 1 & 4,080 & 2 & 8,160 \\
\hline Receiving cyclone & 9,725 & 2 & 14,740 & 1 & 14,740 \\
\hline Cyclone fan & 17,160 & 2 & 26,010 & 1 & 26,010 \\
\hline Discharge conveyor & 7,580 & 1 & 7,580 & 2 & 15,160 \\
\hline Hammermill & 8,160 & 2 & 12,368 & 1 & 12,368 \\
\hline Receiving hopper & 7,110 & 2 & 10,777 & 1 & 10,777 \\
\hline Filter collector & 5,000 & 2 & 7,579 & 1 & 7,579 \\
\hline \multicolumn{5}{|c|}{$\begin{array}{l}\text { Total } \\
\text { Including installation factor of } 2\end{array}$} & $\begin{array}{l}224,357 \\
448,714\end{array}$ \\
\hline
\end{tabular}

Table 17 shows the total capital cost for the installed drying system is \$NZ 449,000. In comparison the sawmilling scenario in this thesis had a drying cost of $\$ \mathrm{NZ} 1.3 \mathrm{~m}$. This is a significant saving and more than halves the drying capital cost. Because the total capital of the overall plant includes a contingency and fee as well as working capital based on a fraction of the installed plant cost the savings are even more significant. The overall capital investment reduces from \$NZ $10.6 \mathrm{~m}$ to \$NZ $9.52 \mathrm{~m}$. In turn the breakeven electricity price reduces from $11.6 \mathrm{c} / \mathrm{kWh}$ to $9.93 \mathrm{c} / \mathrm{kWh}$. This brings the breakeven price to below the price paid for electricity on the grid of 10.46 $\mathrm{c} / \mathrm{kWh}$. 


\subsection{Gas Engine Generator Set}

The gas engine genset is the most critical area for an alternative to be found. In the case of LVL A mill the gas engine genset makes up $41 \%$ of the total capital cost of the energy plant. Currently the choice of engine generator set is a Jenbacher. Whilst they are very good engines the cost is very high.

There are several alternatives to a high capital cost engine generator set.

- Find an alternative lower priced engine manufacturer and buy a gas specific engine generator set brand new.

- Find a second hand gas engine generator set with very low hours.

- Find a second hand gas engine generator set with high hours and factor in a rebuild cost.

- Source a brand new diesel engine generator set and convert to spark ignition or dual fuel.

- Source a second hand diesel engine generator set and convert to spark ignition or dual fuel.

The suggested alternatives above range from what is expected to be the most expensive but more ideal scenario, to what is expected to be the cheapest alternative, but also the least practical and potentially the least reliable.

Rationalisation to a shortlist of the most appropriate scenarios to investigate yields

- A second hand gas engine with low hours.

- A second hand gas engine with high hours and include a rebuild cost.

The reasons for this rationalisation are as follows

- If a brand new engine was to be purchased it is unlikely an engine could be bought at a price significantly less than that of the expensive high quality option that still had suitable attributes. For a brand new engine to be much cheaper than another brand new engine there would almost certainly have to be a significant quality difference.

- A major reason for purchasing a new engine would be the warranty package included with the engine. However, because the engine would be running on 
producer gas rather than natural gas it is very likely the engine manufacturer will not honour a warranty package (Hedley, 2008). This makes a low hour second hand engine more appealing if it can be bought at a significantly cheaper price.

- Engines with high hours can be very much cheaper than other scenarios. It may be the case that the installation is somewhat of a proof of concept. In this case it is likely the engine will run suitably for a long enough time to prove the energy plant system. After a proving period the engine could be rebuilt to continue to run. If not, a large investment has not been initially outlaid.

- The converted or dual fuel diesel engine may be a suitable choice for a small scale plant investigating the feasibility of gasifier/gas engine combinations but is unlikely to be as efficient and reliable as a gas specific engine for a commercial energy plant. It also adds an extra complication to an already novel process of having to modify and tune an engine.

While academic research should not typically rely on web references a canvas of second hand industrial equipment sites gives an indication of the market and has yielded a number of suitable gas engines at a range of operating hours and sizes. Due to the large number available it should not be difficult to find a suitable engine within given constraints of size and operating hours. Table 18 shows engines with low or no hours bought from second hand retailers while Table 19 shows engines with higher operating hours.

Table 18: No or low hour natural gas engine gensets from second hand industrial retailer

\begin{tabular}{lccccc}
\hline Manufacturer and Model & Run hours & Rating (MW) & Cost (\$NZ) & Cost per unit (\$NZ/kW) \\
MTU & 16V4000L61 & 0 & 1.3 & 660,000 & 508 \\
Cummins & QSV91 & 0 & 1.75 & 871,795 & 498 \\
Caterpiller & G3520C & 5,000 & 2 & 576,923 & 288 \\
& & & & Average & $\mathbf{4 3 1}$ \\
\hline
\end{tabular}

Table 19: High hour natural gas engine gensets from second hand industrial retailer

\begin{tabular}{lccccc}
\hline Manufacturer and Model & Run hours & Rating (MW) & Cost (\$NZ) & Cost per unit (\$NZ/kW) \\
Jenbacher & J620GS & 32,000 & 2.72 & 600,000 & 221 \\
Nigata & 12V26HX-G & 44,000 & 1.90 & 179,487 & 94 \\
Nigata & 16V26HX-G & 44,800 & 2.50 & 350,000 & 140 \\
Waukesha & 12V-AT25GL & 61,000 & 1.9 & 280,000 & 147 \\
& & & & Average & $\mathbf{1 5 2}$ \\
\hline
\end{tabular}


From Table 18 and Table 19 it can be seen there is a significant cost saving in using this type of engine in comparison to the $\$ \mathrm{NZ} 839$ per $\mathrm{kW}$ used for pricing of the Jenbacher engine.

There however is the need to consider the derating of the engines as they are designed for natural gas. This will push the effective cost per $\mathrm{kW}$ higher.

\subsubsection{Calculation of engine derating}

The intention of the following section is to lay out a simple step by step process for derating a natural gas engine for producer gas. While a small amount of literature can be found on this topic (Dasappa, 2001) it is somewhat difficult to follow. This section takes relevant aspects of the derating method from literature (Dasappa, 2001) and is applied to the parameters in this thesis. The method achieves very good comparability to experimental results (Dasappa, 2001) which is a significant driver to apply the method in this thesis.

When derating a gas engine there are several variables that need to be taken into account. They are as follows

- Compression ratio

- The energy density of the fuel/air mix in the cylinder

- Change in moles between the reactants and products

- Adiabatic flame temperature and its effect on peak pressure in the cylinder

\section{Compression ratio}

The compression ratio needs to be taken into account because the ratio may need to be lowered to prevent knocking, based on the combustion characteristics of the fuel. However, in this case it is assumed the gas engines already have a lower compression. This is partly because of the knock resistance limitations of natural gas, and the engines being spark ignited not requiring high compression for compression ignition. It is assumed the compression ratio will not need to be lowered any further to accommodate a producer gas feed. 


\section{Energy density factor $\left(\mathbf{E}_{\mathbf{f}}\right)$}

The energy density describes the calorific value of the air/fuel mix within the cylinder. The stoichiometric air/fuel ratio has a significant effect on the energy density. Table 20 shows the calorific value of the producer gas, as well as that of natural gas $\left(\mathrm{CH}_{4}\right)$.

\begin{tabular}{lcc}
\multicolumn{3}{c}{ Table 20: Calorific value of producer gas based on chemical equilibrium model } \\
\cline { 2 - 3 } Producer Gas & Mol Fraction & $\mathbf{H H V ~}\left(\mathbf{M J} / \mathbf{m}^{\mathbf{3}}\right)$ \\
Mol Frac $\mathrm{CH}_{4}$ & 0.0013 & 34.39 \\
Mol Frac $\mathrm{CO}$ & 0.2685 & 10.98 \\
Mol Frac $\mathrm{H}_{2}$ & 0.4904 & 10.97 \\
& HHV of producer gas & $\mathbf{8 . 3 7}$ \\
\hline
\end{tabular}

The calorific value of natural gas is considerably higher than that of producer gas, however, for stoichiometric combustion of natural gas the air/fuel ratio is 9.52 compared to 2.14 for producer gas. This indicates there is significantly more dilution of natural gas in the cylinder compared to producer gas. Table 21 summarises the energy density for natural gas and producer gas.

Table 21: Summary of air/fuel (A/F) ratio and energy density for natural gas and producer gas at varying levels of excess air

\begin{tabular}{lcccccc}
\hline & \multicolumn{2}{c}{$\begin{array}{c}\text { Stoichiometric } \\
\text { A/F ratio }\end{array}$} & $\begin{array}{c}\text { Energy density } \\
\left(\mathbf{M J} / \mathbf{m}^{\mathbf{3}}\right)\end{array}$ & $\begin{array}{c}\mathbf{5 \%} \text { excess air } \\
\text { A/F ratio }\end{array}$ & $\begin{array}{c}\text { Energy density } \\
\left(\mathbf{M J} / \mathbf{m}^{3}\right)\end{array}$ & \multicolumn{2}{c}{$\mathbf{1 5 \%}$ excess air } \\
A/F ratio & $\begin{array}{c}\text { Energy density } \\
\left(\mathbf{M J} / \mathbf{m}^{3}\right)\end{array}$ \\
Natural gas & 9.52 & 3.27 & 10 & 3.13 & 10.95 & 2.88 \\
Producer gas & 2.14 & 2.97 & 2.24 & 2.88 & 2.09 & 2.71 \\
Energy density factor & $\mathbf{0 . 9 1}$ & & $\mathbf{0 . 9 2}$ & & $\mathbf{0 . 9 4}$ \\
\hline
\end{tabular}

\section{Mole change factor $\left(\mathrm{M}_{\mathrm{f}}\right)$}

When certain fuels combust the number of moles of product can be different to the number of moles of reactant. In the case of natural gas the ratio is 1:1. However producer gas can be less. Table 22 shows the calculation of the mol change factor based on producer gas fractions from the chemical equilibrium model as used in the economic modelling in this thesis. It can be seen based on the producer gas fractions used there is a reduction in moles of $14 \%$ from the reactants to the products. This has an effect on the peak pressure inside the cylinder and therefore power. 
Table 22: Calculation of mole change factor using predicted producer gas fractions from chemical equilibrium model

\begin{tabular}{|c|c|c|c|c|c|}
\hline & Mol Fraction & Mol flow in & & Mol flow out & Reaction \\
\hline Mol Frac $\mathrm{CH}_{4}$ & 0.0013 & 0.0013 & & 0.0000 & $\mathrm{CH}_{4}+2 \mathrm{O}_{2}=\mathrm{CO}_{2}+2 \mathrm{H}_{2} \mathrm{O}$ \\
\hline Mol Frac CO & 0.2685 & 0.2685 & & 0.0000 & $\mathrm{CO}+0.5 \mathrm{O}_{2}=\mathrm{CO}_{2}$ \\
\hline Mol Frac $\mathrm{CO}_{2}$ & 0.0911 & 0.0911 & & 0.3609 & \\
\hline Mol Frac $\mathrm{H}_{2}$ & 0.4904 & 0.4904 & & 0.0000 & $\mathrm{H}_{2}+0.50_{2}=\mathrm{H}_{2} \mathrm{O}$ \\
\hline Mol Frac $\mathrm{H}_{2} \mathrm{O}$ & 0.1487 & & & 0.4930 & \\
\hline Stoic. $\mathrm{O}_{2}$ & & 0.3821 & & & \\
\hline $\mathrm{N}_{2}$ & & 1.4373 & & 1.4373 & Products/Reactants $\left(\mathrm{M}_{\mathrm{f}}\right)$ \\
\hline & Total entering & 2.6706 & Total leaving & 2.2912 & 0.86 \\
\hline
\end{tabular}

\section{Adiabatic Flame Temperature $\left(\mathbf{T}_{\mathbf{f}}\right)$}

Based on ideal gas laws the flame temperature will affect the peak pressure achieved in the cylinder, in turn affecting the power output. To calculate the temperature a reactor was used in HYSYS to model the combustion reactions for both natural gas (methane) and producer gas. The feed to the reactor was either methane or producer gas excluding the water fraction, and air at stochiometric ratio or excess. Table 23 shows the results at various levels of excess air. It can be seen the adiabatic flame temperature of the producer gas is in fact higher than natural gas resulting in an effective increase in engine power over natural gas based on the temperature factor.

Table 23: Adiabatic flame temperature comparisons for natural gas and producer gas

\begin{tabular}{lccc}
\hline & & Temperature (K) \\
& Stoichiometric & 5\% Excess Air & 15\% Excess Air \\
Natural Gas & 2296 & 2232 & 2114 \\
Producer Gas & 2409 & 2355 & 2254 \\
Temperature Factor & 1.05 & 1.06 & 1.07 \\
\hline
\end{tabular}

\section{Overall Engine Derating Calculation}

From the above factors the power for an engine running on producer gas rather than natural gas can be calculated.

Power $_{\text {producer gas }}=$ Power $_{\text {natural gas }} \times \mathrm{E}_{\mathrm{f}} \times \mathrm{M}_{\mathrm{f}} \times \mathrm{T}_{\mathrm{f}}$

Therefore for an engine running on $5 \%$ excess air

Power $_{\text {producer gas }}=$ Power $_{\text {natural gas }} \times 0.833$

And for and engine running on $15 \%$ excess air

Power $_{\text {producer gas }}=$ Power $_{\text {natural gas }} \times 0.861$ 
Utilising the data from Table 18 and Table 19 the cost per $\mathrm{kW}$ of second hand gas engines running on producer gas is shown in Table 24.

Table 24: Comparison of average capital cost of second hand engines when derating factors

\begin{tabular}{lccc} 
& applied \\
& Non derated & \multicolumn{3}{c}{ Derating Basis } \\
Low hour engine average cost $(\$ N Z / \mathrm{kW})$ & 431 & $\mathbf{5 \%}$ excess air & $\mathbf{1 5 \%}$ excess air \\
High hour engine average cost $(\$ N Z / \mathrm{kW})$ & 152 & 518 & 501 \\
\hline
\end{tabular}

The producer gas composition used in the derating calculations is based on results from the chemical equilibrium model. This is in keeping with the rest of the thesis. For comparison, however, it is thought prudent to calculate the derating based on the producer gas compositions from the CAPE laboratory scale FICFB gasifier. A typical composition of gas is shown in Table 25.

Table 25: Producer gas compositions and heating value of CAPE lab scale FICFB gasifier

\begin{tabular}{|c|c|c|}
\hline Producer Gas & Mol Fraction & $\mathrm{HHV}\left(\mathrm{MJ} / \mathrm{m}^{3}\right)$ \\
\hline Mol Frac $\mathrm{CH}_{4}$ & 0.1400 & 34.39 \\
\hline Mol Frac CO & 0.3470 & 10.98 \\
\hline Mol Frac $\mathrm{H}_{2}$ & 0.2350 & 10.97 \\
\hline Mol Frac $\mathrm{C}_{2} \mathrm{H}_{4}$ & 0.0420 & 49.80 \\
\hline \multirow[t]{2}{*}{ Mol Frac $\mathrm{C}_{2} \mathrm{H}_{6}$} & 0.0072 & 58.40 \\
\hline & HHV of producer gas & 11.20 \\
\hline
\end{tabular}

Table 25 shows the heating value of the producer gas is higher, therefore one would expect the derating to be less. This, however, proves to be incorrect because when the calculations are applied, the derating of the engine is more. The main factor influencing the extra derating is the energy density factor. While the producer gas is higher in heating value there is also a much higher air requirement for complete combustion. This has the effect of diluting the producer gas so the overall energy density of the charge to the engine is significantly less. The capital cost of the derated engines as shown in Table 24 has been recalculated for the lab gasifier producer gas composition and is shown in Table 26. 
Table 26: Recalculated second hand engine capital costs based on CAPE lab scale FICFB gasifier producer gas composition

\begin{tabular}{lccc}
\hline & Non derated & \multicolumn{2}{c}{ Derating Basis } \\
& & $\mathbf{5 \%}$ excess air & $\mathbf{1 5 \%}$ excess air \\
Low hour engine average cost $(\$ N Z / \mathrm{kW})$ & 431 & 584 & 574 \\
High hour engine average cost $(\$ N Z / \mathrm{kW})$ & 152 & 206 & 202 \\
\hline
\end{tabular}

\subsubsection{Economics of incorporating a second hand gas engine into the base scenario}

As with the drying alternative section the new gas engine price will be added to the sawmill model to consider the overall economic affects of a reduced gas engine cost. An excess air of $5 \%$ will be used as in literature this is indicated as typical for a gas engine (Dasappa, 2001). The Jenbacher engine is a lean burn engine with a much higher air/fuel ratio (GE Jenbacher, 2005). If this were to be taken into account the derating of an engine running on producer gas would be significantly less. However, because the engines in comparison may not be lean burn it is considered a conservative option to use $5 \%$ excess air.

Also to be conservative in cost estimates, the derating based on the experimental producer gas data will be used (Table 26). While this is not consistent with the thesis it is deemed appropriate so not to underestimate the derating of the gas engine in a real scenario.

The engine size for the sawmill is $1421 \mathrm{~kW}$ resulting in a base engine cost of $\$ \mathrm{NZ}$ 829,000 . An installation factor of 2 is used giving an installed engine cost of $\$ N Z$ $1.66 \mathrm{~m}$. Once the influence on working capital and contingency and fee is incorporated the overall capital cost reduces from \$NZ $10.6 \mathrm{~m}$ to \$NZ $9.67 \mathrm{~m}$. The breakeven electricity price reduces from 11.6 to $10.2 \mathrm{c} / \mathrm{kWh}$. 


\section{Power Market Opportunities}

In the base economic study in this thesis an average power price of $10.46 \mathrm{c} / \mathrm{kWh}$ (Dang \& New Zealand Ministry of Economic Development, 2007) has been used. Section 3.2 reviewed the long term trends of the power price and discussed future predictions, however, this will be an average of both time and location. The power price varies within both of these parameters and therefore an investigation will be made into whether there are any opportunities to configure the gasification plants or associated mills within this study to best take advantage of the New Zealand power market.

Having internal generation allows a mill to play the power market based on the assumption that the mill buys electricity on the spot market. While any mill could potentially play the market by choosing when to or when not to operate, the internal generation gives a mill more strings to its bow, allowing more flexibility and profit potential.

The power price has peaks and dips throughout a typical day depending primarily on demand. The peaks are normally based around breakfast and dinner time but this is not absolute. Live five minute power prices are freely available from

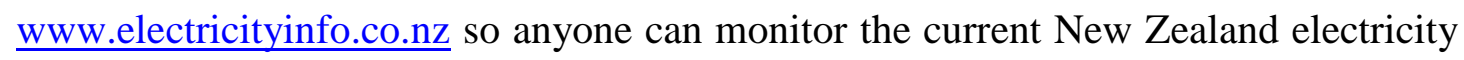
price. There is not, however, significant historical data on this website. Data for this study was obtained directly from the electricity commission via their centralised dataset (Electricity Commission, 2008).

Within the power market, each day is broken up into 48 trading periods. An average of each of these trading periods for a year is calculated to give an average daily spread in the power price. The average spot price for each of these half hour periods for an example node is shown in Figure 44. 


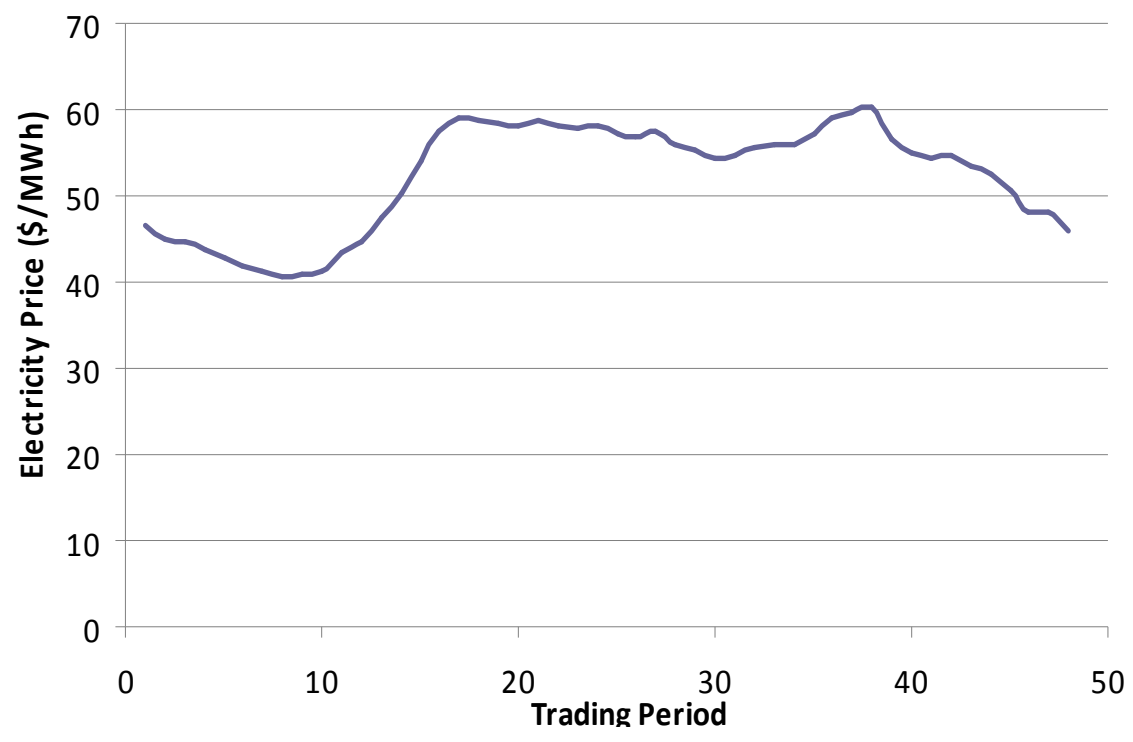

Figure 44: Average trading period price in 2007 for OTA2201

From Figure 44 it can be seen there are distinct periods where the power price is higher. This opens up options for different strategies to take advantage of this price fluctuation in a sawmill based CHP arrangement. In all cases it is assumed the output from the gas engine is kept constant, rather than varying load, to match market opportunities. This is set as the base case, as a conservative approach, in order to allow a steady state operation of the gasifier and associated energy plant.

Different approaches can be taken to reap the benefits of the fluctuating prices, each having specific advantages and disadvantages typically based on the profit potential vs. the practicality of taking downtime.

In this case the sawmill has been chosen over the LVL or MDF plants. The reason being the sawmill scenario only mills logs and therefore uses peak power for 8 hours per day. The remaining 16 hours only use electricity for drying. The advantage arises from the fact that because the drying requirement is 24 hours the energy plant always needs to be running which means electricity always has the potential to be generated. There is the ability to move the 8 hours of milling throughout the day to best take advantage of the power price. Using the case of the example mill size in this thesis, there is an electrical demand of $1421 \mathrm{~kW}$ for 8 hours per day, with the remaining 16 hours only requiring $362 \mathrm{~kW}$. This allows an excess capacity of $1059 \mathrm{~kW}$ of power to be sold onto the grid. The MDF and LVL differ in that any downtime to take advantage of power prices directly impacts on production. Therefore the profit 
potential of the mill selling their product needs to be factored into any advantage gained on the power market by taking downtime. MDF and LVL will therefore not be considered in this case as the benefit is not likely to be as significant as for a sawmill.

The different scenarios considered to take advantage of the power price fluctuations are

- The mill keeps an eye on the power price and stops production when the price hits a specified value. Production is sporadic based on price throughout the day until the days production is met. The advantage of this scenario is the profit potential from playing the power market is maximised. The disadvantage is the practicality and production cost of this strategy. Starting and stopping a plant on a continual basis is difficult, and spreading the milling throughout potentially a whole day necessitates extra shifts which carries a significant cost.

- The mill selects what is estimated to be the most cost effective 8 hour period for that day, and mills continuously within that time. The disadvantages of this system is it requires an estimate of the best 8 hours to run which may not eventuate as being the most accurate, and it also requires a very flexible shift which is impractical.

- The mill performs historical research as to which is the most cost effective time to run for an 8 hour period, and then adhers to this scenario. This still has time of use benefits but removes some of the impracticalities of variations in run time. The disadvantage is the production time is likely to be outside of natural work hours.

- The final scenario is status quo for production timing, where the mills reaps the benefits of insulation from power price peaks. The disadvantage is that when there is no production and power is being sold, it is generally in the lower price ranges.

The first two scenarios are recognised as being very impractical but are included to show the range of options to maximise profit. 
The third scenario of choosing an eight hour production period that doesn't vary day to day has been selected as the most appropriate.

The centralised dataset was analysed to produce both average power prices for each of the main eleven nodes and an average of each of the 48 daily trading periods to give an average daily trend of the power price movements (as example shows in Figure 44). The analysis was performed for all of 2007. It was deemed appropriate to use at least a years worth of data as power price varies throughout the seasons therefore any shorter period of analysis would skew results. It is acknowledged that there are year to year differences in power price and analysis of several years of data would improve accuracy of analysis further, however, the quantity of data to analyse is significant, and is not warranted for this general study.

Analysis of each node gives a general overview of the price in that area, which is superior in specific case studies in comparison to an average price for New Zealand. To check the validity of using the $220 \mathrm{kV}$ nodes as representative of the wider area the node HLY2201 was compared to KAW0111. This is an $11 \mathrm{kV}$ node in Kawerau compared to the $220 \mathrm{kV}$ node in Huntly. Overlaying the average trading periods yielded the same trend, and the average annual price was very similar, therefore excluding any significant disruptions to the generation or network it can be assumed the main $220 \mathrm{kV}$ nodes are suitable for analysis of the general area.

For each of the nodes each of the 48 trading periods were averaged to give a daily profile of the power price for that node. From this it was possible to select the period with the lowest 16 trading periods in a row. This is intended to be the 8 hours the mill has to run to take maximum advantage of the power market. From the analysis of the 2007 data this period was consistently through most nodes from 10:30pm until 6:30am. Therefore the data has been split into this 8 hour period and the remaining 16 hour period, with each period averaged to give the price during that period. The results are summarised in Table 27 for the North Island nodes and Table 28 for the South Island nodes. 
Table 27: Power price analysis for North Island main nodes

\begin{tabular}{|c|c|c|c|c|c|c|}
\hline Node & HAY2201 & SFD2201 & TUl1101 & WKM2201 & HLY2201 & OTA2201 \\
\hline Average Price (\$/MWh) & 51.9 & 49.8 & 51.5 & 50.7 & 50.8 & 52.3 \\
\hline 8 hour low price average $(\$ / M W h)$ & 46.0 & 43.6 & 45.1 & 43.9 & 43.5 & 44.1 \\
\hline 16 hour high price average ( $\$ / \mathrm{MWh})$ & 54.9 & 52.9 & 54.7 & 54.1 & 54.4 & 56.3 \\
\hline Low price deviation from average $\%$ & -11.4 & -12.5 & -12.4 & -13.4 & -14.3 & -15.6 \\
\hline High price deviation from average $\%$ & 5.7 & 6.2 & 6.2 & 6.7 & 7.1 & 7.8 \\
\hline Price deviation from average for high price $(\$ / M W h)$ & 3.0 & 3.1 & 3.2 & 3.4 & 3.6 & 4.1 \\
\hline Saving by selling power on peak compared to average (\$/annum) & 17,448 & 18,227 & 18,760 & 19,970 & 21,303 & 23,887 \\
\hline North Island average saving (\$/annum) & 19,933 & & & & & \\
\hline North Island avearage power price (\$/MWh) & 51.2 & & & & & \\
\hline
\end{tabular}

Table 28: Power price analysis for South Island main nodes

\begin{tabular}{lccccc}
\hline Node & INV2201 & HWB2201 & BEN2201 & ISL2201 & STK2201 \\
Average Price $(\$ / M W h)$ & 51.9 & 51.1 & 50.8 & 54.2 & 55.9 \\
8 hour low price average $(\$ / M W h)$ & 49.3 & 48.7 & 47.6 & 49.8 & 51.3 \\
16 hour high price average $(\$ / M W h)$ & 53.2 & 52.3 & 52.4 & 56.4 & 58.2 \\
Low price deviation from average \% & -5.0 & -4.7 & -6.2 & -8.1 & -8.1 \\
High price deviation from average \% & 2.5 & 2.4 & 3.1 & 4.1 & 4.1 \\
Price deviation from average for high price (\$/MWh) & 1.3 & 1.2 & 1.6 & 2.2 & 2.3 \\
Saving by selling power on peak compared to average (\$/annum) & $\mathbf{7 , 6 1 9}$ & $\mathbf{7 , 0 5 6}$ & $\mathbf{9 , 3 1 6}$ & $\mathbf{1 2 , 9 3 4}$ & $\mathbf{1 3 , 3 4 9}$ \\
$\quad$ South Island average saving (\$/annum) & $\mathbf{1 0 , 0 5 5}$ & & & & \\
\hline
\end{tabular}

The price deviation from average to the higher 16 hour period is where the potential savings are to be achieved. This is the period where the power is being sold, as only the drying component of the mill is operating at this time. Multiplying this power sold per year by the electricity price difference to average in the 16 hour period yields a saving per year of operating in this configuration. The results are shown in Table 27 and Table 28. On average the North Island sites have the most variation in power price throughout the day and therefore the greatest savings, however, with the largest saving being just $\$ 23,800$ per year at the OTA2201 node, it is in no way worth converting a sawmill to run at night. The level of saving simply does not justify the operational and personnel difficulties associated with running the majority of the operation of a sawmill outside normal work hours.

If the conclusion is that the night operating scenario is unsuitable then the opposite becomes ideal in terms of the movement of the power price. In the case where a mill is operating during the day and then selling power while only drying at night, the ultimate scenario is one where the power price does not fall significantly during the night. From the nodes in Table 28 it shows the South Island on average now becomes the more appropriate scenario. The combination of higher average price and less variation in power price throughout the day is more suitable. 


\subsection{Location of wood resource in relation to power market}

Of interest is how the variations in power price throughout New Zealand compare to the available wood resource. The ideal justification for a gasification based energy centre at a mill is where the localised power price is the highest, and there is substantial forestry activity in that area.

Figure 45 has been created to show the comparison between the localised wood resource and the power price.

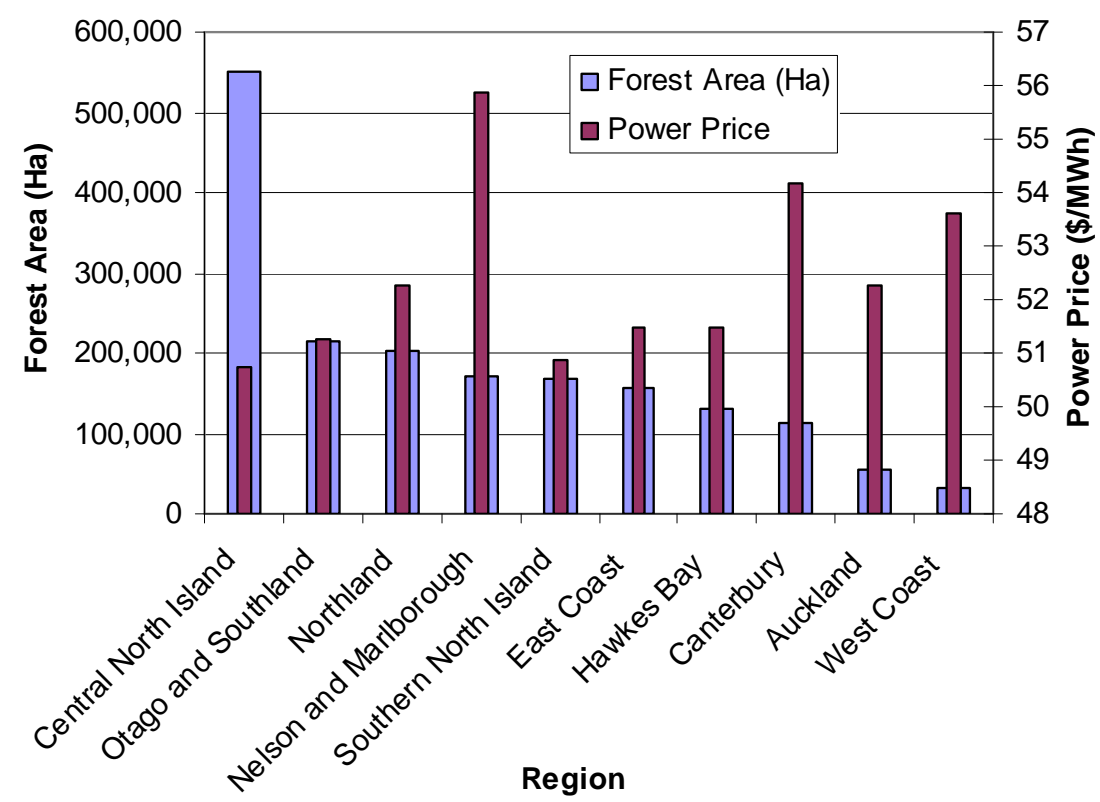

Figure 45: Wood resource by region compared to estimated power price for the region.

(Electricity Commission, 2008; Ministry of Agriculture and Forestry, 2006)

Figure 45 has the wood resource ordered from most area planted to the least. The estimated power price for that particular region has been overlaid. The power price for each area was estimated by selecting the node nearest the area, or averaging nodes around the area where it wasn't so clearly defined geographically.

The intention of the graph was to match a geographical region where there is a substantial quantity of wood alongside a high power price. From the graph there isn't any particular obvious situation that would make selection of a location for a gasification plant simple. The Nelson/Marlborough region contains a moderate amount of wood, along with the highest power price, however, the LVL and MDF 
mill at Nelson Pine would likely use significant quantities of the residues from sawmills thus pushing up the residue price.

The East Cape and Coromandel are two areas that are outside the economic working circle of pulp mills and MDF, therefore significant residues exist (Weir, 2008). However, the power prices for these areas based on main nodes (taken to be the East Coast and Central North Island respectively) are not among the highest. Although the power price does not line up favourably with the wood scenario, these areas are potentially the best location. The small difference in power price would be significantly offset by obtaining a moderately priced and stable wood supply.

Because the East Cape and Coromandel are recognised as potential areas in terms of wood availability it was deemed sensible to drill down to more localised nodes in these areas to determine if there were obvious areas of higher power prices due to constraints. Table 29 shows the average power price for July 2007 of several nodes in these general areas. Northland nodes were also included as there is high forestry activity and a relatively high power price.

Table 29: Average power price for selected nodes for July 2007

\begin{tabular}{llc} 
& Table 29: Average power price for selected nodes for July 2007 \\
\hline Node & Location & Average Price (\$/MWh) \\
DAR0111 & Dargaville - Northland & 66.7 \\
TKH0111 & Te Kaha - Eastern Bay of Plenty/East Cape & 65.6 \\
MPE0331 & Maungatapere - Northland & 65.4 \\
MTO0331 & Maungaturoto - Northland & 65.4 \\
MDN0141 & Marsden Point - Northland & 64.4 \\
KPU0661 & Kopu - Lower Coromandel & 62.8 \\
WKO0331 & Lower Coromandel & 62.4 \\
WAI0111 & Waiotahi - Eastern Bay of Plenty & 62.1 \\
& Average & $\mathbf{6 4 . 3}$ \\
\hline
\end{tabular}

Once again, as with comparison to the main nodes, there isn't a significant difference in average power prices in these regions. The average price of the main nodes in the upper North Island for the same period was $60.3 \$ / \mathrm{MWh}$. The prices are slightly higher than the average of the main nodes up to $10.5 \%$ at the DAR0111 node. 


\subsection{Conclusions}

Unfortunately this study of the power market did not realise any significant opportunities for a gasification based combined heat and power distributed generation scenario. The power price does not vary enough either throughout the day or from location to location to warrant recommending a particular area due to power market opportunities.

From this higher level analysis it is concluded that targeting an area with suitable wood availability is more critical than targeting power markets. However, this study did not take into account specific scenarios. There are potentially case specific scenarios where if a mill were to expand there would be network constraints that could make for favourable conditions for embedded generation. An example is the Red Stag Timber sawmill in the Rotorua area (EECA, 2007) where the mill needs more power to run than the transmission lines can provide. While the economic details are commercially sensitive and therefore confidential one could speculate that they would have a more favourable deal with the lines company than an average scenario as their embedded generation allows the lines company to defer capital investment in that area. Finding other scenarios in this position is a level of detail beyond this thesis, however, this study forms a basis for a reader in the potential scenario where they can realise the benefits of a network constraint. 


\section{Novel Plant Integration}

The intention of this section is to review potential novel opportunities for incorporation of gasification based combined heat and power plants in both sawmills and LVL mills. The often expressed advantage of gasification over combustion is the versatility a producer gas affords rather than just heat production. It was therefore the intention of this section to investigate if the versatility can be taken advantage of in novel ways to integrate the energy plant into the associated mill to reduce capital and/or operating cost.

\subsection{Novel LVL plant integration}

LVL has more opportunities for novel use of the technology compared to the sawmill because of the variety of energy needs in the process. Heat is needed in various areas of the process, of varying grade. This leads to the potential for a high efficiency plant with less unit operations if some novel approaches are taken.

There are several needs for heat in a LVL mill

- $\log$ conditioning

- press heating

- veneer drying

Several suggestions were made as to novel LVL integration by a consultant in the field (Burggraaf, 2008). Some of the suggestions were modelled in HYSYS to gauge the actual performance. The flow diagram of the trialed system can be seen in Figure 46. 


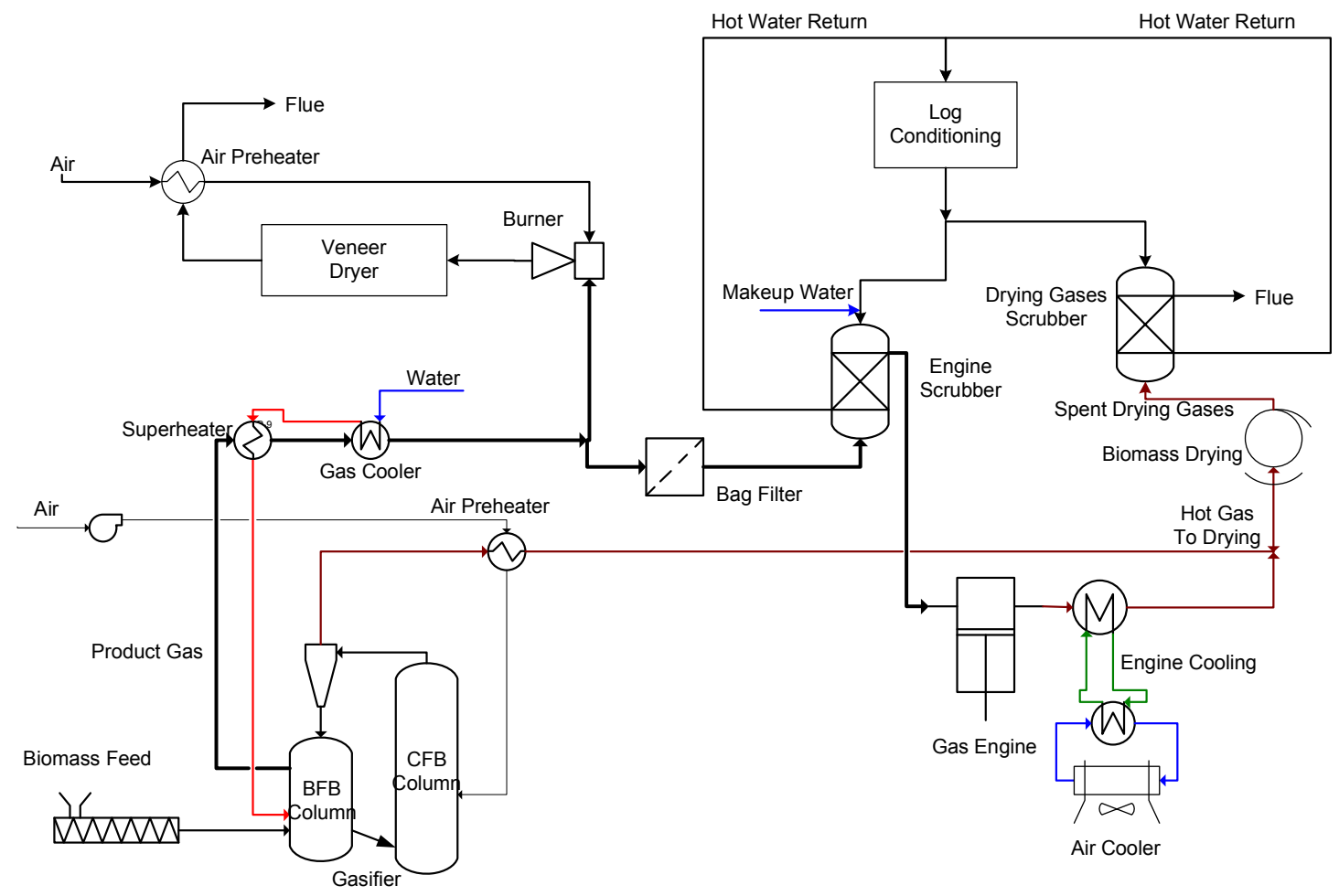

Figure 46: Schematic of proposed novel LVL plant integration

As can be seen in Figure 46 the main novel approaches are

- The use of the CFB and engine waste gas as the gas for biomass drying, from which the spent gas is used directly in a scrubber with the log conditioning water

- Scrubbing the producer gas directly with log conditioning water

- Direct firing of the veneer dryer with producer gas

The system in Figure 46 will only work for the LVL A system as the press is electrically heated. In the LVL B scenario either a small boiler, or a thermal oil heater would be necessary. However, the HYSYS modelling did not focus on this area, as it is an extra complication for what is likely little extra gain. Post HYSYS modelling, the direct veneer drying was deemed to be a potentially troublesome configuration. The direct coupling of the gasifier to the veneer dryer leaves little buffer if the gasifier has deviations from steady state. The boiler size and pressure required to perform the duty does not carry a significant capital cost, therefore the potential problems are not outweighed by the capital saving. 
Using the log conditioning stage as a thermal reservoir for engine cooling was also considered but it was concluded the engine cooling is too critical to be reliant on another process and any subsequent fluctuations.

Scrubbing directly using the log conditioning water acts as a form of heat exchange minimising the need for other heat recovery equipment (including a boiler if combined with the direct firing) therefore reducing complexity and cost. Another benefit of scrubbing with the water is to avoid the use and therefore expense of running a biodiesel/solvent scrubber. The effectiveness of water scrubbing was a concern. It is suspected condensed but insoluble tars could cause build-up problems in the scrubbing system. However, literature suggests (Han \& Kim, 2008) that water scrubbers are common and are an effective means of removing particulates, tars and other contaminants, with a reduction to $20-40 \mathrm{mg} / \mathrm{m}^{3}$ of $\operatorname{tar}$ and $10-20 \mathrm{mg} / \mathrm{m}^{3}$ of particulates. By comparison the Guessing plant which incorporates a bag filter and solvent scrubber has a tar concentration post the gas cleanup system of $10-40 \mathrm{mg} / \mathrm{m}^{3}$ (Hofbauer, Rauch, Bosch et al., 2002). This level of tars has been running through the gas engine successfully for a significant time period with no problems, therefore if the same order of cleanup could be achieved via water scrubbing then one could assume the producer gas quality from such a plant is suitable for use directly in an engine without the need for further cleanup (except potentially more cooling to a suitable temperature for the engine, and to condense excess moisture). The other advantage of using the log conditioning water directly is that the log conditioning process releases contaminants into the water and so has to undergo treatment before disposal, therefore addition of tars and particulates to the stream is not likely to be a problem (Burggraaf, 2008).

While the idea is good in principle, the HYSYS model (using Peng Robinson equation of state) identified problems with the system. The main concern when scrubbing with the $\log$ conditioning water is a significant quantity of moisture is carried over in the gas stream. Also, the hot gas does not provide the level of water heating expected. This is due to the vapour pressure of the water at the scrubbing temperature. In the producer gas scrubber the temperature in the scrubber is $58{ }^{\circ} \mathrm{C}$ and the moisture content of the gas is $17.7 \mathrm{~mol} \%$. This fraction of water in the gas is not overly difficult to manage as the gas would need to be cooled further for the engine, resulting 
in water dropout. In the dryer gas scrubber, however, the temperature in the scrubber (and resultant liquid) is $77{ }^{\circ} \mathrm{C}$ and the moisture content in the gas is $42 \mathrm{~mol} \%$. As the scrubbing temperature increases the quantity of moisture in the gas increases rapidly. The temperature of the water feed is $85^{\circ} \mathrm{C}$ so the water temperature actually decreases through the scrubber. While this seems unusual it is the balance of sensible heats of the entry to exit streams in the scrubber that yield this temperature drop. The heat of the gas is being used to evaporate the water to match the fraction of water vapour in the gas stream thermodynamically predicted at the scrubber temperature. In practice it is unlikely this equilibrium point would be reached, however, it is expected that at the very least it wouldn't provide much heating at all. The system only serves to create a moisture laden gas. If the purpose was to scrub the liquid only, the process could be performed at a lower temperature minimising the water lost in the vapour. However because the intention is to heat the water to a final target temperature of 85 ${ }^{\circ} \mathrm{C}$ in the $\log$ conditioners the process is not suitable. There is not the potential to scrub directly at a cooler temperature, and then use other forms of heat recovery to heat the water because the water recycled to the scrubber, from the log conditioning is still very hot. This method would also add extra complexity, which the novel method intended to avoid.

Rather than dismiss the water scrubber concept an alternative arrangement has been used. It focuses solely on the top up water requirement of the log conditioning to scrub the producer gas. As the logs pass through the log conditioning stage they absorb water, therefore there is a requirement for makeup water to the log conditioning stage. The main consideration is will the topup water be enough to scrub the gas to the engine without heating up to a point where there will be an excess of moisture carry over in the gas. A basic HYSYS model of the isolated scrubbing system was created as shown in Figure 47. The scrubbing system is considered to be a spray scrubber chosen for its simplicity of design. Concerns over suitable contacting can be addressed by recycling more water back to the scrubber. 


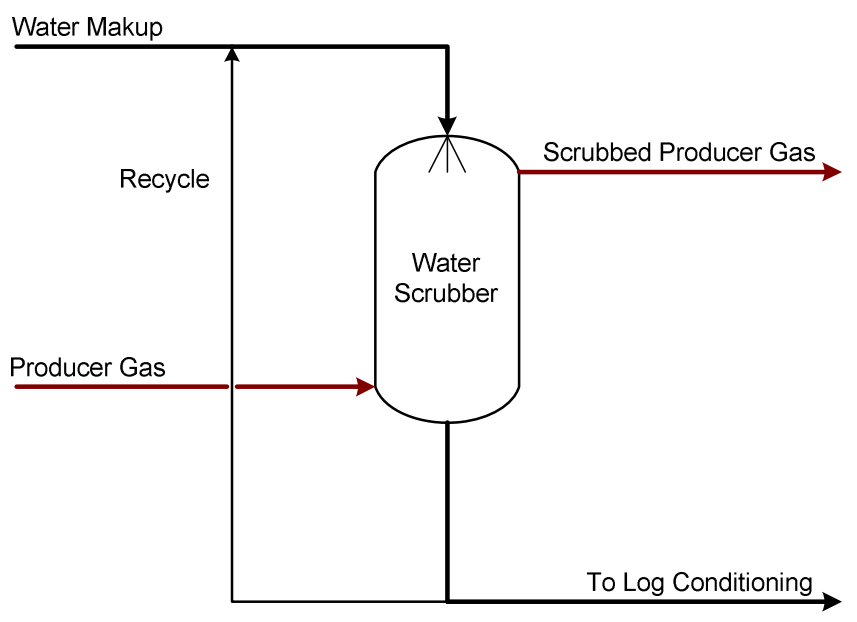

Figure 47: Simple flow diagram of water scrubbing

From the LVL energy model (J. Li \& Pang, 2006) the requirement of top up water is 14.8 L/min. However, the HYSYS model identified that a fraction of the scrubbing water is carried out in the gas, requiring more overall water feed to the scrubber $(18.5$ $\mathrm{L} / \mathrm{min}$ ). The temperature in the scrubber was $61.5{ }^{\circ} \mathrm{C}$ which resulted in a water carryover of $21.1 \mathrm{~mol} \%$ gas fraction. It is acknowledged this is slightly higher than in the dual scrubber scenario and will need further cooling and moisture removal for a gas engine but this is not difficult, and cooling would also be necessary in a biodiesel scrubbing system so doesn't add extra complexity or cost.

Based on the gas flow rate of $6039 \mathrm{~m}^{3} / \mathrm{hr}$ it is necessary to have a recycle loop of scrubbing water to enable sufficient contacting of liquid. The recycle stream has been set so $3020 \mathrm{~L} / \mathrm{hr}(50 \mathrm{~L} / \mathrm{min})$ enters the scrubber to give a liquid to gas ratio of 0.5 $\mathrm{L} / \mathrm{m}^{3}$ (Perry \& Green, 2008). The particular flow of this recycle stream can be increased to give better scrubbing if required as the particular flow does not influence the overall heat balance.

The system is of benefit as it allows the partial heating of the top up water. The other advantage of this system as opposed to using the actual log conditioning water is that there is not the level of contaminants that could cause problems such as blockages in the scrubber. The water is fresh apart from any buildup of tars. There is, however, a very high purge ratio as the flow leaving is $30 \%$ of the flow into the scrubber. This is compared with $1 \%$ purge ratio in the biodiesel system. It is therefore, likely there will 
be little overall buildup of tar and contaminant concentration within the scrubber recycle.

Of greatest interest is the overall economic effect of running the water scrubber instead of the biodiesel scrubber. It could be assumed that the capital cost between the water scrubber and the biodiesel scrubber would be similar. If anything the water scrubber would be cheaper as the requirement for biodiesel storage and then water and biodiesel separation is eliminated. However, in the interests of being conservative and keeping the analysis simple it is assumed the capital cost does not change. The most obvious cost saving therefore is the elimination of biodiesel usage. In the LVL B scenario as has been modelled for the novel LVL process the annual cost of biodiesel is $\$ 503,000$. This makes up nearly $20 \%$ of the total operating costs. If this cost is eliminated the breakeven electricity cost drops from $7.9 \mathrm{c} / \mathrm{kWh}$ to 6.3 $\mathrm{c} / \mathrm{kWh}$ and the breakeven time from 17 years to 14 years.

\subsection{Novel Sawmill Opportunities}

The intention of this section is to investigate what novel opportunities are available within a sawmill to make use of gasification technology that differs from a traditional combined heat and power scenario.

\subsubsection{Direct Kiln Drying}

Gasification systems generally run very low particulate emissions, therefore there may be the potential for direct drying from the combustion of producer gas. The advantages of this system is the reduction in necessary unit operations (mainly the boiler) and therefore capital cost saving. This is the most obvious and practical scenario to take advantage of the differences between gasification and combustion.

The choice of gasifier style comes into question. If there were only the requirement for thermal energy a fixed bed style gasifier would be more suitable for the simplicity and efficient use of the energy. However, as the theme of this thesis has been combined heat and power a scenario will be investigated that will incorporate this. The FICFB gasifier will be used as the basis because the higher calorific value producer gas is more suitable for power generation. The challenge is, making 
sufficient use of the CFB stream. It is thought appropriate not to mix the CFB stream into the gas going to the dryer as it is suspected the circulating fluidised bed would result in more particulate carryover.

The scenario that is deemed to make the best use of the available heat is shown in Figure 48 .

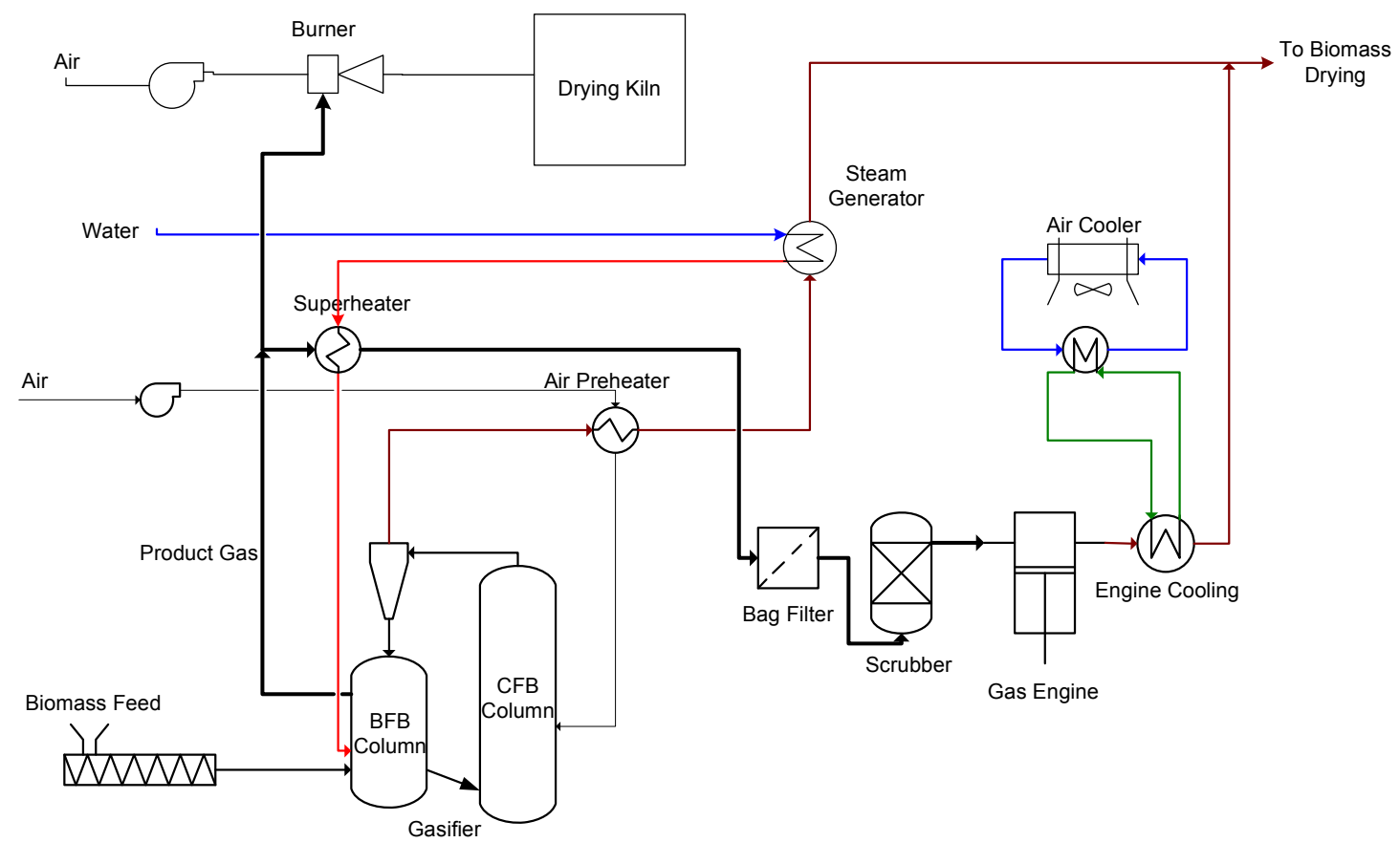

Figure 48: Gasification Direct Kiln Drying Process

It can be seen in Figure 48 that heat from the CFB stream is utilised in biomass drying and steam generation for the gasifier.

The system was modelled in HYSYS to see if the distribution of heat flows were suitable, particularly around the CFB flue gas. It was assumed that the heat requirement for the kiln drying supplied by the gas burner was the same heat requirement as if using steam heated kilns.

From the HYSYS model the energy flows were well balanced. Using the CFB gas to generate the steam for gasification, and combining the resultant flue gas with the engine flue gas, the resulting gas can be used for drying. The gas temperature after allowing for biomass drying energy is $50{ }^{\circ} \mathrm{C}$. 
A new capital cost has been calculated for the system. The main change is the elimination of the boiler, with a much smaller steam generator being needed to supply the steam for the gasifier. Table 30 outlines the main capital items. The system is sized as per the base economic study where electrical generation meets internal demand.

Table 30: Capital cost for sawmill based energy plant configured for direct kiln drying

\begin{tabular}{lc}
\hline Capital Item & Cost $\mathbf{( \$ N Z )}$ \\
Biomass Drying & $1,295,630$ \\
Feed Handling & $1,403,030$ \\
Gasifier & $1,592,574$ \\
Gas Cleaning & 291,367 \\
Gas Engine & $2,460,026$ \\
Steam Generator & 120,647 \\
Misc. & 22,851 \\
Contingency and Fee & $1,293,503$ \\
Working Capital & 847,963 \\
Total & $\mathbf{9 , 3 2 7 , 5 9 2}$ \\
\hline
\end{tabular}

Table 30 show that the capital cost is predicted to be $\$ N Z 9.3 \mathrm{~m}$. This is a reduction of $\$ N Z 1.3 \mathrm{~m}$ from the original capital cost of $\$ N Z 10.6 \mathrm{~m}$. The system reached a suitable heat balance using the same wood feed rate. Therefore the operating costs of the plant have not significantly changed. The economic model generated a breakeven electricity price of $10.8 \mathrm{c} / \mathrm{kWh}$.

\subsubsection{Potential Problems to Overcome}

Apart from analysing whether the FICFB gasifier direct drying and producing power is an efficient means of energy conversion there are other potential problems which need to be overcome or mitigated for it to be a viable option.

- Will the gasifier always act correctly and in a clean manner that will allow direct drying without discolouration or deposits?

- What will be the availability of this technology? For example, if the energy plant runs at $95 \%$ availability but it has some short deviations from steady state can this gas still be used for drying, how often would this happen, how long will it take to come back to steady state and what is the resultant actual availability? A boiler is somewhat of a reservoir or buffer if there are interruptions, with direct drying there is nothing. 
Direct drying kilns are not as common as steam or hot water heated kilns. Older literature (Culpepper, 2000) suggests that direct fired kilns are hard to control, have ash deposition issues and if there is to be a reasonable size set of kilns then steam drying would be just as economic. There are plenty of kiln manufacturers offering direct drying as an option, however, the manufacturers do tend to focus on steam/hot water heated kilns as their core business which is an indicator from the industry of which method is best practice. Direct fired kilns are more suitable when the wood post the dryer is being planed as this removes the ash deposits or discolouration on the surface of the timber.

The conclusion is the capital reductions from direct drying are not significant enough to justify dealing with the extra complications that direct drying may present. The opportunities for lower capital cost alternatives to the existing arrangement are considered a better area to target due to the greater savings and lower risk. 


\section{Specific Case Study}

The intention of this section is to apply the model to a real world scenario by selecting a mill, and sizing and costing a gasification based combined heat and power plant to suit. In the analysis and selection of different operating scenarios and the associated advantages and disadvantages of each, the plant is considered to be the first demonstration plant installed with the technology, therefore a different set of assumptions into the reliability and risk of such a plant is considered compared to a situation where the technology was well developed.

While the sawmill scenario was the least economic in the base investigation a sawmill has been chosen as the case study for a variety of reasons

- There are more potential sites requiring a new energy centre in a sawmill context than LVL or MDF. Therefore, the realistic likelihood of finding a sawmill application for the technology is far higher than that of an MDF or LVL scenario.

- The specific case study is selected as the owner of the sawmill has expressed significant interest in the technology. An active and enthusiastic investor is considered to be a key driver to the success of a plant.

- Because of the nature of the operation of the sawmill with a peak electrical demand for an 8 hour period during milling, and a lower electrical demand on a continuous basis there is more potential to vary configuration of an energy plant to the most suitable for the scenario. 


\section{Case Study Basis - Bay Lumber}

Bay Lumber is a sawmill in Kerikeri, Northland. The current production of the mill is around $100 \mathrm{~m}^{3} /$ day. The owner wants to expand the mill to around $400 \mathrm{~m}^{3} / \mathrm{day}$. This is moving from a moderate sized sawmill to quite a large mill. Currently there is no drying capacity at the mill and the owner is interested in a gasification system to provide heat for the drying process and to generate electricity. Looking to the future he is also interested in producing fuel to run his moving equipment.

The current sawdust production from the mill is 600 tonnes per month of wet sawdust. The sawdust is very wet so it will be assumed the moisture content is $100 \%$ (dry basis). A fourfold increase in production would increase the sawdust production to 2400 wet tonnes per month. This assumes in increasing the size of the mill there are no conversion efficiency gains that impact on the sawdust production. The sawdust currently does not have a specific market so is assumed to have no value. In some instances if it were dumped it could be assumed to be a negative value but to be conservative in the study this is not taken as the case.

The chip produced at the mill currently has an export market with a value of $\$ 30$ per tonne. While being ideal fuel for the plant, this should not be used as the primary fuel due to the high opportunity cost.

For this case study it has been assumed the sawdust is the first material used for the gasifier, with chip supplementing any shortfall. The amount of fuel used therefore has a large influence on the $\$ /$ tonne fuel feed costs.

The current mill average electrical requirement is approximately $250 \mathrm{~kW}(40,000$ $\mathrm{kWh}$ per month). This is for $100 \mathrm{~m}^{3} /$ day of production and does not include any drying component. By applying the model developed by Li (J. Li, 2007) for 400 $\mathrm{m}^{3} /$ day production including drying the peak electrical requirement is $1677 \mathrm{~kW}$ and the off peak requirement (i.e. electricity required for drying only) is $482 \mathrm{~kW}$. The thermal requirement from the model for the drying is $10182 \mathrm{~kW}$. 
For the first two scenarios it is assumed to follow a standard approach using steam heated kilns and a gas engine for electricity generation. Three scenarios have been evaluated based on varying levels of risk for both investment and affect on mill availability and are described below.

\subsection{Full system meeting all thermal and electrical needs}

The first scenario investigated is one that parallels the base study in this thesis. The system is designed so to provide for the complete thermal and electrical needs of the associated sawmill. There are both advantages and disadvantages to such a system in a real world context. These are considered below

\section{Advantages}

- The system takes the most advantage of economies of scale of any of the scenarios. There is more 'revenue' gained from the plant for the level of capital investment and complexity. The fixed operating costs of the plant such as operating labour do not change with scale (within reason) so the larger plant is more economically viable.

- There are no competing technologies on site. This is by no means an admission that other technologies are superior to gasification, however, the technology is new compared to combustion based processes therefore will require more development and hence effort to reach an acceptable standard of reliability. In a scenario where both technologies were present, it would allow the potential to fall back on existing technology rather than pushing the development of the new technology to a level where it was accepted as comparable in reliability and ease of use as that of the combustion based process.

\section{Disadvantages}

- The second advantage could also be seen as a potential disadvantage. While there isn't the competing technology on site, the entire operation of the mill is hinged on new technology under development. Realistically there will be a longer commissioning time than with an already proven technology. It is not acceptable for a utility such as steam to be the bottleneck for the availability of a mill. Ways around this will be necessary such as commissioning and optimisation of the plant 
before a requirement of steam is realised. This relies on a mill not having an exceptionally tight timeframe on development.

- In this scenario a purchaser of excess exported electricity is required. It is not necessarily guaranteed that there will be a willing purchaser of the electricity, and the selling price is not an absolute.

- Higher biomass fuel usage resulting in higher wood cost due to the fraction of chip required.

\subsubsection{Modelling results}

The capital and operating costs have been calculated for this scenario and the important parameters are shown in Table 31.

Table 31: Economic data for full plant case study

\begin{tabular}{lc}
\hline Capital Item & Cost (\$NZ) \\
Biomass Drying & $1,558,970$ \\
Feed Handling & $1,625,462$ \\
Gasifier & $1,840,856$ \\
Gas Cleaning & 205,852 \\
Gas Engine & $2,892,977$ \\
Boiler & $1,367,522$ \\
Misc. & 160,581 \\
Contingency and Fee & $1,737,400$ \\
Working Capital & $1,138,962$ \\
Total & $\mathbf{1 2 , 5 2 8 , 5 8 2}$ \\
Wood Feed Rate (odkg/s) & 1.01 \\
Wood Cost (\$/odt) & 31 \\
Fuel Power (MW) & 20.3 \\
Breakeven Electricity Cost (c/kWh) & 13.4 \\
Payback Time (years) & never \\
Economics If Wood Cost Is Zero & \\
Breakeven Electricity Cost (c/kWh) & 6.7 \\
Payback Time (years) & 17 \\
\hline
\end{tabular}

The most significant issue affecting the economics of this scenario is the biomass supply. Sawdust can only supply just under half of the biomass requirements. The remainder is chip priced at $\$ 30$ per wet tonne which is assumed to be $\$ 60$ per odt (based on $100 \%$ moisture content dry basis). 


\subsection{Meeting base (off peak) load}

The second scenario is a more conservative overall approach. The plant is sized such that all the thermal needs are met and the electrical generation is sized to only provide enough generation to offset the off peak electricity requirement $(482 \mathrm{~kW})$. This off peak requirement is the electrical needs of the kiln drying which operate continuously. As with the previous scenario there are several advantages and disadvantages.

\section{Advantages}

- This is an 'in between' scenario. This scenario has the benefit of not having to find a purchaser of excess electricity, while still offsetting a significant fraction of the overall electricity use.

\section{Disadvantages}

- There are less economies of scale in this approach in comparison to the scenario maximising electrical production.

- Because of the thermal requirements being supplied by the plant the mill availability is still hinged off the reliability of the energy plant.

- During the day while there is timber milling and therefore at its peak electricity requirement the mill is left open to purchase power. This is when the mill will encounter the highest electricity spot price.

\subsubsection{Modelling results}

The capital and operating costs have been calculated for this scenario and the important parameters are shown in Table 32.

The feasibility of this system is once again significantly affected by the feed cost. Because this system has less electrical requirement the feed flows are lower therefore the sawdust fraction of feed is higher reducing the overall feed cost per tonne. The cost, however, is still very high. If, for example, 3300 tonnes per month of sawdust were produced instead of 2400 the electrical breakeven price would drop to 11.5 $\mathrm{c} / \mathrm{kWh}$. The most extreme example is that if no wood feed cost could be realised the breakeven electricity cost drops to a very low $2.6 \mathrm{c} / \mathrm{kWh}$. 
Table 32: Economic data for off peak plant case study

\begin{tabular}{lc}
\hline Capital Item & Cost (\$NZ) \\
Biomass Drying & $1,379,420$ \\
Feed Handling & $1,476,227$ \\
Gasifier & $1,673,207$ \\
Gas Cleaning & 83,330 \\
Gas Engine & 841,177 \\
Boiler & $1,362,755$ \\
Misc. & 169,960 \\
Contingency and Fee & $1,257,494$ \\
Working Capital & 824,357 \\
Total & $\mathbf{9 , 0 6 7 , 9 2 7}$ \\
Wood Feed Rate (odkg/s) & 0.86 \\
Wood Cost (\$/odt) & 26.5 \\
Fuel Power (MW) & 17.3 \\
Breakeven Electricity Cost (c/kWh) & 19.6 \\
Payback Time (years) & never \\
Economics If Wood Cost Is Zero & \\
Breakeven Electricity Cost (c/kWh) & 2.6 \\
Payback Time (years) & 18 \\
\hline
\end{tabular}

\subsection{The 'safe demonstration' plant option-}

The last scenario investigated is a more novel option in comparison to the base scenario in this thesis, however, it is considered to be a safe way to prove a plant at a demonstration scale.

There are boiler systems on the market currently in New Zealand that consist of a biomass burner with a secondary combustor (Mallinson, 2008b). The hot gas from the secondary combustor is fed to a boiler to generate steam. It is envisaged a gasifier could be coupled to the system so that the producer gas enters the secondary combustor area, and the heat from the CFB to the hot gas stream. Producer gas could then be bypassed to a gas engine. The combustion system can be ramped up to offset the removal of the producer gas maintaining consistency of steam supply to the mill. The gasifier could be sized to produce enough gas to have an engine that meets the base load needs of the mill. A schematic of this process can be seen in Figure 49. 


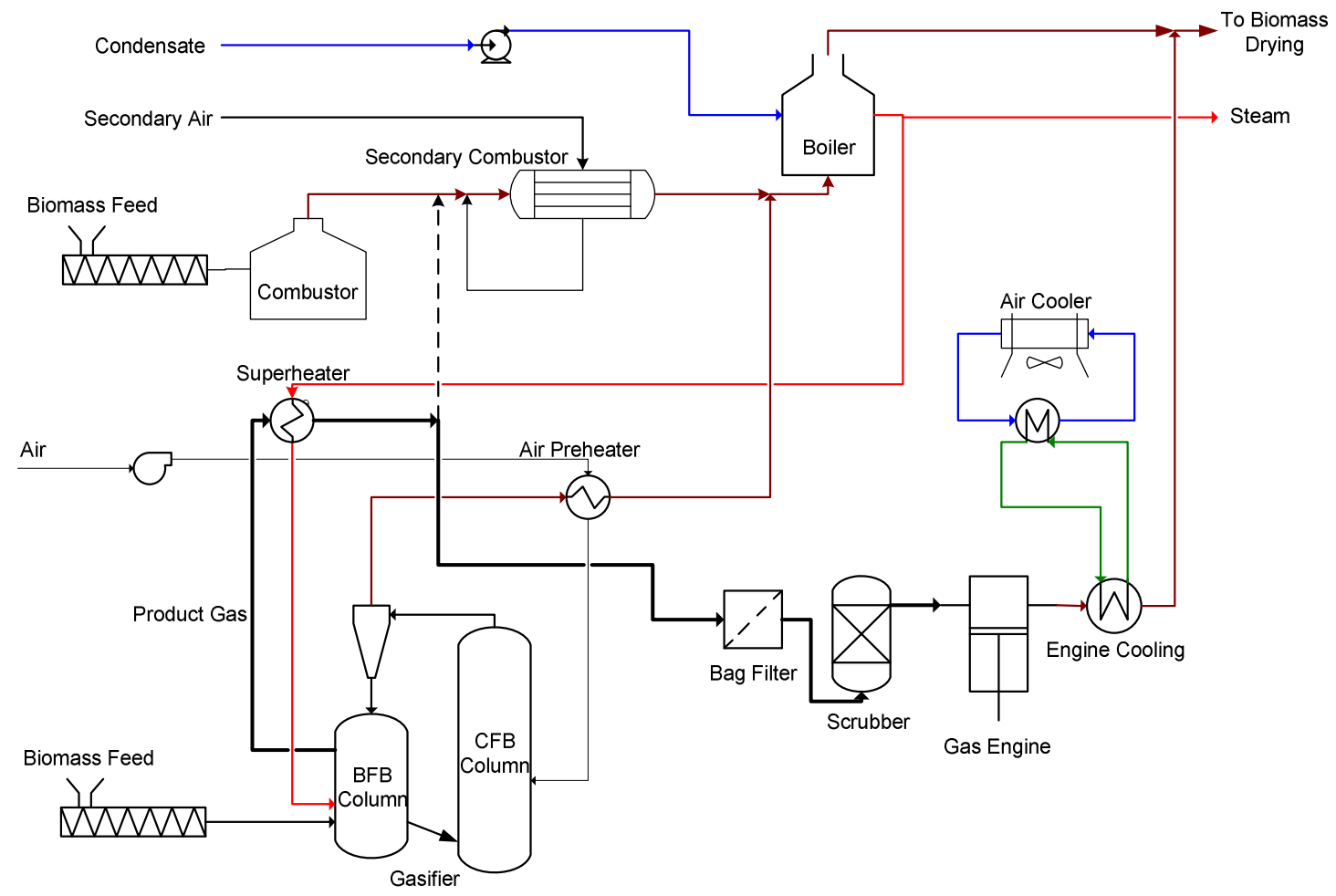

Figure 49: 'Safe demonstration scenario' incorporating combustion and gasification technologies

This scenario has a very different set of advantages and disadvantages compared to the other scenarios and are somewhat a reverse of the full plant scenario.

\section{Advantages}

- The availability of the mill is not dependent on the reliability of the new technology gasification system.

- There is less investment cost in the more novel technology aspect of the energy plant. This is more likely to attract an investor keen to prove the technology but not willing to risk upsetting a whole mill's production.

\section{Disadvantages}

- The capital cost of the plant will be the highest of all the scenarios for the given output. The likely way to make this technology affordable would be for the mill to purchase the combustion system with the gasification system and engine genset built under a capital grant where the government helps offset some of the capital cost. 
- The system allows competing technologies on site that are realistically simpler to run at least in the early phase. There is the risk of the mill saying 'we can't be bothered because we have got the steam we need with combustion'.

- There will potentially be sacrifices in efficiency as a simpler system with less incorporation of heat recovery is the most sensible arrangement.

\subsubsection{Modelling results}

Modelling this process is not as simple as the others. It needs an assumed cost of the combustion based plant and then a gasifier sized to meet the electrical needs of the off peak electrical load.

As a base the combustion plant including the feed handling silos, burners and boilers is estimated at $\$ \mathrm{NZ} 4 \mathrm{~m}$. This system incorporates a feed storage of $1600 \mathrm{~m}^{3}$, and two 5 MW burner and boiler systems (Mallinson, 2008a).

Table 33 is an economic estimation for a gasifier system that supplies about $50 \%$ more gas than necessary to power a $482 \mathrm{~kW}$ engine genset. It is based on manipulation of the existing models. Extrapolating the capital cost correlations to such a low value may introduce errors but gives an order of magnitude idea of costs.

\begin{tabular}{lc} 
Table 33: Economic data for 'safe demonstration' & plant case study \\
\hline Capital Item & Cost $\mathbf{\$ N Z}$ ) \\
Biomass Drying & 505,610 \\
Feed Handling & \\
Gasifier & 672,000 \\
Gas Cleaning & 19,932 \\
Gas Engine & 841,176 \\
Boiler & \\
Misc. & 78,000 \\
Contingency and Fee & 317,507 \\
Working Capital & 243,422 \\
Total & $\mathbf{2 , 6 7 7 , 6 4 7}$ \\
Wood Feed Rate (odkg/s) & 0.13 \\
Wood Cost (\$/odt) & 26.5 \\
Fuel Power (MW) & 2.613 \\
Breakeven Electricity Cost (c/kWh) & 20.5 \\
Payback Time (years) & never \\
Economics If Wood Cost Is Zero & \\
Breakeven Electricity Cost (c/kWh) & 17.5 \\
Payback Time (years) & never \\
\hline
\end{tabular}


Note the price of the wood was taken at $\$ 26.5$ per odt as with the previous scenario. It is assumed the combustion system and the gasifier both receive the same blend of wood feed.

It is difficult to estimate a payback on this scenario as the operating costs and necessary wood flows on the combustor are unknown. However if we consider the gasifier separately with the only revenue stream being that of the electrical generation and the leftover gas providing a small amount of steam generation, costs can be approximated from the model. A breakeven price of $20.5 \mathrm{c} / \mathrm{kWh}$ is generated, and if zero wood costs are incorporated the breakeven price drops to $17.5 \mathrm{c} / \mathrm{kWh}$. One of the main cost factors influencing the economics is labour. In other scenarios labour is approximately $\$ 400,000$ a year assuming two operators on shift. In this case it has been halved to $\$ 200,000$ per annum assuming one operator can deal with the gasifier/gas engine process. This may be an overestimation but for a demonstration plant and the associated possible operational issues it is considered a safe estimate.

\subsection{Conclusions}

Out of all the scenarios the most feasible situation regardless of breakeven electricity price is the third case study. There is realistically no way a developing technology with an availability in the order of $70 \%$ can be relied upon as a continuous utility in a manufacturing environment.

The economics of the plant are very dependent on the value of the feedstock. A more accurate prediction of the quantity of sawdust is important to gain a better understanding of the cost of feedstock.

Capital cost in the final scenario is not exceptionally high but there are again cost reductions possible in the drying and gas engine areas. Certainly a cheaper alternative engine should be employed in this case being a demonstration plant. 


\section{Idealised Case Studies}

It is the intention of this section to perform economic modelling of a plant that incorporates realistic aspects of the optimisation chapters to gauge the viability of a plant if an optimistic set of conditions were realised.

For a sawmill scenario the aspects that will be taken into account are

- Lower capital cost alternatives

In the sawmill case it has been decided not to incorporate the novel aspects researched, or any influence from power price. The novel aspect of direct kiln drying does not lower capital cost significantly compared to the added operational challenges, and unless a very specific scenario is chosen where there may be grid constraints the power market does not play a significant role in changing economic conditions.

For a LVL scenario the aspects that will be taken into account are

- Lower capital cost alternatives

- Incorporation of a water scrubber rather than a biodiesel scrubber

As with the sawmill, fluctuations in the power market both in terms of location and time have not been incorporated due to the very small effect on economics. The most economically favourable and technically feasible of the novel techniques - the water scrubber using log conditioning make-up water is included in the study, as well as the lower capital cost alternatives.

\subsection{Sawmill Scenario}

For the lower capital cost alternatives the gas engine that will be used is a low hour second hand engine generator set. This has most of the benefits of a new engine generator set, although not the price. The other capital item considered is the drying section. The system priced will be a multi deck turbo dryer. This has been designed for sawdust, which is likely to be the predominant feedstock in a sawmill scenario. It 
is assumed the gas engine still holds the same efficiency of electricity and heat production of the Jenbacher.

Table 34: Capital cost for sawmill energy plant incorporating lower capital cost main plant items

\begin{tabular}{lc}
\hline Capital Item & Cost (\$NZ) \\
Biomass Drying & 448,714 \\
Feed Handling & $1,403,030$ \\
Gasifier & $1,592,574$ \\
Gas Cleaning & 188,354 \\
Gas Engine & $1,731,580$ \\
Boiler & $1,102,458$ \\
Misc. & 138,219 \\
Contingency and Fee & $1,188,887$ \\
Working Capital & 779,382 \\
Total & $\mathbf{8 , 5 7 3 , 1 9 7}$ \\
\hline
\end{tabular}

Table 34 shows the new capital cost with the reduction in biomass drying and gas engine, which also translates to a reduction in working capital and contingency and fee. This results in an overall reduction of capital cost from \$NZ $10.6 \mathrm{~m}$ to \$NZ 8.6 $\mathrm{m}$. The basic operating costs remain the same but the reduction in capital cost reduces the breakeven electricity price from $11.6 \mathrm{c} / \mathrm{kWh}$ to $8.6 \mathrm{c} / \mathrm{kWh}$. This is a very encouraging result as it brings the breakeven electricity price lower than the average price used in the study of $10.46 \mathrm{c} / \mathrm{kWh}$ resulting in a positive NPV for the sawmill scenario. The breakeven time for the energy plant using the average electricity price is 19 years which includes two years of construction and commissioning, and a $10 \%$ discount factor.

As the minor changes in electricity price, or any changes in wood price based on region have not been incorporated, a sensitivity analysis (Figure 50) is performed to allow the reader to apply data to a particular scenario. 


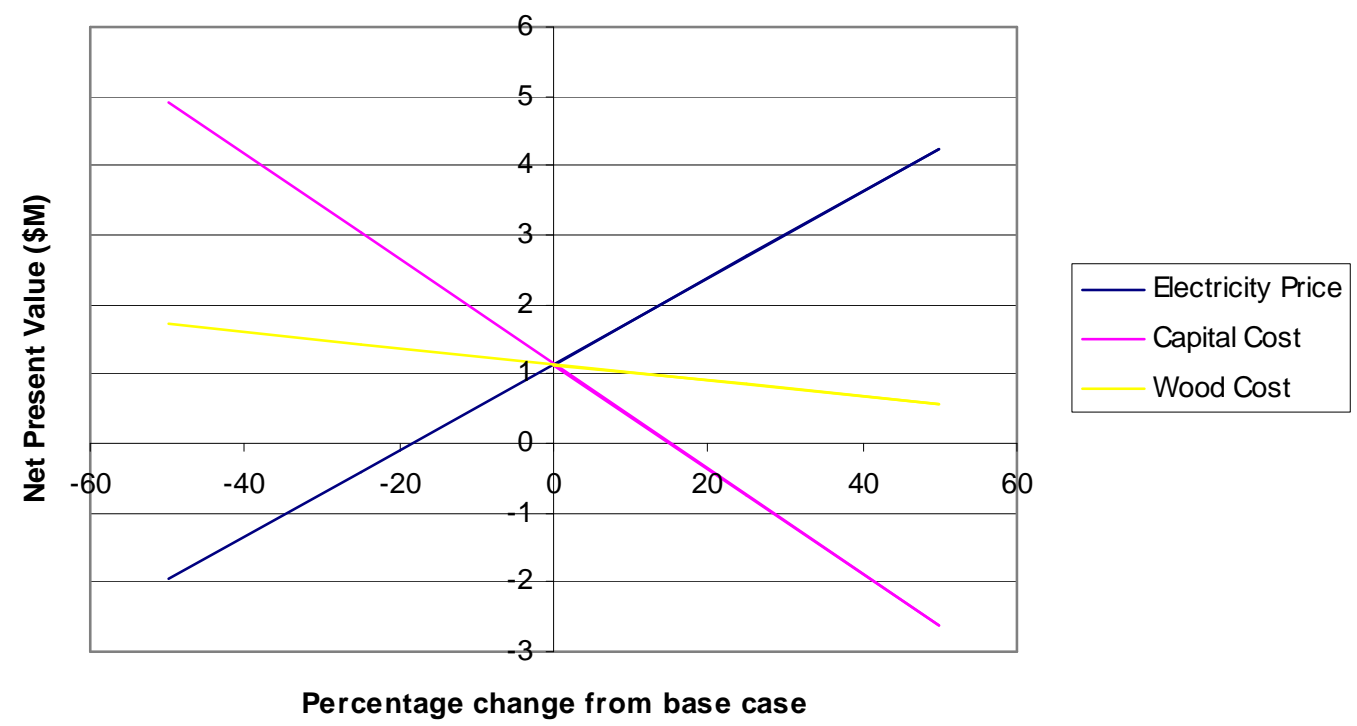

Figure 50: Sensitivity analysis for idealised sawmill scenario

\subsection{LVL Scenario}

Again the lower capital cost items will be a low hour second hand engine, and a multi deck turbo dryer. Although the feedstock may be more varied, the drying system includes a hammer mill to reduce the size to provide a consistent supply to the gasifier.

The gas engine is priced at $584 \$ \mathrm{NZ} / \mathrm{kWh}$ as with the sawmill scenario. In the capital item alternatives section (Section 9) the drying system was sized and costed for the sawmill scenario. To convert this to an LVL scenario the capital cost was scaled based on the biomass feed rates, with a scaling factor of 0.6 applied. Breakdown of capital costs can be seen in Table 35 .

Table 35: Capital cost for LVL scenarios incorporating lower capital cost main plant items

\section{Capital Item}

Biomass Drying

Feed Handling

Gasifier

Gas Cleaning

Gas Engine

Boiler

Misc.

Contingency and Fee

Working Capital

Total

\section{Cost (\$NZ)}

LVL A

LVLB

$632,514 \quad 607,794$

$1,976,602 \quad 1,899,477$

$1,901,985 \quad 1,838,438$

$595,039 \quad 456,122$

$6,103,991 \quad 4,159,268$

$1,444,025 \quad 1,648,116$

$158,529 \quad 161,884$

2,306,283 $\quad 1,938,798$

$1,511,897 \quad 1,270,990$

$16,630,864 \quad 13,980,886$ 
Because the water scrubbing as described in the LVL novel section is incorporated (Section 11.1) the operating cost has been significantly reduced due to the elimination of the biodiesel use. This reduction in the operating cost has a significant effect because it is accrued annually.

\subsubsection{LVLA}

Table 35 shows there is a significant reduction in capital cost by using the lower capital cost alternatives (from \$NZ $21.1 \mathrm{~m}$ to $\$ N Z 16.6 \mathrm{~m}$ ). The large gain for the LVL A scenario is due to the higher electrical generation of 5.1 MW meaning the gas engine was a significant component of the original capital cost. Being able to significantly reduce this cost greatly improves the economics. The elimination of the biodiesel has the most significant effect on operating cost in the LVL A scenario again due to the higher electrical generation, resulting in a higher flow of producer gas needing scrubbed.

The resultant lowering of the capital and operating costs brings the breakeven electricity price down from $8.9 \mathrm{c} / \mathrm{kWh}$ to $5.0 \mathrm{c} / \mathrm{kWh}$. The savings also translate into a reduced payback period (using the normal electricity price of $10.46 \mathrm{c} / \mathrm{kWh}$ ) of 10 years. This includes a 2 year construction and commissioning period, and a $10 \%$ discount factor.

\subsubsection{LVLB}

For LVL B Table 35 shows there has been a significant reduction in capital cost (from \$NZ $17.3 \mathrm{~m}$ to $\$ \mathrm{NZ} 14.0 \mathrm{~m}$ ). The most significant component of this is the second hand gas engine reducing the installed engine cost from $\$ \mathrm{NZ} 5.9 \mathrm{~m}$ to $\$ \mathrm{NZ} 4.2 \mathrm{~m}$.

As with LVL A the drop in breakeven electricity price is significant. The reduction in capital and operating costs result in a lowering of the breakeven electricity price from $7.9 \mathrm{c} / \mathrm{kWh}$ to $3.9 \mathrm{c} / \mathrm{kWh}$. The new payback period is the same as the LVL A scenario at 10 years.

A sensitivity analysis is included and shown in Figure 51 and Figure 52 to allow the reader to apply data in relation to electricity price or wood cost. 


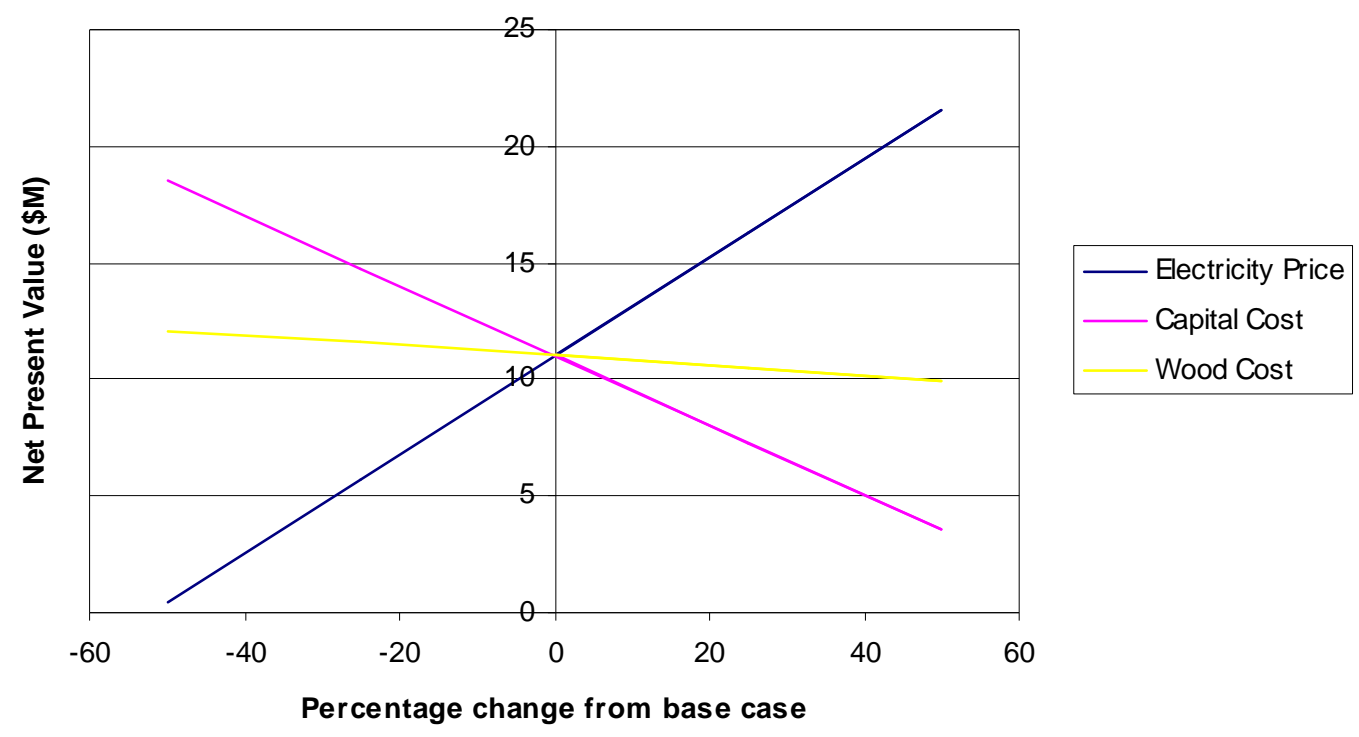

Figure 51: Sensitivity analysis for idealised LVL A scenario

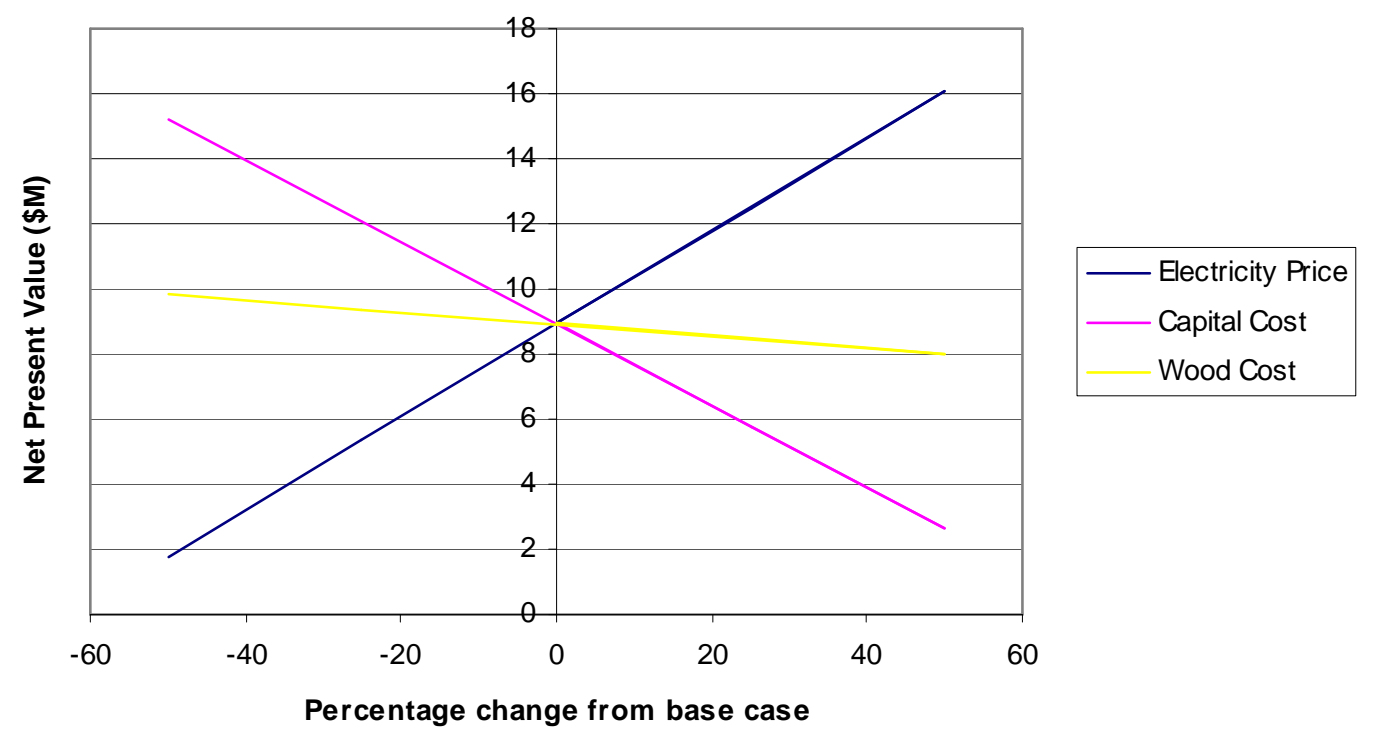

Figure 52: Sensitivity analysis for idealised LVL B scenario 


\section{Final Conclusions and Recommendations}

This thesis has investigated a number of areas in order to gauge the feasibility of gasification plant in the New Zealand wood processing industry. The intention was to use traditional economic analysis as a base for comparison, but move beyond the pure economics to gauge a true feasibility for the technology in the New Zealand context.

Results show that the technology in the base case is similar in economics to other forms of renewable generation (see Figure 32), however, the inclusion of lower priced capital items and novel means of plant integration can improve economics beyond most other forms of renewable electrical energy.

The application can be seen as very niche, in that the wood supply, the technology, the localised power scenario and local political and public perception are all influential factors. It can be concluded that finding the niche situation for such a combined heat and power plant should be a significant focus. This focus is potentially as important as the technology development if commercial installations are to be realised. Overseas comparisons back this conclusion. A stable and positive political climate, locked in biomass supply and economical operating conditions are key to the long term success of a gasification plant.

New Zealand does have a distinct and likely stable political stance on the need for renewable generation, however, there currently are not significant financial incentives that will encourage potential investors to invest in a new technology such as gasification. While the government encourages both bioenergy and distributed generation as being both renewable and efficient means of supplying power, there currently is no significant proactive means to encourage such investment.

If the government can implement solid policies in regards to distributed generation, and the technology can be applied sensibly using lower capital cost items a gasification based combined heat and power plant is feasible in the New Zealand wood processing context. 


\section{References}

Ahrenfeldt, J., \& Knoef, H. (2005). Handbook biomass gasification contributors, Jesper Ahrenfeldt ... [et al.] ; editor, Harrie Knoef. Enschede, The Netherlands: BTG Biomass Technology Group.

Asset Disposals Ltd. (2008). Communication of Second Hand Drying Equipment. Auckland.

BANZ. (2007). Blue Mountain Lumber Energy Facility. Retrieved 8 November, 2007 , from http://www.bioenergy.org.nz/documents/publications/articles/RefProjects/Bio energyRef1.pdf

Blower, R. (2008). Interview in relation to differences in hazards, control and monitoring of varying boiler sizes and pressures. Christchurch.

Bodger, P. (2007). Interview In Relation to the New Zealand Power Market and Opportunities for Distributed Generation. Christchurch.

Bolhar-Nordenkampf, M., Bosch, K., Rauch, R., Kaiser, S., tremmel, H., Aichernig, C., et al. (2002, June). Biomass CHP Plant Guessing - Using Gasification for Power Generation. Paper presented at the International Conference on Biomass Utilisation, Thailand.

Bouman, R. W., Jesen, S. B., Wake, M. L., \& Earl, W. B. (2005). Process Capital Cost Estimation for New Zealand 2004. Christchurch: Society of Chemical Engineers New Zealand.

Brammer, J. G., \& Bridgwater, A. V. (1999). Drying technologies for an integrated gasification bio-energy plant. Renewable and Sustainable Energy Reviews, 3(4), 243-289.

Brammer, J. G., \& Bridgwater, A. V. (2002). The influence of feedstock drying on the performance and economics of a biomass gasifier - Engine CHP system. Biomass and Bioenergy, 22(4), 271-281.

Brown, J. (2006). Biomass gasification : fast internal circulating fluidised bed gasifier characterisation and comparison : a thesis submitted in fulfilment of the requirements for the degree of Master of Engineering in Chemical and Process Engineering, University of Canterbury.

Bull, D. (2008). Performance Improvements to a Fast Internally Circulating Fluidized Bed (FICFB) Biomass Gasifier for Combined Heat and Power Plants : a thesis submitted in fulfilment of the requirements for the degree of Master of Engineering in Chemical and Process Engineering. University of Canterbury, Christchurch.

Burggraaf, H. (2008). Communication of potential novel methods for gasification plant.

CAENZ. (2003). Distributed Generation - A Study of Opportunities. Christchurch: Centre for Advanced Engineering.

Campion, J. (2006, October). Biomass Engineering Ltd Gasification Systems. Paper presented at the IEA Task 33 Workshop, Chicago.

CHRISGAS. (2008, April). CHRISGAS Intermediate Report. from www.chrisgas.com

Cox, B. (2008). Where May Gasification Fit in the New Zealand Bioenergy Market, Presentation at Biomass Gasification Technology and Biomass Energy 
Conference: 13 February 2008. University of Canterbury, Wood Technology Research Centre.

Culpepper, L. (2000). Softwood drying : enhancing kiln operations. San Francisco: Miller Freeman Books.

Dang, H., DT, \& New Zealand Ministry of Economic Development. (2007). New Zealand Energy Data File June 2007. Retrieved 15 August, 2007, from http://www.med.govt.nz/upload/48437/000-200707.pdf

Dang, H., DT, Tamayo, J., Wilkinson, D., \& Ministry of Economic Development. (2007). New Zealand Energy in Brief - June 2007. Retrieved 5 December, from http://www.med.govt.nz/upload/48821/EIB\%20010807.pdf

Dasappa, S. (2001, Dec). On the Estimation of Power From a Diesel Engine Converted for Gas Operation - A Simple Analysis. Paper presented at the Seventeenth National Conference on I.C. Engines and Combustion.

Department of Labour. (2004). Approved Code of Practice for the Design, Safe Operation, Maintenance and Servicing of Boilers. Wellington.

Douglas, J. M. (1988). Conceptual design of chemical processes. New York: McGraw-Hill.

Dupont, C., Boissonnet, G., Seiler, J.-M., Gauthier, P., \& Schweich, D. (2007). Study about the kinetic processes of biomass steam gasification. Fuel, 86(1-2), 3240.

East Harbour Management Services. (2005). Availabilities and Costs of Renewable Sources of Energy for Generating Electricity and Heat 2005 Edition. Wellington: New Zealand Ministry of Economic Development.

EECA. (2007). Waipa sawmill turns out timber - and electricity Retrieved 3 November, 2007, from http://www.bioenergygateway.org.nz/Portals/0/docs/Red\%20Stag_FINAL.pdf

Electricity Commission. (2008). Centralised Dataset April 2008.

Energy for Industry. (2005). Evaluation of Opportunities for Distributed Electricity Generation. Wellington.

Fernando, T. (2008). Communication of New Zealand Manufactured Rotary Drum Dryer Costs. Auckland.

GE Jenbacher. (2005). Jenbacher Gas engines, One Concept, Four Types. Retrieved 20 November, 2007, from http://www.gepower.com/prod_serv/products/recip_engines/en/downloads/ge jenbacher_en.pdf

GE Jenbacher. (2006). Jenbacher Type 6. Retrieved 20 November, from http://www.geenergy.com/prod_serv/products/recip_engines/en/downloads/type6_enver.pdf

Gerrard, A. M. (2000). Guide to capital cost estimating (4th ed.). Rugby, Warwickshire, U.K.: Institution of Chemical Engineering : Association of Cost Engineers.

Hall, P., \& Gifford, J. (2007). Bioenegy Options for New Zealand - A Situational Analysis of Biomass Resources and Conversion Technologies: SCION.

Han, J., \& Kim, H. (2008). The reduction and control technology of tar during biomass gasification/pyrolysis: An overview. Renewable and Sustainable Energy Reviews, 12(2), 397-416.

Hedley, G. (2008). Communication in regards to engine genset options. Auckland. Higman, C., \& Burgt, M. v. d. (2003). Gasification. Boston: Gulf Professional Pub.

Hofbauer, H., Rauch, R., Bosch, K., Koch, R., \& Aichernig, C. (2002, October). Biomass CHP Plant Guessing - A Success Story. Paper presented at the Expert 
Meeting on Pyrolysis and Gasification of Biomass and Waste, Strasbourg, France.

Hofbauer, H., Rauch, R., Loeffler, G., Kaiser, S., Fercher, E., \& Tremmel, H. (2002, June 2002). Six Years Experience with the FICFB-Gasification Process Paper presented at the 12th European Conference and Technology Exhibition on Biomass for Energy, Industry and Climate Protection, Amsterdam.

IEA Bioenergy. (2004). Thermal Gasification of Biomass: BWV's Updraft Gasification Process. Retrieved 24 August, 2008, from www.ieabioenergy.com/media/49_BiomassGasificationSuccessStories.doc

Li, J. (2007). Modelling of Energy Demand in a Sawmill - Personal Communication. Christchurch: University of Canterbury.

Li, J. (2008, 13 Feb). Energy demand and biomass supply in NZ wood processing plants. Paper presented at the Workshop of Biomass Gasification Technology and Biomass Energy, Christchurch.

Li, J., McCurdy, M., \& Pang, S. (2006). Energy demand in wood processing plants. New Zealand Journal of Forestry, 51(2), 13-18.

Li, J., \& Pang, S. (2006). Modelling of Energy Demand in a LVL Plant - Personal Communication. Christchurch: University of Canterbury.

Li, X. T., Grace, J. R., Lim, C. J., Watkinson, A. P., Chen, H. P., \& Kim, J. R. (2004). Biomass gasification in a circulating fluidized bed. Biomass and Bioenergy, 26(2), 171-193.

Mallinson, R. (2008a). Interview with Rob Mallinson from Living Energy about the potential for producer gas feed to the Bio-T boiler system.

Mallinson, R. (2008b, 12 March). Wood Fuel at a Dairy Company. Paper presented at the FIDA Projects and BioChar-Pyrolysis, Auckland.

Meijer, I. S. M., Hekkert, M. P., \& Koppenjan, J. F. M. (2007). The influence of perceived uncertainty on entrepreneurial action in emerging renewable energy technology; biomass gasification projects in the Netherlands. Energy Policy, 35(11), 5836-5854.

Ministry of Agriculture and Forestry. (2006). A National Exotic Forest Description. Wellington.

Ministry of Economic Development. (2006). New Zealand's Energy Outlook to 2030. Retrieved 14 December, 2007, from http://www.med.govt.nz/upload/38641/eo-2006-final.pdf

Ministry of Economic Development. (2007a). Electricity Prices. Retrieved 11 December, 2007, from http://www.med.govt.nz/templates/Page_30174.aspx

Ministry of Economic Development. (2007b). New Zealand Energy Strategy to 2050 Powering Our Future. Retrieved 14 December, 2007, from http://www.med.govt.nz/upload/52164/nzes.pdf

Openshaw Plant Machinery Ltd. (2008). Communication of Alternative Drying Equipment and Costs. Palmerston North.

Pang, S. (2008, 13 Feb). Overview of Up to Date Progress and Challenges in Biomass Gasification. Paper presented at the Workshop of Biomass Gasification Technology and Biomass Energy, Christchurch.

Pang, S., \& Li, J. (2006). BIGCC system for New Zealand: An overview and perspective. New Zealand Journal of Forestry, 51(2), 7-12.

Perry, R. H., \& Green, D. W. (2008). Perry's chemical engineers' handbook (8th / ed.). New York: McGraw-Hill. 
Pfeifer, C. (2008). Biomass Steam Gasification - A Success Story, Presentation at Biomass Gasification Technology and Biomass Energy Conference: 13 February 2008. University of Canterbury, Wood Technology Research Centre.

Piterou, A., Shackley, S., \& Upham, P. (2008). Project ARBRE: Lessons for bioenergy developers and policy-makers. Energy Policy, 36(6), 2044-2050.

Prins, M. J., Ptasinski, K. J., \& Janssen, F. J. J. G. (2007). From coal to biomass gasification: Comparison of thermodynamic efficiency. Energy, 32(7), 12481259.

Rauch, R., Hofbauer, H., Bosch, K., Siefert, I., Aichernig, C., Tremmel, H., et al. (2004, May 2004). Steam Gasification of Biomass at CHP Plant in Guessing Status of the Demonstration Plant Paper presented at the 2nd World Conference and Technology Exhibition on Biomass for Energy, Industry and Climate Protection, Rome, Italy.

Rutherford, J. (2006). Heat and Power Applications of Advanced Biomass Gasifiers in New Zealand's Wood Processing Industry : a thesis submitted in fulfilment of the requirements for the degree of Master of Engineering in Chemical and Process Engineering. University of Canterbury, Christchurch.

Smith, R. (2005). Chemical process design and integration. Hoboken, NJ: Wiley.

Standards Australia. (2005). AS 4343 - 2005: Pressure Equipment - Hazard Levels.

Thumann, A., \& Mehta, D. P. (2001). Handbook of energy engineering (5th ed.). Lilburn, GA: Fairmont Press.

TUV. (2008). The FICFB Gasification System. Retrieved 2 June, from http://www.ficfb.at/

Ulrich, G. D., \& Vasudevan, P. T. (2004). Chemical Engineering Process Design and Economics (Second Edition ed.). New Hampshire: Process Publishing.

Upham, P., \& Shackley, S. (2007). Local public opinion of a proposed 21.5 MW(e) biomass gasifier in Devon: Questionnaire survey results. Biomass and Bioenergy, 31(6), 433-441.

VVBGC. (2008). Vaxjo Varnamo Biomass Gasification Centre. Retrieved 12 August, 2008, from www.vvbgc.se/

Waldheim, L. (2006, October). Greve, ARBRE and CHRISGAS. Paper presented at the IEA Task 33 Workshop, Chicago.

Weir, P. (2008, 13 Feb). Forestry and NZ's Energy Future - What will be Plantation Forests Contribution Under NZ's Emissions Trading Scheme? Paper presented at the Workshop of Biomass Gasification Technology and Biomass Energy, Christchurch. 


\section{Appendix A - Financial Statements for Gasification to Combustion Comparison}

Table 36: Profit and loss statement for gasification plant generating $7.8 \mathrm{MW}_{\text {th }}$ and $1.4 \mathrm{MW}_{\mathrm{e}}$

\section{Raw Materials}

Wood

Utilities

Diesel

Labour

Process Operation

Supervision

Administrative and General Overh

Maintenance

Local taxes

Insurance

Operating Supplies

\section{Annual Use}

23668 Dry T/yr

$111366.8 \mathrm{~L}$

$20800 \mathrm{hrs}$

$15 \%$ of operating labour

$60 \%$ of labour + maintenance

$2 \%$ of capital cost

$1 \%$ of capital cost

$1.5 \%$ of capital cost

$15 \%$ of maintenance cost
$\$ / y r$

236,678

133,640

$1.2 \mathrm{~L}$

416,000

62,400

402,841

193,002

96,501

144,751

28,950

Total Operating Costs (\$NZ)

Revenue from sales

Savings from not purchasing electricity and surplus electricity sold

$1,152,332$

Savings from not purchasing steam

$1,722,558$

Net Annual Profit

Sales revenue

$2,874,890$

Less Operating Costs

$1,714,762$

Net Annual Profit after operating costs, before tax

Less depreciation on fixed capital

10 years straight line

$1,160,127$

Net annual profit after depreciation

$1,061,509$

Less tax

$33 \mathrm{c} / \$$

98,619

32,544

Net Annual Profit after tax (\$NZ) 66,075

Add back depreciation

$1,061,509$

Total Net Annual Cashflow (\$NZ)

$1,127,583$


Table 37: Profit and loss statement for combustion based plant operating at 60 bar and generating 7.8 $\mathrm{MW}_{\text {th }}$ and 1.4 $\mathrm{MW}_{\mathrm{e}}$

Raw Materials

Wood

Labour

Process Operation

Supervision

Administrative and General Overhead

Maintenance

Local taxes

Insurance

Operating Supplies
Wood price \$/odt

10

hrs 20800

$15 \%$ of op labour

$60 \%$ of labour + maint

$2 \%$ of capital

$1 \%$ of capital

$1.5 \%$ of capital

$15 \%$ of maintenance
$\$ / y r$

314,019

416,000

62,400

519,019

386,631

193,316

289,973

57,995

Total Operating Costs (\$NZ)

\section{Revenue from sales}

Savings from not purchasing electricity and surplus electricity sold

$1,152,332$

Savings from not purchasing steam

Net Annual Profit

Sales revenue

$2,874,890$

Less Operating Costs

$2,239,353$

Net Annual Profit after operating costs, before tax

635,537

Less depreciation on fixed capital

10 years straight line

$1,933,156$

Net annual profit after depreciation

$-1,297,619$

Less tax

$33 \mathrm{c} / \$$

$-1,297,619$

Add back depreciation

$1,933,156$

Total Net Annual Cashflow (\$NZ)

635,537 


\section{Appendix B - Component List of Multi-Deck Turbo Drying System}

The following is a breakdown of the main plant items for the complete drying system utilising a multi-deck turbo dryer (Openshaw Plant Machinery Ltd, 2008).

Intake receiving hopper

Painted carbon steel

Capacity of $5 \mathrm{~m}^{3}$

Cost: \$NZ 6580

\section{Cleated transfer belt conveyer}

Overall length: $7500 \mathrm{~mm}$

Overall width: $450 \mathrm{~mm}$

Drive from a $2.2 \mathrm{~kW}$ shaft mounted gear unit

Cost: \$NZ 11,370

\section{Used multi deck turbo dryer}

Capacity: Up to $1750 \mathrm{~kg} / \mathrm{hr}$ dried material

Stainless steel construction

$7.5 \mathrm{~kW}$ gear drive for sweep arm assembly

Cost: \$NZ 48,425

\section{Rotary valve}

Capacity up to $6 \mathrm{MTPH}$

$2.0 \mathrm{~kW}$ gear drive

\$NZ 4,080

\section{Hot air heat exchanger set}

Including fan

Cost: \$NZ 35,790

Receiving cyclone and ancillary equipment

Fabricated from $2.0 \mathrm{~mm}$ galvanised steel 
Stand enamelled carbon steel

Discharge fitted with rotary valve

Capacity $37,383 \mathrm{~m}^{3} / \mathrm{hr}$

Cost: \$NZ 9,725

\section{Cyclone fan}

Includes support frame, belt guard, rubber isolating mounts, silencer

Capacity $37,383 \mathrm{~m}^{3} / \mathrm{hr}$

Cost: \$NZ 17,160

\section{Discharge transfer cleated belt conveyor}

Overall length: $4500 \mathrm{~mm}$

Overall width: $450 \mathrm{~mm}$

$2.2 \mathrm{~kW}$ shaft drive

Cost: $\$ N Z 7,580$

\section{Hammermill}

Capacity up to $3 \mathrm{MTPH}$

Motor $22 \mathrm{~kW}$

Cost: $\$ N Z 8,160$

\section{Receiving/Pack off hopper}

Discharge rotary valve

Capacity: 5 MT

Cost: \$NZ 7,110

\section{Filter collector}

Capacity: $6 \mathrm{~m}^{2}, 720 \mathrm{cfm}$ approx

$1.1 \mathrm{~kW}$ exhaust fan

Filter socks cleaned via reverse pulse timed sequential system

Carbon steel enamel painted finish

Cost: \$NZ 5,000 